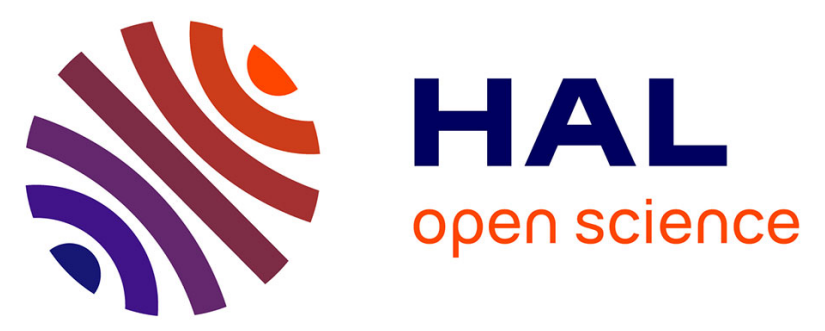

\title{
Phylogeography of a widespread Palaearctic forest bird species: the White-backed Woodpecker (Aves, Picidae)
}

Jean-Marc Pons, David Campión, Giorgio Chiozzi, Antonia Ettwein, Jean-Louis Grangé, Łukasz Kajtoch, Tomasz D Mazgajski, Marko Rakovic, Hans Winkler, Jérôme Fuchs

\section{To cite this version:}

Jean-Marc Pons, David Campión, Giorgio Chiozzi, Antonia Ettwein, Jean-Louis Grangé, et al.. Phylogeography of a widespread Palaearctic forest bird species: the White-backed Woodpecker (Aves, Picidae). Zoologica Scripta, 2020, 10.1111/zsc.12466 . hal-03064527

\section{HAL Id: hal-03064527 \\ https://hal.sorbonne-universite.fr/hal-03064527}

Submitted on 14 Dec 2020

HAL is a multi-disciplinary open access archive for the deposit and dissemination of scientific research documents, whether they are published or not. The documents may come from teaching and research institutions in France or abroad, or from public or private research centers.
L'archive ouverte pluridisciplinaire HAL, est destinée au dépôt et à la diffusion de documents scientifiques de niveau recherche, publiés ou non, émanant des établissements d'enseignement et de recherche français ou étrangers, des laboratoires publics ou privés. 
Pons J.-M.

Phylogeography of a widespread Palaearctic forest bird species: the White-backed Woodpecker (Aves, Picidae)

\author{
Jean-Marc PONS*, David CAMPIÓN, Giorgio CHIOZZI, Antonia ETTWEIN, Jean- \\ Louis GRANGÉ, Łukasz KAJTOCH, Tomasz D. MAZGAJSKI, Marko RAKOVIC, \\ Hans WINKLER and Jérôme FUCHS
}

\author{
Jean-Marc Pons \\ ${ }^{1}$ UMR7205 Institut de Systématique, Evolution, Biodiversité, CNRS MNHN UPMC EPHE, Sorbonne \\ Universités, Muséum National d'Histoire Naturelle, CP 51, 57 rue Cuvier, F-75231 Paris Cedex 05, \\ France \\ jean-marc.pons@mnhn.fr \\ ${ }^{*}$ Corresponding author \\ David Campión \\ 2Área de Biodiversidad, Biodibertsitate Arloa, Padre Adoain, 219 Bajo/AitaAdoain 219, Beheko \\ solairua.31015 Pamplona-Iruñea. Navarra-Nafarroa, Spain \\ dcampion.dc@gmail.com \\ Giorgio Chiozzi \\ ${ }^{3}$ Museo di StoriaNaturale di Milano, Corso Venezia 55, I-20121 Milano, Italy \\ giorgio.chiozzi@comune.milano. \\ Antonia Ettwein \\ ${ }^{4}$ Swiss Ornithological Institute, Seerose 1, 6204 Sempach, Switzerland \\ antonia.ettwein@vogelwarte.ch \\ Jean-Louis Grangé \\ ${ }^{5}$ Groupe Ornithologique des Pyrénées et de l'Adour 81, Avenue du Laü 64000 Pau, France \\ lilfordi64@orange.fr \\ ŁukaszKajtoch: \\ ${ }^{6}$ Institute of Systematics and Evolution of Animals, Polish Academy of Sciences, Sławkowska 17, 31-016 \\ Kraków, Poland \\ lukasz.kajtoch@gmail.com \\ Tomasz D Mazgajski \\ ${ }^{7}$ Museum and Institute of Zoology Polish Academy of Sciences, Wilcza 64, 00-679 Warszawa, Poland \\ mazgaj@miiz.waw.pl \\ Marko Rakovic \\ ${ }^{8}$ Natural History Museum of Belgrade, Njegoseva 51, Serbia \\ markorakovic@gmail.com \\ Hans Winkler \\ ${ }^{9}$ Konrad Lorenz-Institute of Ethology, Department of Integrative Biology and Evolution, Savoyenstraße \\ 1A, A-1160 Vienna, Austria \\ hans-christoph.winkler@oeaw.ac.at
}


Pons J.-M.

Jérôme Fuchs

${ }^{1}$ UMR7205 Institut de Systématique, Evolution, Biodiversité, CNRS MNHN UPMC EPHE, Sorbonne Universités, Muséum National d'Histoire Naturelle, CP 51, 57 rue Cuvier, F-75231 Paris Cedex 05, France

jerome.fuchs@mnhn.fr

Running title: Phylogeography of Dendrocopos leucotos Jean-Marc Pons et al. 
Pons J.-M.

\begin{abstract}
In the present study, we use multilocus molecular data and species distribution modelling to investigate the phylogenetics and the phylogeography of the White-backed Woodpecker (Dendrocopos leucotos), a bird species widely distributed over the entire Palaearctic.
\end{abstract}

Our phylogenetic results reveal three well supported clades within D. leucotos: the Chinese endemic subspecies (tangi, insularis), the northerly distributed subspecies leucotos, uralensis as well as the four poorly genetically differentiated Japanese subspecies (subcirris, stejnegeri, namiyei, owstoni), and the south-western Palaearctic lilfordi subspecies. According to our results, the Amami Woodpecker, endemic to Amami-Oshima Island (Ryukyu archipelago, Japan) sometimes treated as full species D. owstoni, does not deserve any species-level status.

Based on mitochondrial phylogeographic results, the Japanese archipelago was recently colonized only once by D. leucotos from eastern Eurasia. Our results suggest a split between the leucotos and lilfordi lineages that dates back to mid-Pleistocene (around 0.6 Mya) with likely no gene flow between these two subspecies since then. Our results thus do not support a phylogeographic pattern in which central and northern Europe were recolonized from one or several southern glacial refugia where lilfordi populations persisted through several Pleistocene glacial periods. Spatial variation in mitochondrial diversity across leucotos populations and niche ecological modelling suggest a possible eastward population expansion from a unique glacial refugium likely located in central Europe.

Molecular species delimitation methods, gene flow analyses and differences in adult and juvenile plumage indicate that the lilfordi subspecies may warrant to be ranked as a valid phylogenetic species. Further studies are nevertheless needed in the Balkans, where leucotos and lilfordi came recently into contact to measure the effectiveness of reproductive barriers and gene flow. 
Pons J.-M.

Keywords: Biogeography, Glacial Refugia, Palaearctic, Pleistocene, Species limits, Dendrocopos leucotos 
Pons J.-M.

\section{INTRODUCTION}

The White-backed Woodpecker Dendrocopos leucotos (Bechstein, 1802) is a forestdwelling bird widely distributed over the entire Palaearctic from western Europe to eastern Russia, Mongolia, China and Japan (Fig. 1). It is part of a large Palaearctic and Indo-Malayan radiation (genus Dendrocopos, ten species see Fuchs \& Pons 2015) of large pied woodpeckers (body size $23-28 \mathrm{~cm}$ ), with its closest relative being the Okinawa Woodpecker (D. noguchii) (Winkler \& Christie, 2020; Fuchs \& Pons, 2015). The White-backed Woodpecker has a specialized ecological niche. Indeed, it is more dependent on old-growth deciduous or mixed forests with rotten wood especially standing trees, where it can forage on large wood-boring insect larvae, than other codistributed Dendrocopos woodpeckers (Gorman, 2014; Winkler \& Christie, 2020).

Nowadays, eleven or twelve morphological subspecies are generally recognized based on plumage and body size variations (Gill \& Donkers, 2020; Winkler \& Christie, 2020). Four of them (subcirris, stejnegeri, namiyei, owstoni), endemic to the Japanese archipelago where they occur from sea-level to mountain forests, are distributed from northern Hokkaido up to the small islands in the southern Ryukyu archipelago. The Amami Woodpecker D. l. owstoni which differs from other subspecies by its darker plumage, is only found on Amami-Oshima (Ryukyu archipelago) where it inhabits old mature evergreen broadleaved forests and has been treated as a full species in recent checklists (Gill \& Donkers, 2020; Winkler et al., 2020). Two other subspecies occur in central (D. l. tangi) and southern (D. l. fohkiensis) mainland China and another subspecies (D. l. insularis) is endemic to the island of Taiwan. In Eurasia, the nominate subspecies has a very wide and continuous range spreading from northern and central Europe to eastern Asia along with the poorly differentiated subspecies D. l. uralensis (Winkler \& Christie, 2020), which is distributed from the Ural Mountains to Lake Baikal. Finally, the southern subspecies D. l. lilfordi, which has well-marked distinctive plumage characteristics (six black bars on rump and back versus none or partial in nominate), is larger than D. l. leucotos with which it is in geographical contact in central Europe (Croatia, Serbia, Slovenia). Unlike the nominate subspecies, D. l. lilfordi 
Pons J.-M.

possesses a fragmented range restricted to old mountainous forests of the southern Palaearctic (Pyrenees, Apennines, Balkans, Asia Minor and Caucasia).

Quaternary (-2.58 million years ago to nowadays) climatic oscillations caused historical range contractions and expansions of organisms and were therefore important factors affecting the phylogeographical structure and the levels of genetic diversity of many taxa throughout the temperate Northern hemisphere (Avise \& Walker 1998; Avise, 2000; Hewitt, 2000; Taberlet et al., 1998). Regarding the White-Backed Woodpecker several plausible phylogeographical hypotheses could explain its present-day geographical distribution and genetic structure across the Western Palaearctic. One scenario is that northern leucotos populations of the Western Palaearctic would originate from the lilfordi lineage which expanded from one or several southern Pleistocene glacial refugia when the climate became favorable to population expansion after the Last Glacial Maximum (in Europe, around $20 \mathrm{kya}$ ). This scenario has been described for many organisms exhibiting varied dispersal abilities (Hewitt, 2000; Weiss \& Ferrand, 2007). The Western Palaearctic contains at least four primary areas that acted as refugia for forest birds: the Iberian Peninsula, Central Italy, the Balkans and the Caucasia (e.g. Drovetski et al., 2018; Hewitt, 2004). Under this scenario we expect low genetic divergence, the sharing of mitochondrial haplotypes between leucotos and lilfordi and higher genetic diversity in lilfordi populations because it would have successfully persisted through Pleistocene climatic oscillations in one or several southern European refugia (Hewitt, 1996; 2000). The second hypothesis relies upon an independent evolution of leucotos and lilfordi for a significant amount of time. Under this scenario, the western Palaearctic was first colonized by an ancestral Asian lineage that nowadays only persists in small fragmented lilfordi populations found in southern European mountains while the current northern and central European leucotos populations were more recently established from an unknown glacial refugium not located in southern Europe but likely in eastern Asia as suggested by Voous (1947). If this hypothesis is correct an old separation and significant genetic divergence between the subspecies lilfordi and leucotos is expected. Linked to this scenario, we could also expect very little divergence across populations from the northern subspecies, which 
Pons J.-M.

occupies a large and contiguous distribution (from South Korea to Norway); such a pattern was found for two other partly sympatric woodpecker species, the Three-Toed (Picoides tridactylus) and Great-spotted (Dendrocopos major) Woodpecker (Perktas \& Quintero, 2013; Zink et al. 2002a,b).

In the present study, we aim to reconstruct the phylogenetic relationships of the Whitebacked Woodpecker subspecies using multilocus genetic data and we used the mitochondrial gene COI to discriminate between alternative phylogeographical hypotheses that may explain the present-day geographical distribution of the genetic variability within $D$. leucotos. We focused on the phylogeography of the two parapatric subspecies (lilfordi, leucotos) that occur in the western Palaearctic for which efficient sampling was available to infer demographic history and genetic diversity within populations. Using species distribution modelling, we compared the phylogeographical scenario inferred from genetics with the areas where climatic conditions remained potentially favourable to the White-backed Woodpecker during the last 120000 years. We also assessed the possibility that $D$. l. lilfordi, which currently does not occur in Corsica, historically inhabited this island using ecological niche modelling and genetic results we obtained from two museum specimens supposedly collected in Corsica at the end of the nineteenth century.

The taxonomic and conservation implications of our results are discussed taking into consideration that some of the currently defined subspecies of D. leucotos may represent full species as it was recently suggested for other Palaearctic Pied woodpecker species (e.g. Dendrocopos major, Perktas \& Quintero, 2013; Dendrocoptes medius, Kamp et al., 2018). This is particularly important as some populations attributable to these taxa strongly depend on old growth deciduous or mixed forests, which are under threat due to forest management practices. This is for example the case for the Swedish D. l. leucotos population which is classified as critically endangered "CR" on the Swedish national red list and D. l. lilfordi classified as vulnerable "VU" in France and in Italy. In Spain, the latter subspecies is considered "In danger of extinction" on the Spanish Catalogue of Threatened Species (Real Decreto 139/2011). 
Pons J.-M.

\section{MATERIAL AND METHODS}

\section{Sampling}

We obtained fresh (blood, feathers, muscle, $n=62$ ) and dry (toe pads, $n=8$ ) tissue samples from 70 individuals covering a large part of the White-backed Woodpecker distribution (Fig. 1 and see Table S1 for details of exact localities). We further included 10 mitochondrial sequences that were available on GenBank (http:www.ncbi.nlm.nih.gov) in the phylogeographical analyses (Accession numbers in Table S1). Eight (leucotos, lilfordi, subcirris, stejnegeri, namiyei, owstoni, insularis, tangi) out of the eleven subspecies currently recognized (Winkler and Christie 2020) were included in the present study. Two insular subspecies (takahashii, quelpartensis) morphologically very close to $D$. $l$. namiyei and $D$. l. stejnegeri, respectively (Vaurie, 1959; Short, 1982), and one mainland subspecies from South-East China (fohkiensis) were not available for this study. The two Korean subspecies whose validity is often questioned are much likely of recent origin (Winkler \& Christie, 2020). D. l. fohkiensis is distributed in southern China and we sampled the other two subspecies that bound its distribution (tangi and insularis). Furthermore, the subspecies fokhiensis is morphologically intermediate between tangi and insularis (Cheng, 1956). We also sampled two D. l. lilfordi specimens, supposedly collected in Corsica during the nineteenth century, currently preserved at the Museum of Natural History of Bern, Switzerland.

\section{Phylogenetic analyses}

\section{Published data corrections}

During the course of this study, we realized that sequencing/editing errors, involving one base pair in each case, were present in two published sequences (D. l. leucotos ZMUC 141307, GenBank Accession numbers: KR049420, Myoglobin; D. l. leucotos BON-126, GenBank Accession numbers: GU571366, COI). The sequences were corrected prior to the analyses. 
DNA extraction, amplification and sequencing

DNA was extracted from muscle, blood or feather calamus using the DNA Blood and Tissue kit (Qiagen, Valencia) extraction kit. DNA was extracted from historical specimens using the DNA Mini Kit (Qiagen, Valencia) following the manufacturer's protocol except that digestion volume was doubled (400 ul instead of $200 \mathrm{ul}$ ) and $30 \mathrm{ul}$ of DTT was added to the digestion solution. Digestion of tissues was performed for 16 hours.

We amplified and sequenced three nuclear autosomal introns Fibrinogene intron 5 (FGB), Myoglobin intron 2 (MB) and transforming growth factor beta 2 (TGFb2) using standard amplification protocols with varied annealing temperature and primers previously published (Fuchs \& Pons, 2015). We included 75 intron sequences in the phylogenetic analyses among which 39 were retrieved from Genbank (Table S1).

The mitochondrial cytochrome c oxidase subunit I (COI) was amplified and sequenced using primers COIext/FISH1R (Ward et al., 2009; Johnsen et al., 2010) following standard amplification protocols. We designed eight internal primers in order to amplify the COI from the historical specimens: primer details are given in Table 1. Our dataset for D. leucotos comprised 82 COI sequences of which 10 were previously published in Genbank and Bold (see Table S1). We also included in the phylogenetic analyses 32 COI sequences among which 26 were retrieved from Genbank of related Dendrocopos species sensu Fuchs and Pons (2015), including a broad sampling of the widely distributed D. major, in order to have an independent comparison for intra versus interspecific differentiation. Trees were rooted with sequences from Picoides pubescens and Veniliornis mixtus (e.g. Fuchs \& Pons, 2015; Shakya et al., 2017). Detailed information on the sequences included in the analyses is reported in Table S1.

\section{Determining the phase of alleles}

We used PHASE v2.1.1 (Stephens et al., 2001), as implemented in DNASP 5.0 (Librado \& Rozas, 2009), to infer the alleles for each nuclear locus. Genetic diversity parameters 
including haplotype diversity $(\mathrm{Hd})$, Watterson's Theta $(\Theta)$ and nucleotide diversity $(\pi)$ were estimated in DNAsp 5.0 (Librado \& Rozas, 2009) for each lineage.

Gene trees, species tree and molecular divergence time estimates

Nuclear gene tree reconstructions of the unique nuclear alleles were performed using Bayesian inference (BI), as implemented in MrBAYES 3.2 (Ronquist et al., 2012). We used the nst=mixed and rates=invgamma options such that model uncertainty is taken into account during the phylogenetic reconstruction. Four Metropolis-coupled Markov chain Monte Carlo (MCMC) chains (one cold and three heated) were run for $5^{*} 10^{6}$ iterations, with trees sampled every $10^{3}$ iterations.

We estimated the Time to Most Recent Common Ancestor (TMRCA) among the Dendrocopos unique mitochondrial haplotypes using BEAST 1.8.2 (Drummond et al., 2012), with a strict molecular clock model, a TIM + I substitution model selected using TOPALI (Milne et al. 2009) under the Bayesian Information Criterion, and a Yule tree prior. MCMC chains were run for $10^{7}$ steps and were sampled every $10^{3}$ steps. We used three substitution rates and their associated uncertainties to calibrate the trees. The first rate $(0.016 \mathrm{~s} / \mathrm{s} / 1 / \mathrm{myr} ; 95 \%$ HPD: $0.014-0.019 \mathrm{~s} / \mathrm{s} / 1 / \mathrm{myr})$ was based on the complete mtDNA genomes from honeycreepers (Passeriformes, Drepanididae) and calibration points based on the age of volcanic islands in the Hawaiian archipelago as proposed by Lerner et al. (2011). The second rate was the four-fold degenerated sites rate derived from complete mtDNA sequences of Adelie Penguins (Pygoscelis adeliae) (0.073 s/s/1/myr: 95\% HPD: 0.025-0.123 s/s/1/myr; Subramanian et al. (2009). The third rate was a body-mass corrected mitochondrial clock recently proposed by Nabholz et al. (2016). We employed the equation $10^{\wedge}\left(-0.145^{*} \log 10\right.$ (body_mass) +0.459$) / 100$, corresponding to their calibration set 2 , to calculate the body-mass corrected substitution rate for the COI third codon position in our data set. We assumed an average body mass for five of the six sampled Dendrocopos species of $82.6 \mathrm{~g}$ (Dunning, 2007; no body mass data were available for D. noguchii in Dunning (2007), Winkler et al. (2020) or on Vertnet). We used the mitochondrial topology to estimate the third 
codon position branch-lengths using PAML v4.9 (Yang, 2007). The branch-lengths were then converted to divergence times in R using scripts from Nabholz et al. (2016).

We reconstructed a species tree using the coalescent-based model implemented in *BEAST (Heled \& Drummond, 2010). We selected the substitution model for each locus using TOPALI (Milne et al., 2009) under the Bayesian Information Criterion (COI: TrN + I, FGB: TrN, MB: JC + G, TGFb2: K80). Each locus had its own substitution rate matrix and clock model (all assigned to a strict clock model). The species tree analyses, as implemented in *BEAST require pre-defined species or species level lineages. We defined nine species within our data set corresponding to the outgroups ( $P$. pubescens, V. mixtus, D. m. major/pinetorum/numidus, D. syriacus, D. darjellensis, D. noguchii) and the three White-backed Woodpecker clades for which all loci were available (the Japanese endemic subspecies, D. l. leucotos/uralensis and D. l. lilfordi). We used a Yule process for the tree prior with a normal prior distribution for the COI substitution rate (0.016 substitutions/site/lineage/million year -s/s/1/myr; 95\% HPD: 0.011-0.021 $\mathrm{s} / \mathrm{s} / \mathrm{l} / \mathrm{myr})$. We conducted two runs for $25 * 10^{6}$ iterations, with trees and parameters sampled every $5^{*} 10^{3}$ iterations and discarding the first $2.5^{*} 10^{6}$ iterations as the burnin period. TRACER v1.6 (Rambaut \& Drummond, 2009) was used to ensure that our effective sample size of the underlying posterior distribution was large enough (>200) for a meaningful estimation of parameters.

\section{Molecular species delimitation methods}

We used a Bayesian implementation of the general mixed Yule-coalescent model (bGMYC 1.0; Reid \& Carstens, 2012) to delimit species level lineages using molecular data. This implementation is an extension of the GMYC model (Pons et al., 2006) that incorporates gene tree uncertainty by sampling over the posterior distribution of sampled gene trees. We obtained a posterior distribution of ultrametric gene trees from the 33 unique mitochondrial haplotypes using the strategy described above. We ran MCMC for $10^{7}$ iterations with sampling of parameters and trees every 1000 iterations. The first $10 \%$ of the samples were removed as the burn-in period. We analyzed 100 trees sampled randomly from the posterior distribution and used the default setting in 
bGMYC. We ran the MCMC chains for $5^{*} 10^{4}$ iterations, with a burn-in of $4 * 10^{4}$ iterations, and sampled parameters every 100 iterations.

We also used the software BPPv3.4 (Flouri et al., 2018) to estimate the joint probability of the species tree and the speciation probability (model A11, Yang \& Rannala, 2014), testing both algorithm 0 and algorithm 1, for the four-locus data set. We used invgamma priors on the population size parameters $(\theta)$ and the age of the root in the species tree $\left(\tau_{0}\right)$; the values for the invgamma distribution were determined by MinimalistBPP (https://brannala.github.io/bpps/\#/). We allowed the loci to have different rates (locus rate $=1$, Dirichlet distribution) and took into account the differences in heredity scalar (heredity $=2$ ). We ran the rjMCMC analyses for $4 * 10^{5}$ generations with a burn-in period of $4 * 10^{4}$ and different starting seeds. Each analysis was run twice. We did not include the lineages $D$. $l$. insularis/l. tangi and $D$. m. japonicus as they were only represented by the mitochondrial locus.

We used the MCMC method implemented in IMa2 (Hey, 2010) to fit the data to a model that included both isolation and migration to enable us to estimate the level of historical gene flow between the two primary $D$. leucotos lineages: 1) $D$. l. lilfordi and 2) the clade comprising D. l. leucotos/uralensis and all endemic Japanese subspecies. We defined inheritance scales to reflect the difference in inheritance modes among the loci: 0.25 for the mtDNA locus, and 1.0 for the two autosomal loci (TGFb2 had to be excluded because of its low number of variable sites, 1). We used an HKY model of nucleotide substitution for all loci. We used a geometric heating scheme (h1=0.9, h2 = 0.3 ) coupled with 100 chains. For each data set, upper bounds for the prior for the final run were adjusted based on preliminary runs with large uniform priors. Parameters and genealogies were sampled every 100 steps until we had sampled $10^{5}$ genealogies. The fit of 25 demographic models involving different combinations of population sizes and migration rates were then determined using likelihood ratio tests under the L-mode setting in IMa2 (Hey \& Nielsen, 2007). To assess convergence, we monitored the extent of autocorrelation and parameter trend lines throughout the run and we also compared the results between four independent runs. Incorporating a genetically structured population like the $D$. leucotos/Japanese subspecies clade violates one of the 
assumptions of the Isolation with Migration model (Hey \& Nielsen, 2004; 2007). We tested the impact of adding the Japanese endemic subspecies (and hence structure) on gene flow estimates by performing additional runs without them. We expect that the impact will be minimal because empirical and simulation data suggest that the associated bias in parameter estimation introduced by the presence of hidden population structure is limited (Strasburg \& Rieseberg, 2010).

\section{Genetic structure across the Western Palaearctic}

\section{Selection on the mitochondrial loci}

We used the McDonald-Kreitman test (MK) (McDonald \& Kreitman, 1991), as implemented in DnaSP v. 5.10 .01 (Librado \& Rozas, 2009) to test whether selection was acting on the mitochondrial protein-coding gene (COI) used to infer phylogeny and population genetics. MK tests were performed between leucotos and lilfordi the only subspecies for which sample sizes were large enough.

Diversity indices, genetic distance and network

Standard diversity indices for leucotos, uralensis $(\mathrm{N}=44)$ and lilfordi $(\mathrm{N}=23)$ were calculated using Arlequin 3.5 (Excoffier \& Lisher, 2010). Subspecies from Japan and China were not included due to small sample size. We used Arlequin 3.5 to perform Fu's Fs and Tajima' D tests (1000 replicates) to detect signatures of population expansion. Fu's Fs and Tajima' D were initially developed to test for selection but in the absence of the latter, significant negative values are indicative of population expansion. We calculated Dxy (average number of nucleotide substitution per site between taxa pairs using DNAsp (Librado \& Rozas, 2009). We generated a medianjoining network including all subspecies to visualize relationships among haplotypes with NETWORK 10 (Bandlet, Forster \& Rohl, 1999).

\section{Ecological niche modelling}

Species occurrences data were downloaded using the rgbif package (Chamberlain \& Boettinger, 2017; Chamberlin et al,. 2020) using the Coordinate=TRUE and basis Of 
Record $=$ 'PRESERVED_SPECIMEN' filters. These occurrences were complemented by occurrence data derived from the individuals used for the genetic analyses. After checking for georeferencing errors and removing duplicates, the total number of observations was 370 for D. l. leucotos/uralensis, 58 for D. l. lilfordi and 42 for the Japanese subspecies. We did not perform species distribution modelling for the $D$. $l$. insularis/tangi lineage because too few data were available for meaningful species distribution modelling.

We used climatic layers from the Worldclim database (Hijmans et al., 2005; $2.5 \mathrm{~min}$ resolution) and restricted the study area to the following coordinates (latitude extent: 25-70; longitude extent: -11-172); corresponding to the extent of the distribution of $D$. leucotos. Among these 19 Bioclim climatic variables, nine variables were retained for the analyses. These variables were selected using raster.cor.matrix, as implemented in the ENMtools package (Warren et al., 2017) and a correlation threshold of 0.8. Retained variables included: annual mean temperature (BIO1), mean diurnal range (BIO2), isothermality (BIO3), Temperature Seasonality (BIO4), Mean Temperature of Wettest Quarter (BIO8), Annual Precipitation (BIO12), precipitation of the driest month (BIO14), precipitation seasonality (BIO15), and precipitation of the coldest quarter of the year (BIO19).

We built species distribution models for each of the three lineages using the Maximum Entropy algorithm implemented in Maxent ver. 3.3.3 (Phillips et al., 2006). For each lineage, we used $20 \%$ of the observations for testing (on randomly sampled 1000 background points) and $80 \%$ for model training. We used the area under the receiver operating characteristic curve (AUC) to determine whether the predictions generated by Maxent for current conditions were better than random. The AUC is a commonly used measurement for comparison of model performance (Elith et al., 2006). The AUC ranges from 0 to 1 , with greater scores indicating better discrimination ability; an AUC greater than 0.5 indicates that the model discriminates better than random.

Niche models for each lineage were then projected on paleoclimatic layers from three times periods: the Last Interglacial (about 130,000 years ago; Otto-Bliesner et al., 
2006), the Last Glacial Maximum (21,000 years ago) and the Mid-Holocene $(8,326-$ 4,200 years ago) (Fordham et al., 2017). Layers were downloaded from http://www.paleoclim.org/ (Brown et al., 2018).

We tested for differentiation in niche models using the niche.equivalency.test function, as implemented in the phyloclim (Heibl \& Calange, 2018) package. We performed 99 replicates on the occurrence data for each lineage. We did pairwise comparisons for the three primary linages: lilfordi versus leucotos, lilfordi versus Japanese subspecies, leucotos versus Japanese subspecies.

\section{RESULTS}

\section{Multilocus phylogenetic relationships}

Gene trees

We performed the phylogenetic analyses on the $33 \mathrm{COI}$ unique haplotypes from our data set using BEAST 1.8.2 (Fig. 2). Seventeen unique haplotypes were identified for $D$. leucotos. The analyses identified a clade with the Okinawa Woodpecker (D. noguchii) being sister (PP: 1; Fig. 2) to a monophyletic D. leucotos (PP: 0.96). D. leucotos insularis/D. leucotos tangi (PP: 1) was the first lineage to split within the D. leucotos complex but this relationship was not strongly supported (PP: 0.73). Dendrocopos $l$. lilfordi individuals formed a strongly supported clade (PP: 1). The White-backed subspecies found in Japan (ownstoni, steijnegeri, subcirris, nameyi) as well as D. $l$. leucotos/uralensis formed a clade (PP: 1) that was sister to D. l. lilfordi. In addition, $D$. major was not monophyletic with populations from the Western Palaearctic (Austria, France, Morocco, Netherlands, Norway, Russia, Sweden, Tunisia,; D. m. major, D. m. pinetorum, $D$. m. numidus) being more closely related to $D$. darjellensis, whereas the eastern populations of D. major (D. m. japonicus, Russia, South Korea, Japan), were more closely related to $D$. syriacus, although the support for its non-monophyly was quite weak (PP: 0. 78). 
We failed to obtain nuclear DNA from the subspecies D. l. insularis and D. l. tangi. The nuclear gene trees were very poorly resolved (FGB, TGFb2) or polytomised (MB) (Figs. S1-3). In most cases, species were not monophyletic or undisputed species were found to share alleles (e.g. D. major, D. syriacus and D. leucotos subcirris in FGB), suggesting that incomplete lineage sorting is still present in Dendrocopos at these loci. Concerning D. leucotos, the number of alleles found in the nuclear loci were two (TGFb2), five (MB) and six (FGB). For the three nuclear loci, D. leucotos lilfordi had only one allele that was shared with individuals from the northern lineage (MB, TGFb2) or private (FGB). Genetic diversity summary statistics for the three nuclear introns are reported in Table $\mathrm{S} 2$.

\section{Species tree}

The subspecies D. . insularis and D. . tangi could not be included in the species tree analyses (Fig. 3) since no nuclear data were obtained. The topology resulting from the *BEAST analyses indicated that the Japanese subspecies are related to D. leucotos leucotos and D. leucotos uralensis (PP: 0.93) and that all lineages mentioned above are sister to D. leucotos lilfordi (PP: 0.99).

\section{Molecular species delimitations methods}

The bGMYC molecular species delimitation method recovered four species in the sampled members of the genus Dendrocopos. Even well accepted species were lumped (Dendrocopos syriacus with D. major japonicus $(\mathrm{p}=0.08)$, D. darjellensis with D. major major/pinetorum/numidus ( $\mathrm{p}=0.09$ ), although in several cases the $\mathrm{p}$-values were close to significance threshold ( $\mathrm{p}=0.05)$. Within D. leucotos, the $\mathrm{p}$-values were 0.07-0.09 for the species status of D. l. insularis/D. l. tangi versus D. l. leucotos/D. l. lilfordi and 0.11 for D. l. leucotos versus D. l. lilfordi.

The analyses performed with BPP indicated that the nine species model received the highest posterior probability (PP: 0.998 in both algorithms 0 and 1). Noticeably, D. $l$. leucotos/uralensis, the Japanese subspecies clade and D. leucotos lilfordi all received speciation probabilities of 1.0 . The species tree topology was very similar to the $*$ Beast 
results, with the single difference involving the relationships of D. syriacus, D. major (Western) and D. darjellensis.

\section{Divergence time estimates}

Molecular divergence times analyses, performed with the Fringillidae COI rate, a strict clock model and a TIM+I model indicated that D. leucotos diverged from D. noguchii about 1.1 Mya (95\% HPD: 0.7-1.5 Mya), that D. l. insularis/D. l. tangi splitted from the remaining D. leucotos subspecies clade 0.8 Mya (95\% HPD: 0.5-1.1 Mya), and that $D$. leucotos lilfordi splitted from the northern taxa about 0.6 Mya (95\% HPD: 0.4-0.9 Mya). These splits were simultaneous with the splits between $D$. darjellensis and the Western Palearctic D. major (0.7 Mya, 95\% HPD: 0.4-1.0 Mya) and between $D$. syriacus and D. major japonicus (0.8 Mya, 95\% HPD: 0.5-1.1 Mya). Very similar estimates were obtained using the fourfold degenerated rate (e.g. D. leucotos $/ D$. noguchii 0.9 Mya, 95\% HPD: 0.3-1.7 Mya; D. l. leucotos/D. l. lilfordi 0.5 Mya, 95\% HPD: 0.15-0.9 Mya). Estimates obtained using the body-mass corrected rate were about three times older: D. leucotos diverged from D. noguchii about 3.6 Mya (95\%: 2.8-4.4 Mya), D. l. insularis/D. l. tangi from the D. l. leucotos/D. l. lilfordi clade 2.4 Mya (95\%: 1.9-2.9 Mya), the two latter subspecies diverging from each other about 1.9 Mya (95\%: 1.6-2.4 Mya).

Within D. leucotos, divergence times obtained in the species tree analyses (calibrated using the Lerner et al. 2011 rates) were similar to the one obtained using the mitochondrial DNA alone: D. leucotos lilfordi splitted from the northern taxa about 0.6 Mya (95\% HPD: 0.2-1.0 Mya).

The D. major/D. leucotos clade started to diversify about 1.1-2.1 Mya (mtDNA only: Lerner et al. (2011) rate, 95\% HPD: 1.1-2.0 Mya, fourfold rate: 95\% HPD: 0.5-2.6 Mya; species tree: 95\% HPD: 1.3-2.9 Mya).

\section{Population genetics}

Mitochondrial genetic diversity and genetic distance 
Hd and $\pi$ were much higher in lilfordi populations than in leucotos/uralensis populations (see Table 2). The MK tests did not detect any significant evidence of selection in the mitochondrial DNA (COI) gene when comparing leucotos/uralensis with lilfordi (Fischer's exact tests, $\mathrm{p}=0.49$ ). Tajima's D and Fu's tests suggested strong evidence of population expansion for the leucotos/uralensis lineage (Table 2). By contrast, we did not detect any sign of population expansion for lilfordi. These results thus suggest a different historical demography for these two subspecies. The $D_{x y}$ distance between lifordi and leucotos was $2.1 \%$ which compares to the distances between D. noguchii and D. leucotos sensu lato (3.3\%), between D. major (W Palaearctic) and D. darjellensis (1.9\%), and between D. major (E Palaearctic) and D. syriacus $(2.6 \%)$. The $\mathrm{D}_{\mathrm{xy}}$ value for the $D$. l. insularis/tangi versus the remaining $D$. leucotos subspecies was $1.8 \%$.

\section{Median-joining network}

The median-joining network was based on $80 \mathrm{COI}$ sequences and included the two Chinese subspecies (Fig. 4). Seventeen haplotypes clustered in four sub-networks corresponding to the four main clades highlighted in the COI phylogenetic analyses (Fig. 2). The Japanese subspecies sub-network was closely related to the Eurasian leucotos sub-network (2 mutation steps). The most common Japanese haplotype was shared by owstoni, subcirris, stejnegeri and namiyei highlighting both their close genetic proximity and their recent origin. All Japanese subspecies form a monophyletic group. The northern leucotos sub-network displayed a star-like shape with a common central haplotype having a wide geographical distribution at the centre of the network and derived haplotypes weakly differentiated radiating from the ancestral haplotype. Such a pattern is commonly observed in the case of recent population expansion, also suggested for leucotos by the Fu's Fs and Tajima significant tests (Table 2). It is remarkable that the most common leucotos haplotype has a very wide geographical distribution ranging from western Europe to eastern Russia. It is also worth noting the high haplotype diversity found in Poland $(n=4)$ compared to Scandinavia $(n=2)$, other European countries $(n=1)$ and especially Russia and Mongolia which cover huge areas $(\mathrm{n}=1)$. Only two individuals were available for Chinese subspecies (insularis, tangi) 
which group together in the same sub-network and are at the same time well differentiated from both leucotos and lilfordi sub-networks. The most common lilfordi haplotype was shared between White-backed Woodpeckers coming from the Pyrenees and the Balkans (Fig. 4). All individuals from Italy $(n=5)$ hold the same haplotype that diverges from the most common lilfordi haplotype by one mutation step while the only Caucasian White-backed Woodpecker included in the network was more distant (three mutation steps). Both White-backed Woodpeckers supposedly collected in Corsica hold the most common haplotype found in the Balkans and Pyrenees.

\section{Gene flow among D. leucotos lineages}

The results from the isolation-with-migration analyses were slightly different across runs; unrejected models that differed across runs implied the putative existence of differences in population sizes 1 ) between the two defined extant populations (lilfordi versus leucotos/uralensis/owstoni/namiyei/subcirris/steijnegeri) or 2) between the extant leucotos/uralensis/owstoni/namiyei/subcirris/steijnegeri and the ancestral population. Models that were always rejected across runs implied equal population sizes for the two extant populations and the ancestral population. Models that were never rejected included the full model, the models implying different population sizes among populations and models assuming equal population size between $D$. $l$. lilfordi and the ancestral population.

The common feature across all analyses was that the historical migration rate between the two extant populations was estimated to be 0 in all models that were not rejected by the likelihood ratio tests. Hence, the isolation-with-migration analyses strongly indicated that there is no historical gene flow between lilfordi and leucotos/uralensis/owstoni/namiyei/subcirris/steijnegeri and that alleles shared in the nuclear DNA are due to incomplete lineage sorting.

\section{Ecological niche modelling}


Pons J.-M.

For the three lineages, the AUC value was higher than 0.92 (leucotos $=0.93$, lilfordi $=$ 0.97 , Japanese subspecies $=0.99$ ); values higher than 0.76 are considered to correspond to a useful predictive model (Phillips \& Dudík 2008).

Models projected on current bioclimatic data were good representations of the current knowledge regarding the distribution of the species. One exception involves the climatic suitability for D. l. lilfordi, where the current distribution is much more restricted when compared to its potential distribution based on bioclimatic data (see below).

For the Japanese lineage, the highest predicted suitability is along the Japanese archipelago with other suitable areas in the Korean peninsula and southeastern China (Fig. 5). The predicted range of the lineage may have been stable in the Japanese archipelago during the last 120,000 years (Fig. 5), with other continuously putatively stable areas being southeastern China and Central Europe.

For the D. l. leucotos/uralensis lineage, the highest predicted suitability is central and eastern Europe west of the Ural Mountains, around Lake Baikal, northeastern China, the Korean peninsula as well as the isolated Kamtchatka peninsula (Fig. 5). Suitable climatic conditions were highly restricted for this lineage at the Last Glacial Maximum (Fig. 5), with two areas having high suitability, central Europe around the Carpathians Mountains and southeastern China and Japan. Projections of the niche model on paleoclimatic layers indicate a distribution extent very similar to current conditions for the Last Interglacial and Mid-Holocene periods (Fig. 5, Fig. S4).

For D. l. lilfordi, the current distribution is only a fraction of the potential distribution of the lineage based on the bioclimatic data (Fig. 5). Indeed, in addition to regions currently occupied by the lineage, vast areas of Western Europe (France, Great Britain and Scandinavia) are climatically potentially suitable for this lineage. The potential suitable distribution of this lineage has been relatively stable since the Last Interglacial (Fig. 5), with the four southwestern Palearctic refugia (Iberia, Italy, Balkans, Causasia) being suitable throughout. Noticeably, Corsica had suitable, yet limited to the center of the island, climatic conditions for D. l. lilfordi throughout the last 120,000 years (Fig. S4). 
The niche.equivalency.test was highly significant for the three pairwise comparisons, suggesting that the three lineages occupy different niches leucotos/uralensis versus lilfordi: Schoener's $\mathrm{D}=0.13, \mathrm{p}<0.0001$; Japanese subspecies versus lilfordi: Schoener's $\mathrm{D}=0.17, \mathrm{p}<0.0001$; Japanese subspecies versus leucotos/uralensis: Schoener's $\mathrm{D}=0.20$, $\mathrm{p}<0.0001$.

\section{DISCUSSION}

\section{Phylogenetic relationships among morphological subspecies}

Our phylogenetic results support the existence of three well-supported monophyletic groups within $D$. leucotos and confirm that $D$. noguchii is the sister species of $D$. leucotos (Fuchs \& Pons, 2015; Winkler et al., 2005). Relationships among the three primary lineages are not well resolved most probably because of the relatively short sequences data upon which our phylogenetic analyses were based. Nevertheless, our results suggest that the Chinese subspecies (tangi, insularis) were the first to branch off around 0.8 Mya. A similar phylogenetic pattern was found for the Great Spotted Woodpecker Dendrocopos major for which the lineage distributed in China was also the first to split around 0.8 Mya (Perktas \& Quinteros, 2013); we nevertheless highlight that caution should be taken when comparing the divergence times between the two studies because different molecular clocks were used. The second split dated back to about 0.5-0.6 Mya separated the northern leucotos group including two subspecies not genetically differentiated (leucotos, uralensis) and the four Japanese subspecies (namiyei, subcirris, stejnegeri, owstoni) from the southern lilfordi subspecies. Within the northern group, the Japanese subspecies formed a clade with respect to the continental White-Backed Woodpeckers. The Amami Woodpecker sometimes treated as a full species (D. owstoni; Winkler et al., 2020) is not genetically differentiated from other Japanese subspecies with which it shares the most common haplotype found across the Japanese archipelago. Significant differences in plumage and morphology highlighted for this insular taxon, only found in Amami-Oshima Island (northern Ryukyu archipelago), do not reflect an old divergent evolutionary history. They may 
result from a rapid evolution or phenotypic plasticity related to humid subtropical insular environment and/or drift.

One further surprising result is the paraphyly of the Great Spotted Woodpecker. Indeed our mitochondrial results support a topology where the western subspecies of $D$. major are more closely related to $D$. darjellensis than to the eastern D. major japonicus subspecies which is sister to D. syriacus. This hypothesis was not highlighted in previous studies due to limited geographic (Fuchs \& Pons 2015) and/or taxonomic (Perktas \& Quintero, 2015; Zink et al. 2002a) sampling. Additional studies based on a multilocus approach and including individuals from the Chinese and himalayensis populations are necessary to validate this result and test further hypotheses regarding species limits and/or introgression of mitochondrial DNA across species.

\section{Biogeographic history}

Our molecular data clearly suggest that the Japanese archipelago was recently colonized from eastern Eurasia by D. leucotos only once. The four subspecies are only little genetically differentiated: all morphological subspecies share a common haplotype and the three derived haplotypes differ from this ancestral haplotype by only one to three mutations. The Ryukyu archipelago, which lies off the southern shore of Hokkaido was likely colonized independently by $D$. $l$. owstoni and $D$. noguchii which are not sister relatives. More samples from the eastern range of $D$. leucotos and especially from China would be crucial to understand the biogeographic history of this species in Asia in more details. On the mainland, the Eurasian leucotos group holds a common haplotype over an extremely wide geographical range, from western Europe (Norway) up to eastern Asia (South Korea). Within this group, the genetic variation is very low and not geographically structured, a conclusion also reached by Ellegren et al. (1999) based on the sampling of Polish and Scandinavian populations. The star-like network as well as significant tests of population expansion clearly suggest that all present-day populations recently and rapidly expanded from a unique glacial refugium. However, surprisingly, most of the haplotype diversity is found in Europe and specifically in Poland, which holds four of the six haplotypes found in the Eurasian leucotos group. In contrast, in 
Pons J.-M

Russia and Mongolia, where twelve White-backed Woodpeckers were sampled over a large area, only one haplotype was detected. Such a geographical distribution of the genetic variability within the leucotos group is hardly compatible with the most common phylogeographical pattern generally invoked for forest bird species, that is a colonisation of the western Palaearctic from an Eastern Palaearctic refugium, which was ice-free during the last glacial maximum while most of Europe was still covered by ice (Adams, 1997; Hewitt, 1996; Hughes et al.; 2013; Pons et al., 2015; Penzold et al., 2013; Schmitt \& Varga, 2012; Voous, 1947, Zink et al., 2002a). Our mitochondrial data could support the persistence of a leucotos population in Central Europe in a so-called cryptic glacial refugium, possibly located around the Carpathians (see below), from which the subspecies expanded eastward across Siberia after the Last Glacial Maximum. Consistent with mitochondrial data, climatic niche modelling suggests that suitable climatic conditions might have persisted in Central Europe during the Last Glacial Maximum (Fig. 5). In further support of this hypothesis, a post glacial eastward range expansion from Central Europe to Siberia has also been suggested for the Adder (Vipera berus) (Schmitt \& Varga, 2012) and the Willow Tit (Poecile montanus) (Pavlova et al., 2006). The classical view of glacial stages where trees were restricted to localized refugial areas in southern Europe and the Mediterranean basin was challenged by paleobotanical evidence (Birks \& Willis, 2008) and tree megafossils (Kulmann, 2002). These authors suggest that during the glacial periods tree ranges were more extensive than previously believed and that many local areas of small tree populations in Central Europe persisted in cryptic refugia. In a study devoted to the phylogeography of the bank vole Clethrionomys glareolus, a European rodent species strongly associated with forest habitat, Deffontaine et al. (2005) stated that the endemic Mediterranean phylogroups did not contribute to the postglacial recolonization of much of the Palaearctic species range. Instead, the major part of this region was apparently recolonized by bank voles that survived in a glacial refugium possibly around the Carpathian Mountains, which were covered by small patches of mixed forests of coniferous and deciduous trees during the last glacial maximum (see also Provan \& Bennett, 2008 for a review on the existence of a Carpathian cryptic refugia for mammals, reptiles and amphibians). More studies based on larger samples especially 
from the eastern range of the species' distribution would be welcomed to confirm the eastward range expansion of leucotos from a European cryptic refugium.

By contrast with the wide and continuous range of D. l. leucotos, D. l. lilfordi occupies a fragmented geographical range, restricted to the mountainous regions of the southwestern Palaearctic. In line with its scattered geographical distribution, our mitochondrial results suggest a completely different historical demography for this southern subspecies. D. $l$. lilfordi holds a much higher genetic diversity than $D . l$. leucotos and unlike the latter its populations did not show any sign of recent expansion. Although based on small sample sizes in the Apennines $(n=5)$ and Caucasia $(n=1)$, the geographical distribution of lilfordi haplotypes suggests a strong structure of the genetic variability among allopatric populations. Each mountainous population (Pyrenees, Abruzzi, Caucasia) holds its private haplotypes and does not share any haplotype with their counterparts. The only exception to this pattern are the Balkans which hold the most common Pyrenean haplotype, suggesting possible past gene flow between both regions and a more extended geographical distribution of lilfordi in the past than nowadays as predicted by our climatic niche modelling results (Fig. 5). Tomialojć (2000) also suggested that the White-backed Woodpecker, being the most dependent woodpecker species on decaying deciduous timbers, failed to survive in lowlands of western Europe because of woodland management since the medieval times.

\section{Western Palaearctic phylogeographical pattern}

The Pleistocene has played a major role in the differentiation at the intraspecific and interspecific level of many temperate palaearctic organisms including forest and woodland birds (e.g. Brito, 2005; Drovetski et al., 2018; Hewitt, 2004; Kvist et al., 2004; Pons et al., 2011; 2015; Schmitt, 2007). Our genetic results support a midPleistocene divergence between lilfordi and leucotos. The two subspecies possess different phylogeographic structures and demographic histories. In contrast to lilfordi, whose allopatric small populations are genetically slightly differentiated and persisted through the Pleistocene climatic oscillations in southern Europe, our results suggest no 
Pons J.-M

geographical structure and recent spatial expansion of the leucotos lineage from a unique refuge, as suggested by the negative values of Tajima's D and Fu's Fs statistics. In Europe, the White-backed Woodpecker has a two-clade genetic structure corresponding to D. l. leucotos found in central and northern regions and D. l. lilfordi restricted to southern mountainous areas. Both subspecies are presently in geographical contact in the northern Balkans following the recent southward range expansion of $D . l$. leucotos (Hans Winkler, unpublished data). Our results do not support a phylogeographical pattern in which central and northern Europe would have been recolonized from one or several southern glacial refugia where lilfordi populations persisted during the Quaternary. Penzold et al. (2013) found a similar two-clade genetic structure for the European populations of the Coal tit (Periparus ater) as well as Pons et al. (2015) for the Eurasian Treecreeper (Certhia familiaris). In both species, an old lineage mostly restricted to southern Europe co-exists with a much more widely distributed lineage whose range extends from western Europe up to eastern Asia. To explain such a pattern, the authors propose a double colonization of Europe from the eastern Asian range because the northern subspecies $(P$ a ater and $C$. $f$. familiaris/macrodactyla, respectively, see Penzold et al., 2013; Pons et al., 2015) were closely related to eastern subspecies. This is probably not the case for the White-backed Woodpecker for which both Chinese subspecies are the first to branch off while lilfordi and leucotos are sister taxa. Duriez et al. (2007) highlighted a similar phylogenetic structure in the Western Capercaillie (Tetrao urogallus) which has a sister Asian species (T. parvirostris) and includes two divergent European lineages (the "aquitanus" lineage with a southern scattered mountainous distribution and the "urogallus" lineage with a much wider Eurasian range). Moreover, it is worth noting that D. leucotos shares a concordant phylogeographic pattern with its main preys, saproxylic beetles, especially Cerambycidae, which are also associated with old-growth deciduous or mixed forests where rotten trees are available (e.g. Drag et al., 2015). Interestingly, a shared phylogeographic between predator and preys is also known for other woodpecker species and their respective preys (e.g. Three-toed woodpecker and bark beetles; Zink et al., 2002b; Sallé et al, 2007). 
Pons J.-M.

\section{Presence of the White-backed Woodpecker in Corsica?}

In the present study, we also included two White-backed Woodpeckers specimens, putatively collected in Corsica. These two specimens were probably collected during the second half of the nineteenth century when the White-backed Woodpecker was possibly still found in Corsica according to some authors (Chappuis, 1976; Grangé, 2015a; Moltoni \& Brichetti, 1977; but see Thibault \& Bonaccorsi, 1999 for an opposite opinion). In addition, the vocalizations of the White-backed Woodpecker were recorded once in Corsica in the middle of the twentieth century by Chappuis (1976) but a possible confusion with the Great Spotted Woodpecker cannot be fully excluded (Grangé, 2015a). The two putative Corsican specimens included in this study hold the most common lilfordi haplotype distributed in the Pyrenees and the Balkans. If the putative presence of the White-backed woodpecker in Corsica resulted from an ancient colonization event, one would have expected that both specimens hold a slightly divergent haplotype from the most ancestral haplotype as it is observed in the Abruzzi and the Caucasia (see Fig. 4) but this is not the case. The second hypothesis of a more recent colonization from the nearby Italian Peninsula, possibly during the last glacial maximum when the sea level was lower than today, can also be rejected because the putative Corsican specimens do not show the Abruzzi haplotype. The hypothesis that Corsica was colonized by what can possibly be an older and more widespread Pyrenean/Balkans lineage cannot be ruled out by our data set. Our mitochondrial data neither strongly argue for the Corsican origin of these two museum specimens nor can definitively reject it. Interestingly, the species distribution modelling suggests that Corsica had potentially suitable habitats for lilfordi throughout the last 120,000 years (Fig. S4). The absence of D. leucotos sensu lato fossils in Corsica and the fact that $D$. major is known from two Pleistocene sites in Corsica (Grangé 2015a) would argue for the hypothesis that D. leucotos never colonized Corsica. Yet, D. leucotos is usually much scarcer than D. major and the fact that the latter, although present, was only found in two localities suggests that the probability of finding D. leucotos fossils is very low. As a consequence, the problem remains currently unresolved and only genome wide data may help to solve it. 
Pons J.-M.

\section{Taxonomic conclusions}

The current taxonomy applied to the White-backed Woodpecker does not correctly reflect the species evolutionary history. According to our genetic results four lineages emerge: 1 - the Chinese species group includes at least two morphological subspecies. Based on its geographic distribution and morphology (Cheng, 1956) the subspecies fokhiensis, which could not be sampled, very likely belongs to this group. This lineage split from other White-backed woodpeckers around 0.8 Mya (mid-Pleistocene); 2 - the leucotos group currently includes two morphological subspecies (leucotos and uralensis) which are not genetically distinguishable in the present study; 3 - the Japanese subspecies group includes four morphological subspecies which are of recent origin and sister to the leucotos group. Our results do not support the species rank which is sometimes assigned to the insular owstoni (Winkler et al., 2020); 4 - the lilfordi group includes only one morphological subspecies which split from the leucotos group around 0.3-0.4 Mya.

The molecular species delimitation methods and the gene flow analyses (support for no historical gene flow) in line with the differences in ecology (Grangé, 2015b), adult plumage (rump mostly black, back barred black, red below more extensive than in leucotos) and juvenile plumage (undertail coverts not reddish and females without red on crown) (Grangé, unpublished results) suggest that the subspecies lilfordi may be elevated to the species rank. We also highlight that further studies are needed in the Balkans, where leucotos and lilfordi are geographically intertwined (Hans Winkler, unpublished data) to assess whether both subspecies are ecologically segregated, lilfordi exhibiting habitat preferences for mountainous forests over most of its distribution range, or syntopic and able to form mixed pairs. Given that the present work would support the species status for lilfordi, a species status is automatically deserved, under the Phylogenetic Species Concept, to the D. l. insularis/ D. l. tangi lineage, Dendrocopos insularis (Gould, 1863) by priority. The inclusion of D. l. fokhiensis will be needed to confirm the hypothesis that it is part of this group, as suggested according to morphology (Cheng, 1956). 
Pons J.-M.

\section{Conservation issues}

The White-backed Woodpecker is currently assigned to the "Least Concern" category in the world IUCN red list of threatened species. Our mitochondrial results nevertheless stress the important conservation role of Białowieża Forest, the last remnant of primeval forest in lowlands of Europe, as well as of the Carpathians forests, in sheltering the most genetically diversified population of leucotos while Eastern Palaearctic populations seem to be more uniform. Following the present study which emphasizes the genetic distinctiveness of lilfordi and knowing its fragmented range and relatively small breeding populations at the Western edge e.g. 400-550 pairs for the French Pyrenean population and around 100 pairs on the Spanish side of the Pyrenees (Grangé, unpublished results, Campión \& Senosiain, 2004; Carcamo, 2016), it all appears that the conservation status of this subspecies, as well as that of the Chinese subspecies, should be evaluated independently from other members of the northern Eurasian leucotos group. Most lilfordi populations are restricted to old-growth deciduous forests located in mountains in which dead trees and fallen timbers are abundant (Winkler \& Christie, 2020). Yet a large part of these habitats is subject to major threats due to intense logging activities. According to our ecological niche modelling, the current distribution of lilfordi is only a small part of its potential geographic distribution that could potentially include lowlands of western France and Great-Britain if forested habitats were favourable to its ecological requirements in old forests and decaying deciduous timbers. In line with this, in Spain, there is a slow westward geographic expansion of the species that occupies new beech forests (Campión, unpublished results). This is probably due to the abandonment of charcoal manufacturing in the mid-20th century and the consequent ecological improvement of these forests, intensively exploited since the Middle Ages.

The conservation of lilfordi populations which are currently at risk in mountains of south-western Europe is thus directly dependent on the preservation of large areas of mature deciduous forests. 
Pons J.-M.

\section{ACKNOWLEGMENTS}

We warmly thank all contributors whose names are listed in the Table S1 for providing us with tissue samples. We are very grateful to G. Boano (Museo Civico di Storia Naturale di Carmagnola), J. Martens, Institut für Zoologie, Johannes GutenbergUniversität, Germany, Gilberto Pasinelli (Swiss Ornithological Institute), Switzerland and Paul Harris for their precious help to obtain tissue samples from Italy and Mongolia. Many thanks to Eva Remešová, Robert Špilák, Daniel Křenek and Kateřina Ševčíková for helping with the collection of samples from the Czech Republic, Robert Kruszyk, Tomasz Mokwa and Tomasz Baziak for providing some samples from Poland. We also thank M. Balman, BirdLife International and NatureServe for providing the shape files used for Fig. 1. We are particularly grateful to S. Birks (University of Washington, Burke Museum, Seattle, USA), Manuel Schweitzer (Bern Museum, Switzerland) and S. Kobayashi (Yamashina Institute for Ornithology) who provided tissue samples for molecular analyses. Many thanks to the small GOPA team (P. Urbina-Tobias, E. Q. Champagne, S. Duchateau, S. Hommeau, L. Joubert, D. Laban, H. Lafitte, P. Marsaguet, P. Navarre) for helping during the field work in the French Pyrenees approved by the Centre de Recherches sur les Populations d'Oiseaux (MNHN). The fieldwork in Spain (Navarre) was part of the Poctefa HABIOS program, financed by EU FEDER funds, and was done thanks to D. Villanúa and JM Elosegui and other technicians and Forest Rangers (G. Gorospe, G. Deán, S. Cárcamo, A. Senosiain, X. Azpirotz and J. Zuazu). We are grateful to two anonymous referees for their relevant suggestions on a previous version of this manuscript. We are also grateful to the technical staff of the "Acquisition et Analyse de Données", Pôle Analyse de Données et Service de Systématique Moléculaire, Muséum national d'Histoire naturelle who helped us with the laboratory work. This work was partly supported by the "Action Tranversale du Muséum", Muséum National d'Histoire Naturelle. 


\section{REFERENCES}

Adams, J. M. (1997). Global land environments since the last interglacial. Oak Ridge National Laboratory, TN, USA. http://www.esd.ornl.gov/ern/qen/nerc.html

Avise, J. C., \& Walker, D. E. (1998). Pleistocene phylogeographic effects on avian populations and the speciation process. Proceedings of the Royal Society of London. Series B: Biological Sciences, 265, 457-463.

Avise, J. C. (2000). Phylogeography: the history and formation of species. Harvard University.

Bandelt, H. J., Forster, P., \& Rohl, A. (1999). Median-joining networks for inferring intraspecific phylogenies. Molecular Biology and Evolution, 16, 37-48.

Becker, R. A., \& Wilks, A. R., (2013). mapdata: Extra Map Databases. R version by Brownrigg R. (2013) R package version 2.2-2. Available via http://CRAN.Rproject.org/package $=$ mapdata.

BirdLife International and NatureServe. (2013). Bird species distribution maps of the world. BirdLife International, Cambridge, UK and NatureServe, Arlington, USA.

Birks, H. J. B., \& Willis, K. J. (2008). Alpines, trees, and refugia in Europe. Plant Ecology \& Diversity, 1, 147-160.

Bivand, R. \& Lewin-Koh, N., (2014). maptools: Tools for reading and handling spatial objects. $\mathrm{R}$ package version 0.8-29. Available via http://CRAN.Rproject.org/package $=$ maptools.

Brito, P. H. (2005). The influence of Pleistocene glacial refugia on tawny owl genetic diversity and phylogeography in western Europe. Molecular Ecology, 14, 3077-3094.

Brown, J., Hill D., Dolan, A., Carnaval A. C. \& Haywood, A. M. (2018). PaleoClim, high spatial resolution paleoclimate surfaces for global land areas. Scientific Data, 5, 19. 
Campión, D., \& Senosiain, A. (2004). Pico dorsiblanco, Dendrocopos leucotos. In: Madroño A, González C. \& Atienza J.C. (eds). Libro Rojo de las Aves de España. Dirección General para la Biodiversidad-SEO/BirdLife. Madrid. pp. 307-309.

Carcamo, S. (2016). Distribution du Pic de Lilford Dendrocopos leucotos lilfordi à l'ouest des Pyrénées espagnoles. Le Casseur d'Os, 16, 96-104.

Chamberlain, S, Barve, V, Mcglinn, D, Oldoni, D, Desmet, P, Geffert, L, \& Ram, K. (2020). rgbif: Interface to the Global Biodiversity Information Facility API_. R package version 2.2.0, https://CRAN.R-project.org/package=rgbif.

Chamberlain, S., \& Boettiger, C. (2017). "R Python, and Ruby clients for GBIF species occurrence data." PeerJ PrePrints. https://doi.org/10.7287/peerj.preprints.3304v1.

Chappuis, C. (1976). Origine et évolution des vocalisations de certains oiseaux de Corse et des Baléares. Alauda, 44, 475-495.

Cheng T. (1956). A new form of White-backed Woodpecker (Dendrocopos leucotos tangi susp. Nov.) from Szechwan (China). Acta Zoologica Sinica, 8, 133-142.

Clement, M., Posada, D., \& Crandall, K.A. (2000). TCS: a computer program to estimate gene genealogies. Molecular Ecology, 9, 1657-1659.

Deffontaine, V, Libois, R, Kotlik, P, Summer, R, Searle, J. B., \& Michaux J. R. 2005. Beyond the Mediterranean peninsulas: evidence of central refugia for a temperate forest mammal species, the bank vole (Clethrionomys glareolus). Molecular Ecology 14: $1727-1739$

Drag, L., Hauck, D., Bérces, S., Michalcewicz, J., Šerić Jelaska, L., Aurenhammer, S., \& Cizek L. (2015). Genetic differentiation of populations of the Rosalia longicorn, Rosalia alpina (Coleoptera: Cerambycidae) in Central and South-east Europe. Biological Journal of the Linnean Society, 116, 911-925.

Drovetski, S. V., Fadeev, I. V., Raković, M., Lopes, R. J., Boano, G., Pavia, M., .. \& \& Voelker G. (2018). A test of the European Pleistocene refugial paradigm, using a 
Western Palaearctic endemic bird species. Proceedings of the Royal Society B, 285, 20181606.

Drummond, A. J., Suchard, M. A., Xie D. \& Rambaut A. (2012). Bayesian phylogenetics with BEAUti and the BEAST 1.7. Molecular Biology and Evolution, 29, 1969-1973.

Dunning J. B. (2007). CRC handbook of avian body masses, second edition: CRC Press.

Duriez, O., Sachet, J. M., Ménoni, E., Pidancier, N., Miquel, C., \& Taberlet, P. (2007).

Phylogeography of the capercaillie in Eurasia: what is the conservation status in the Pyrenees and Cantabrian Mounts? Conservation Genetics, 8, 513-526.

Elith, J., Graham, C. H., Anderson, R. P., Dudik, M., Ferrier, S., Guisan, ... \& Zimmermann, N. E. (2006). Novel methods improve prediction of species' distributions from occurrence data. Ecography, 29, 129-151.

Ellegren, H., Carlson, A., \& Stenberg, I. (1999). Genetic Structure and Variability of White-Backed Woodpecker (Dendrocopos Leucotos) Populations in Northern Europe. Hereditas, 130, 291-299.

Excoffier, L. \& Lischer, H. E. L. (2010). Arlequin suite ver 3.5: A new series of programs to perform population genetics analyses under Linux and Windows. Molecular Ecology Resources, 10, 564-567.

Flouri, T., Jiao, X., Rannala, B., \& Yang, Z. (2018). Species Tree Inference with BPP using Genomic Sequences and the Multispecies Coalescent. Molecular Biology and Evolution, 35, 2585-2593.

Fordham, D. A., Saltré, F., Haythorne, S., Wigley, T. M. L., Otto Bliesner, B. L., Chan, K. C., \& Brook, B. W. (2017). PaleoView: a tool for generating continuous climate projections spanning the last 21000 years at regional and global scales. Ecography, 40, $1348-1358$. 
Fuchs, J., \& Pons, J. M. (2015). A new classification of the Pied Woodpeckers assemblage (Dendropicini, Picidae) based on a comprehensive multi-locus phylogeny. Molecular phylogenetics and evolution, 88, 28-37.

Gill, F., Donsker, D., \& Rasmussen, P. (Eds). (2020). IOC World Bird List (v10.1). doi: 10.14344/IOC.ML.10.1.

Gorman, G. (2014). Woodpeckers of the world: the complete guide. Christopher Helm, London.

Grangé J.-L. (2015a). Le pic à dos blanc Dendrocopos leucotos sl. en Corse, entre mythe et réalité. Bulletin de la Société des sciences historiques et naturelles de la Corse, 750-751, 183-199.

Grangé, J.-L. (2015b). Breeding biology of the Lilford Woodpecker Dendrocopos leucotos lilfordi in the Western Pyrenees (SW France). Denisia 36, zugleich Kataloge des oberösterreichischen Landesmuseums Neue Serie, 164, 99-111.

Grangé, J. L., \& Red'kin, Y., (2019). White-backed Woodpecker does not occur in Kamchatka, Russia. Dutch Birding, 41, 103-106.

Heibl, C., \& Calenge, C. (2018). phyloclim: Integrating Phylogenetics and Climatic Niche Modeling. R package version 0.9.5. https://CRAN.R-

project.org/package $=$ phyloclim

Heled, J., \& Drummond, A. J. (2010). Bayesian Inference of Species Trees from Multilocus Data. Molecular Biology and Evolution, 27, 570-580.

Hewitt, G. M. (1996). Some genetic consequences of ice ages, and their role in divergence and speciation. Biological Journal of the Linnean Society, 58, 247-276.

Hewitt, G. M. (2000). The genetic legacy of the Quaternary ice ages. Nature, 405, 907913. 
Hewitt, G. M. (2004). Genetic consequences of climatic oscillation in the Quaterny. Philosophical Transactions of the Royal Society B; Biological Sciences, 359, 183-195.

Hey, J. (2010). Isolation with migration models for more than two populations. Molecular Biology and Evolution, 27, 905-920.

Hey, J., \& Nielsen, R. (2004). Multilocus methods for estimating population sizes, migration rates and divergence time, with applications to the divergence of Drosophila pseudoobscura and D. persimilis. Genetics, 167, 747-760.

Hey, J., \& Nielsen, R. (2007). Integration within the Felsenstein equation for improved Markov chain Monte Carlo methods in population genetics. Proceedings of the National Academy of Sciences, 104, 2785-2790.

Hijmans, R. J., Cameron, S. E., Parra, J. L., Jones, P. G., \& Jarvis, A. (2005). Very high resolution interpolated climate surfaces for global land areas. International Journal of Climatology, 25, 1965-1978.

Hughes, P. D., Gibbard, P. L., \& Ehlers, J. (2013). Timing of glaciation during the last glacial cycle: evaluating the concept of a global 'Last Glacial Maximum'(LGM). EarthScience Reviews, 125, 171-198.

Hung, C. M., Drovetski, S. V., \& Zink, R. M. (2012). Multilocus coalescence analyses support a mtDNA-based phylogeographic history for a widespread palearctic passerine bird, Sitta europaea. Evolution, 66, 2850-2864.

Johnsen, A., Rindal, E., Ericson, P. G. P., Zuccon, D., Kerr, K. C. R., Stoeckle, M. Y., \& Lifjeld, D. (2010). DNA barcoding of Scandinavian birds reveals divergent lineages in trans-Atlantic species. Journal of Ornithology, 151, 565-578.

Kamp, L., Pasinelli, G., Pietro Milanesi, P., Drovetski, S. V., Kosiński, Z., Kossenko, S., .. \& \& Schweizer, M. (2019). Significant Asia-Europe divergence in the middle spotted woodpecker (Aves: Picidae). Zoologica Scripta, 48, 17-32. 
Karger, D. N., Conrad, O., Böhner, J., Kawohl, T., Kreft, H., Soria-Auza, R. W., ... \& Kessler, M. (2017). Climatologies at high resolution for the earth's land surface areas. Scientific data, 4, 170122.

Kullman, L. (2002). Rapid recent range-margin rise of tree and shrub species in the Swedish Scandes. Journal of ecology, 90, 68-77.

Kvist, L., Viiri, K., Dias P. C., Rytkönen, S., \& Orell, M. (2004). Glacial history and colonization of Europe by the blue tit Parus caeruleus. Journal of Avian Biology, 35, 352-359.

Lerner, H. R. L., Meyer, M., James, H. F., Hofreiter, M., \& Fleischer, R. C. (2011). Multilocus resolution of phylogeny and timescale in the extant adaptive radiation of Hawaiian Honeycreepers. Current Biology, 21, 1838-1844.

Librado, P, \& Rozas, J. (2009). DnaSP v5: a software for comprehensive analysis of DNA polymorphism data. Bioinformatics, 25, 1451-1452.

McDonald, J. H., \& Kreitman, M. (1991). Adaptive protein evolution at the Adh locus in Drosophila. Nature, 351, 652-654.

Milne, I., Lindner, D., Bayer M., Husmeier, D, McGuire, G., Marshall, D. F., \& Wright F. (2009). TOPALi v2: a rich graphical interface for evolutionary analyses of multiple alignments on HPC clusters and multi-core desktops. Bioinformatics, 25, 126-127.

Moltoni, E., \& Brichetti, P. (1977). Osservazioni ornitologiche in Corsica alla fine del maggio 1977. Rivista Italiana di Ornitologia, 47, 149-205.

Nabholz, B., Lanfear, R., \& Fuchs, J., (2016). Body mass-corrected molecular rate for bird mitochondrial DNA. Molecular Ecology, 25, 4438-4449.

Otto-Bliesner, B. L., Marshall, S. J., Overpeck, J. T., Miller, G. H., \& Hu, A, (2006). Simulating Arctic climate warmth and icefield retreat in the last interglaciation. Science, $311,1751-1753$. 
Pavlova, A., Rohwer, S., Drovetski, S. V., \& Zink, R. M. (2006). Different postPleistocene histories of Eurasian parids. Journal of Heredity, 97, 389-402.

Perktaş, U., \& Quintero, E. (2013). A wide geographical survey of mitochondrial DNA variation in the great spotted woodpecker complex, Dendrocopos major (Aves: Picidae). Biological Journal of the Linnean Society, 108, 173-188.

Pentzold, S., Tristch, C., Martens, J., Tietze, D. T., Giacalone, G., Lo Valva, M., ..., Päckert, M. (2013). Where is the line? Phylogeography and secondary contact of western Palearctic coal tits (Periparus ater: Aves, Passeriformes, Paridae). Zoologischer Anzeiger 252, 367-382.

Phillips, S. J., \& Dudík, M. (2008). Modeling of species distributions with Maxent: new extensions and a comprehensive evaluation. Ecography, 31, 161-175.

Phillips, S. J., Anderson, R. P., \& Schapire, R. E. (2006). Maximum entropy modeling of species geographic distributions. Ecological Modelling, 190, 231-239.

Pons, J, Barraclough, T. G., Gomez-Zurita, J, Cardoso, A, Duran, D. P., Hazell, S, ..., Vogler, A. P. (2006). Sequence-based species delimitation for the DNA taxonomy of undescribed insects. Systematic Biology, 55, 595-609.

Pons, J.-M., Olioso, G., Cruaud, C., \& Fuchs, J. (2011). Phylogeography of the Eurasian green woodpecker (Picus viridis). Journal of biogeography, 38, 311-325.

Pons, J.-M., Thibault, J.-C., Fournier, J., Olioso, G., Rakovic, M., Tellini Florenzano, G., \& Fuchs, J. (2015). Genetic variation among Corsican and continental populations of the Eurasian treecreeper (Aves: Certhia familiaris) reveals the existence of a palaeoendemic mitochondrial lineage. Biological journal of the Linnean Society, 115, 134-153.

Provan, J, \& Benett, K.D. (2008). Phylogeographic insights into cryptic glacial refugia. Trends in Ecology and Evolution 23, 564-571.

R Core Team. (2013). R: A language and environment for statistical computing. R 
Foundation for Statistical Computing, Vienna, Austria. Available via http://www.Rproject.org/.

Rambaut, A., \& Drummond, A. J. (2009). Tracer version 1.6. Available via http://beast.bio.ed.ac.uk.

Reid, N. M., \& Carstens, B. C., (2012). Phylogenetic estimation error can decrease the accuracy of species delimitation: a Bayesian implementation of the general mixed Yulecoalescent model. BMC Evolutionary Biology 12, 196.

Sallé, A., Arthofer, W., Lieutier, F., Stauffer, C., \& Kerdelhué, C. (2007). Phylogeography of a host-specific insect: genetic structure of Ips typographus in Europe does not reflect past fragmentation of its host. Biological Journal of the Linnean Society, 90, 239-246.

Schmitt T. (2007). Molecular biogeography of Europe: Pleistocene cycles and postglacial trends. Frontiers in Zoology, 4, 11 doi: 10.1186/1742-9994-4-11

Schmitt, T., \& Varga, Z. (2012). Extra-Mediterranean refugia: the rule and not the exception? Frontiers in Zoology, 9, 22.

Shakya, S. B., Fuchs, J., Pons, J.-M., \& Sheldon, F. H. (2017). Tapping the woodpecker tree for evolutionary insight. Molecular Phylogenetics and Evolution, 116, 182-191.

Strasburg, J. L., \& Rieseberg, L. H. (2010). How robust are "Isolation with Migration" analyses to violations of the IM Model? A simulation study. Molecular Biology and Evolution, 27, 297-310.

Subramanian, S, Denver, D. R., Millar, C. D., Heupink, T, Aschrafi, A, Emslie, S. D.,..., Lambert, D. M. (2009). High mitogenomic evolutionary rates and time dependency. Trends in Genetics, 25, 482-486.

Taberlet, P, Fumagalli, L, Wust-Saucy, A. G., \& Cosson, J. F. (1998). Comparative phylogeography and post glacial colonization. Molecular Ecology, 7, 453-464. 
Thibault, J.-C., \& Bonaccorsi, G. (1999). The Birds of Corsica.An Annotated Check-list. No17. British Ornithologists Union, Tring.

Tomialojć, L. (2000). An East-West gradient in the breeding distribution and species richness of the European woodland avifauna. Acta Ornithologica, 35, 3-17.

Vaurie, C. (1959). Systematic notes on Paleartic birds. American Museum Novitates No 35 Picidae: The genus Dendrocopos (Part 1) 1946, 1-29.

Voous, K. H. (1947). On the history of the distribution of the Genus Dendrocopos. Limosa, 20, 1-142.

Ward, R. D., Hanner, R., \& Hebert, P. D. N. (2009). The campaign to DNA barcode all fishes, FISH-BOL. Journal of Fish Biology, 74,329-356.

Warren, D., Matzke N., Cardillo, M., \& Dinnage, R. (2017). ENMTools: Analysis of niche evolution using niche and distribution models. $\mathrm{R}$ package version 0.2 .

Weiss, S, \& Ferrand, N. 2007. Phylogeography of the Southern Europe Refugia Evolutionary perspectives on the origins and conservation of European biodiversity. Springer, Dordrecht, The Netherlands. 390p.

Wickham, H. (2014). scales: Scale functions for graphics. R package version 0.2.4. Available via http://CRAN. Rproject.org/package=scales.

Winkler, H. \& Christie, D. A. (2020). White-backed Woodpecker (Dendrocopos leucotos). In: del Hoyo, J., Elliott, A., Sargatal, J., Christie, D.A. \& de Juana, E. (eds.). Handbook of the Birds of the World Alive. Lynx Edicions, Barcelona. https://www.hbw.com/node/56224.

Winkler, H., Christie, D. A., Kirwan, G. M., \& Sharpe, C. J. (2020). Okinawa Woodpecker (Dendrocopos noguchii). In: del Hoyo, J., Elliott, A., Sargatal, J., Christie, D.A. \& de Juana, E. (eds.). Handbook of the Birds of the World Alive. Lynx Edicions, Barcelona. https://www.hbw.com/node/56325). 
Winkler, H., Kotaka, N., Gamauf, A., Nittinger, F., \& Haring, E. (2005). On the phylogenetic position of the Okinawa woodpecker (Sapheopipo noguchii). Journal of Ornithology, 146, 103-110.

Yang, Z., (2007). PAML 4: Phylogenetic Analysis by Maximum Likelihood. Molecular Biology and. Evolution, 24, 1586-1591.

Yang, Z., \& Rannala, B., (2014). Unguided species delimitation using DNA sequence data from multiple loci. Molecular Biology and. Evolution, 31, 3125-3135.

Zink, R. M., Drovetski, S. V., \& Rohwer, S (2002a). Phylogeographic patterns in the great spotted woodpecker Dendrocopos major across Eurasia. Journal of Avian Biology, $33,175-178$.

Zink, R. M., Rohwer, S., Drovetski, S., Blackwell-Rago, R. C., \& Farrell, S. L. (2002b). Holarctic phylogeography and species limits of three-toed woodpeckers. The Condor, 104, 167-170. 
Pons J.-M.

\section{TABLES}

Table 1: Information on the two external and the eight internal primers designed to amplify the COI from the historical specimens.

\begin{tabular}{ll}
\hline Forward primer & Reverse Primer \\
\hline COIExt: ACGCTTTAACACTCAGCCATCTTACC leuCOI55H: AATCCCCCGATTATGATGGG \\
leuCOI36L: TCACCGCCCATGCATTTGTG & leuco263H: ACTGTGGAGGAGGCTAGGAG \\
leuco260L: ATAAGCTTYTGACTTCTCCC & leuco403H: TCCTAGGATTGATGAGATGC \\
leuco385L: CTCAGTAGACCTAGCCATCTT & leuco526H: GTACCGGGAGTGATAGGAGT \\
leuco507L: CCTATTCGTCTGATCTGTCC & FISH1R: TAGACTTCTGGGTGGCCAAAGAATCA \\
\hline
\end{tabular}

Table 2: Number of haplotypes, haplotype diversity $(\mathrm{Hd})$, nucleotide diversity $(\pi)$, Tajima's D and Fu's statistics obtained for the northern leucotos group (leucotos and uralensis) and the southern lilfordi group using the mitochondrial gene COI (647bp). Ni $=$ number of individuals, $\mathrm{Nh}=$ number of haplotypes, $\mathrm{Np}=$ number of polymorphic sites. In bold significant values supporting population expansion.

\begin{tabular}{lll}
\hline & leucotos/uralensis & lilfordi \\
\hline $\mathrm{Ni}$ & 44 & 23 \\
$\mathrm{Nh}$ & 6 & 5 \\
$\mathrm{~Np}$ & 5 & 6 \\
$\mathrm{Hd}$ & 0.29 & 0.64 \\
$\pi$ & 0.0005 & 0.002 \\
& & \\
Tajima's D & -1.82 & -1.08 \\
p-value & $\mathbf{0 . 0 2}$ & 0.14 \\
& & \\
Fu's Fs & -5.19 & -0.81 \\
p-value & $\mathbf{0 . 0 0 0 1}$ & 0.28 \\
\hline
\end{tabular}


Pons J.-M.

\section{LEGENDS OF FIGURES}

Figure 1: Distribution of the White-backed Woodpecker (BirdLife International and NatureServe 2013) and sampling localities included in the present study. D. l. leucotos northern group includes leucotos (red) and uralensis (brown). Japanese subspecies (light orange $=$ subcirris $;$ pink $=$ stejnegeri $;$ dark orange $=$ namiyei $;$ yellow $=$ owstoni $)$. Chinese subspecies group (black = insularis; grey = tangi). Southern group lilfordi (blue). Precise sampling localities and sample size are reported in the table S1. Several checklists and monographies considered that D. leucotos was occurring in Kamchatka, Russia (e.g. BirdLife International \& Nature Serve 2013, Vaurie 1959, Winkler \& Christie 2020); a recent review of type specimens concluded that there is no evidence for the presence of D. leucotos in Kamchatka (Grangé \& Red'kin 2019). Maps were made using R (R CoreTeam 2013) libraries maps and mapdata (Becker \& Wilks 2013), maptools (Bivand \& Lewin-Koh 2014) and scales (Wickham 2014).

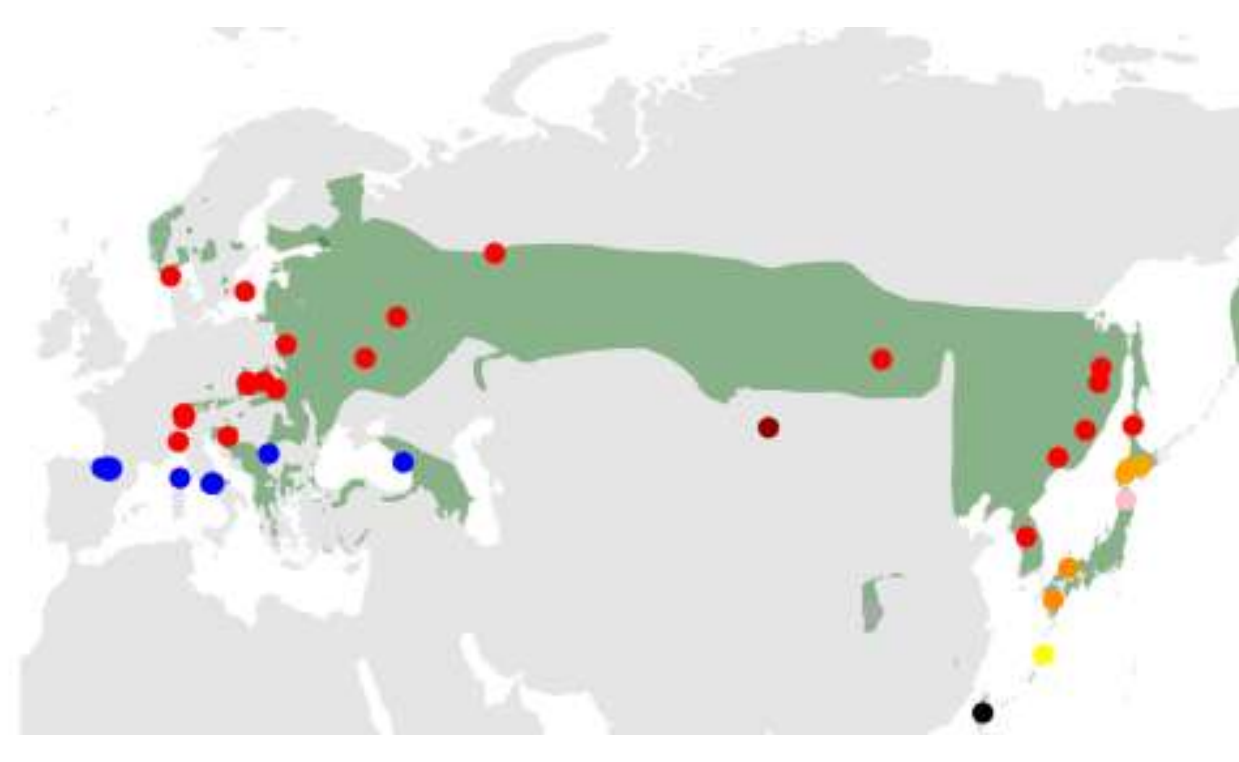


Pons J.-M.

Figure 2: Fifty percent majority-rule consensus tree obtained from the Bayesian analyses of the mitochondrial markers (COI) using BEAST 1.8.2. Only unique haplotypes were included in the matrix. Values close to nodes represent Bayesian posterior probabilities (PP). Veniliornis mixtus and Picoides pubescens were used as outgroup.

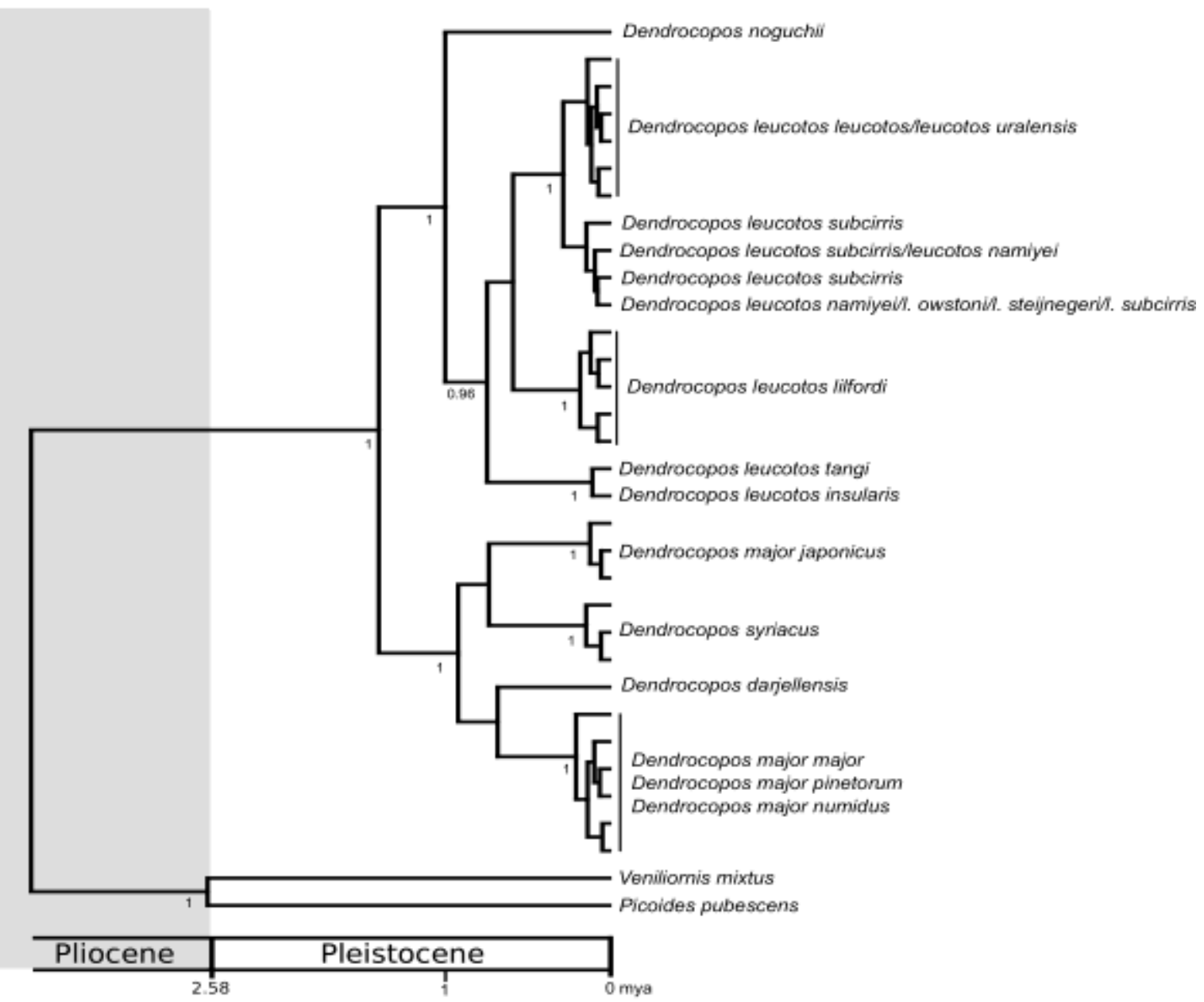


Pons J.-M.

Figure 3: Species tree based on the phased nuclear alleles obtained with *BEAST. Values close to nodes represent Bayesian posterior probabilities (PP). PP values $<0.90$ not shown. Veniliornis mixtus and Picoides pubescens were used as outgroup. Chinese subspecies (tangi, insularis) could not be included in the data set.

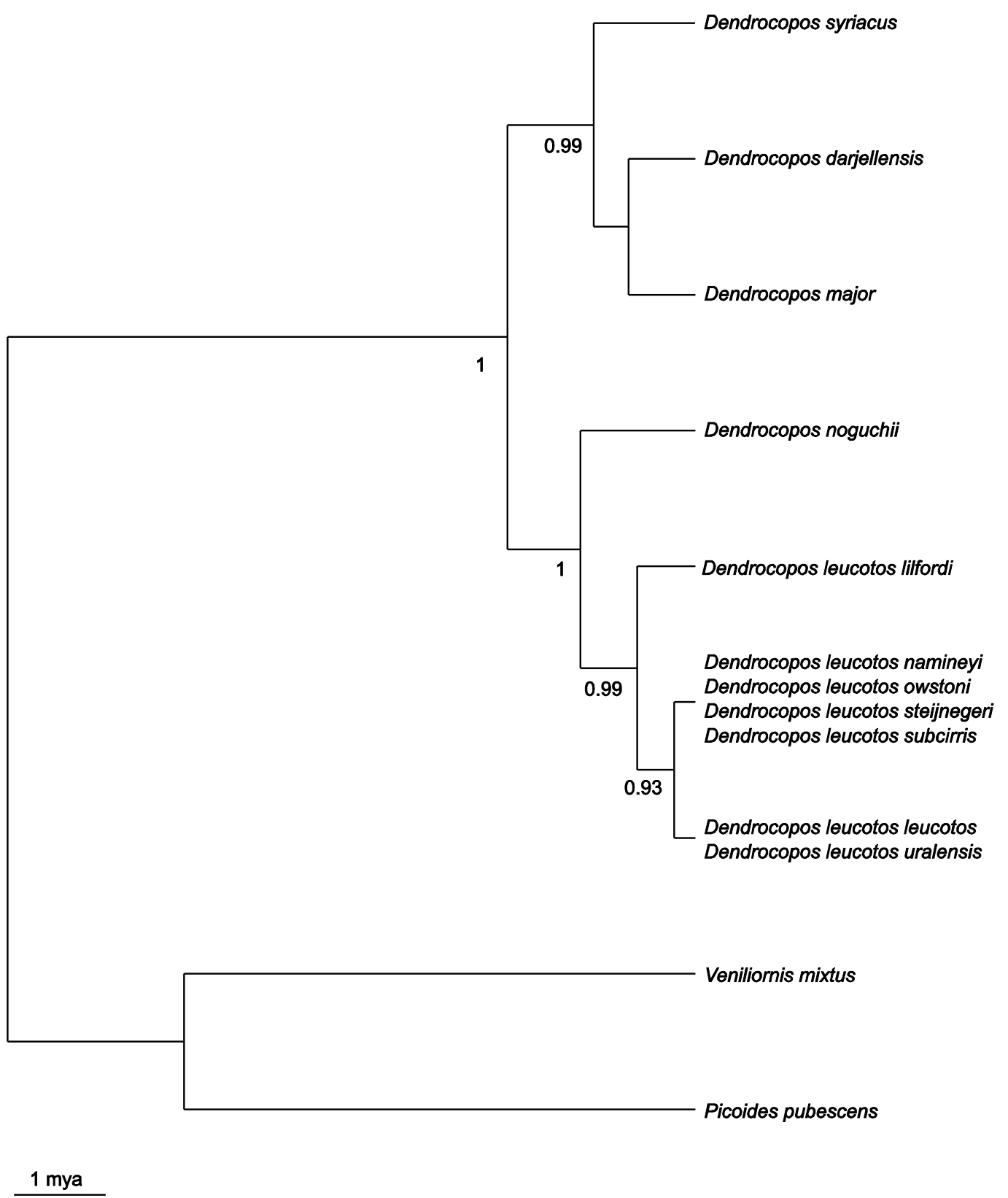


Pons J.-M.

Figure 4: Median joining network showing COI haplotypes relationships among Dendrocopos leucotos subspecies. The size of each circle is proportional to haplotype frequency. Red = Pyrenees; Grey= Corsica? $($ see text $)$; Dark blue = Balkans, Serbia; Pink $=$ Abruzzi, Italia; Violet $=$ Caucasia, southern Russia $;$ Light green $=$ Poland ;reen = Western and central Europa; Black = Russia (west to far east); White = Mongolia; Grey $=$ South-Korea; Light blue $=$ Scandinavia. Small red dots are unsampled haplotypes.

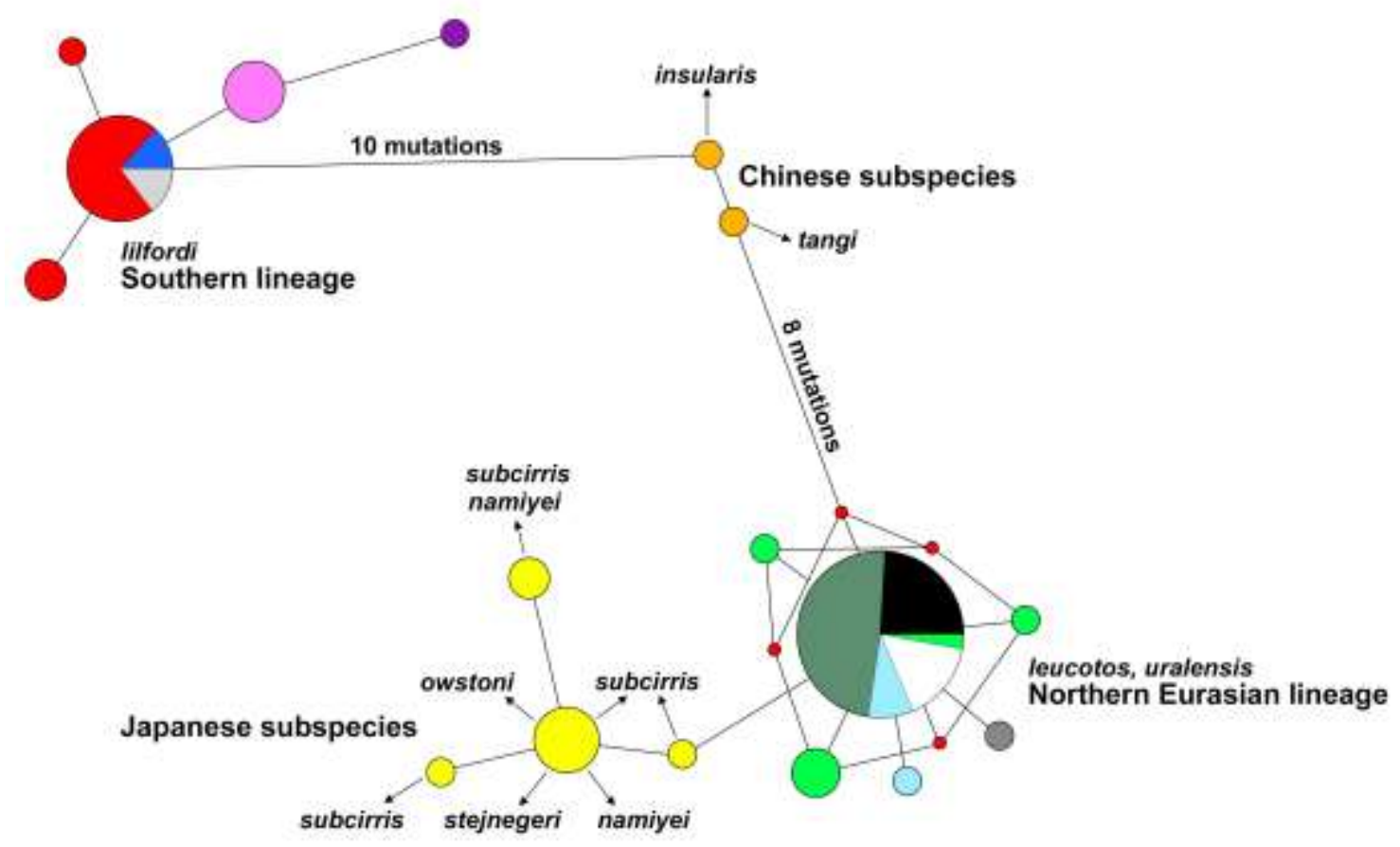

Figure 5: Predicted geographic distributions for leucotos/uralensis, the japanese subspecies clade, and lilfordi subspecies of the White-backed Woodpecker. Nine climatic variables were used to build species distribution models: annual mean temperature (BIO1), mean diurnal range (BIO2), isothermality (BIO3), temperature seasonality (BIO4), mean temperature of wettest quarter (BIO8), annual precipitation (BIO12), precipitation of the driest month (BIO14), precipitation seasonality (BIO15), and precipitation of the coldest quarter of the year (BIO19). The niche models for 
Pons J.-M.

current conditions were projected on paleoclimatic layers from the Last Interglacial (about 130,000 years ago) and the Last Glacial Maximum (21,000 years ago).

Dendrocopos I. leucotos/l. uralensis
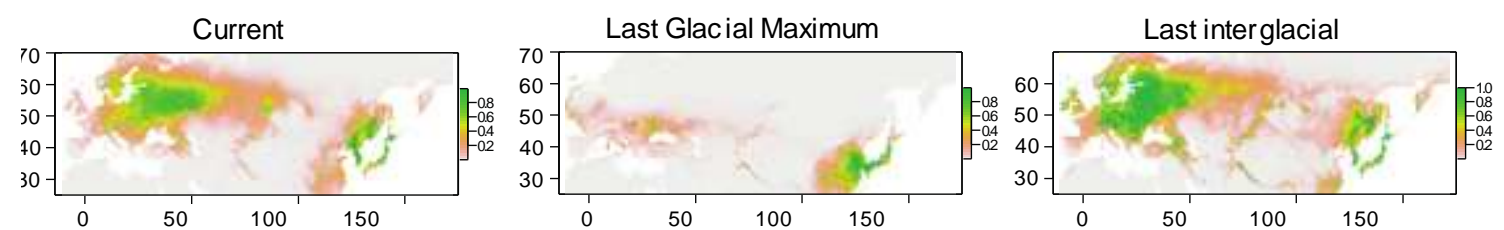

Dendrocopos I. namieyi/l. owstoni /I . stejnegeri/l. subcirris
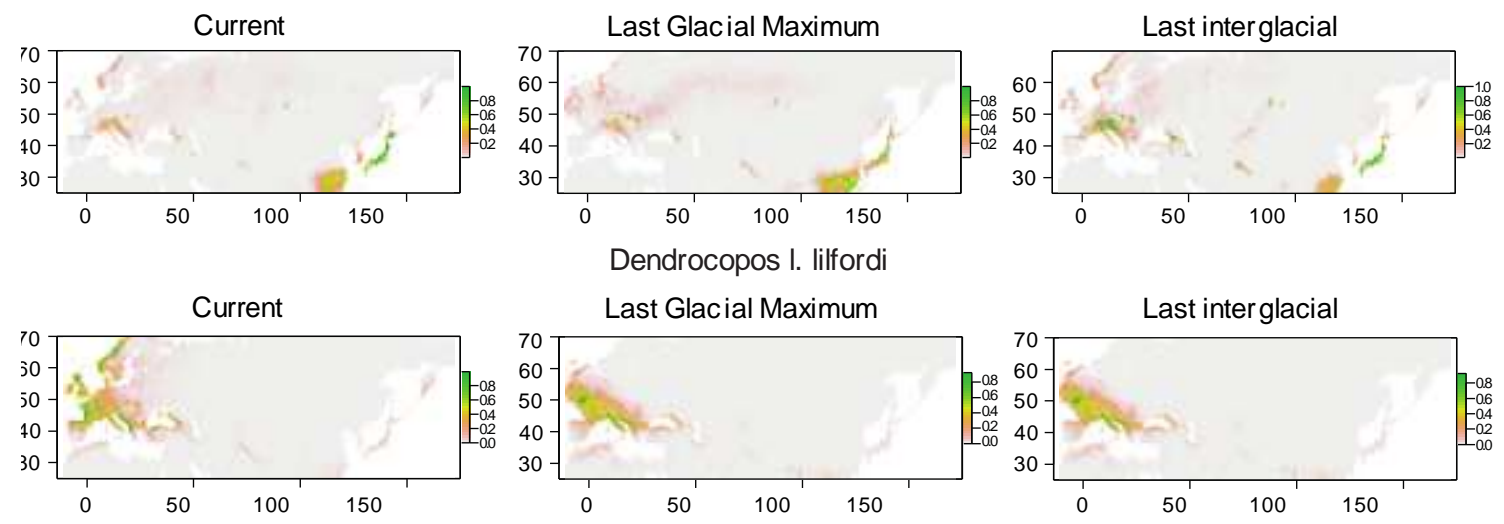


\section{SUPPLEMENTARY MATERIAL}

Table S1: Information on Dendrocopos leucotos specimens and sequences included in the study

Table S2: Summary statistics obtained for the three nuclear introns (FGB, MB and $\mathrm{TGFb} 2$ ). $\mathrm{N}_{\text {ind }}=$ number of individuals, $\mathrm{N}_{\mathrm{chr}}=$ number of chromosomes, $\mathrm{N}_{\text {alleles }}=$ number of alleles, $\mathrm{S}=$ Number of segregating sites, $\mathrm{H}=$ allele diversity, $\pi=$ nucleotide diversity.

Figure S1: Fifty percent majority-rule consensus tree obtained from the Bayesian analyses of the FGB marker using MRBAYES. Values close to nodes represent Bayesian posterior probabilities (PP). PP values $<0.95$ not shown. Veniliornis mixtus and Picoides pubescens were used as outgroup. Chinese subspecies (tangi, insularis) could not be included in the data set.

Figure S2: Fifty percent majority-rule consensus tree obtained from the Bayesian analyses of the TGFb2 marker using MRBAYES. Values close to nodes represent Bayesian posterior probabilities (PP). PP values $<0.95$ not shown. Veniliornis mixtus and Picoides pubescens were used as outgroup. Chinese subspecies (tangi, insularis) could not be included in the data set.

Figure S3: Fifty per cent majority-rule consensus tree obtained from the Bayesian analyses of the MB marker using MRBAYES. All PP values $<0.95$ (not shown). Veniliornis mixtus and Picoides pubescens were used as outgroup. Chinese subspecies (tangi, insularis) could not be included in the data set.

Figure $\mathrm{S} 4_{\mathrm{A}, \mathrm{B}, \mathrm{C}, \mathrm{D}, \mathrm{E}, \mathrm{F}, \mathrm{G}}$ : Predicted geographic distributions for Dendrocopos leucotos subspecies, with a focus on the potential distribution of D. leucotos lilfordi in Corsica. The present niche model was projected on paleoclimatic layers from three times 
Pons J.-M.

periods: the Last Interglacial (about 130,000 years ago, Last Glacial Maximum (21,000 years ago) and the Mid-Holocene (8,326-4,200 years ago). 


\section{SUPPORTING INFORMATION}

\section{TABLES}

Table S2: Summary statistics obtained for the three nuclear introns (FGB, MB and TGFB). $\mathrm{N}_{\text {ind }}=$ number of individuals, $\mathrm{N}_{\mathrm{chr}}=$ number of chromosomes, $\mathrm{N}_{\text {alleles }}=$ number of alleles, $\mathrm{S}=$ Number of segregating sites, $\mathrm{H}=$ allele diversity, $\pi$ = nucleotide diversity.

\begin{tabular}{|c|c|c|c|}
\hline & FGB & MB & TGFB \\
\hline \multicolumn{4}{|c|}{ Leucotos sensulato } \\
\hline $\mathrm{N}_{\text {ind }} / \mathrm{N}_{\text {chr }}$ & $12 / 24$ & $15 / 30$ & $15 / 30$ \\
\hline $\mathrm{N}_{\text {alleles }} / \mathrm{S}$ & $6 / 8$ & $5 / 4$ & $2 / 1$ \\
\hline $\mathrm{H} / \pi$ & $0.728 / 0.0055$ & $0.662 / 0.00125$ & $51 \quad 0.067 / 0.00014$ \\
\hline \multicolumn{4}{|c|}{ Northern group } \\
\hline $\mathrm{N}_{\text {ind }} / \mathrm{N}_{\text {chr }}$ & $8 / 16$ & $11 / 22$ & $11 / 22$ \\
\hline $\mathrm{N}_{\text {alleles }} / \mathrm{S}$ & $5 / 7$ & $5 / 4$ & $2 / 1$ \\
\hline $\mathrm{H} / \pi$ & $0.608 / 0.0045$ & $0.658 / 0.0012$ & $0.091 / 0.00019$ \\
\hline \multicolumn{4}{|c|}{ Japanese ssp } \\
\hline $\mathrm{N}_{\text {ind }} / \mathrm{N}_{\text {chr }}$ & $3 / 6$ & $5 / 10$ & $4 / 8$ \\
\hline $\mathrm{N}_{\text {alleles }} / \mathrm{S}$ & $4 / 4$ & $4 / 3$ & $2 / 1$ \\
\hline \multicolumn{4}{|c|}{ leucotos/uralensis } \\
\hline $\mathrm{N}_{\text {ind }} / \mathrm{N}_{\text {chr }}$ & $5 / 10$ & $6 / 12$ & $7 / 14$ \\
\hline $\mathrm{N}_{\text {alleles }} / \mathrm{S}$ & $1 / 0$ & $3 / 2$ & $1 / 0$ \\
\hline $\mathrm{H} / \pi$ & $0 / 0$ & $0.318 / 0.0005$ & $0 / 0$ \\
\hline \multicolumn{4}{|c|}{ Southern group (lilfordi) } \\
\hline $\mathrm{N}_{\text {ind }} / \mathrm{N}_{\text {chr }}$ & $4 / 8$ & $4 / 8$ & $4 / 8$ \\
\hline $\mathrm{N}_{\text {alleles }} / \mathrm{S}$ & $1 / 0$ & $1 / 0$ & $1 / 0$ \\
\hline $\mathrm{H} / \pi$ & $0 / 0$ & $0 / 0$ & $0 / 0$ \\
\hline
\end{tabular}




\section{FIGURES}

Figure S1: Fifty percent majority-rule consensus tree obtained from the Bayesian analyses of the FGB marker using MR BAYES. Values close to nodes represent Bayesian posterior probabilities (PP). PP values $<0.95$ not shown. Veniliornis mixtus and Picoides pubescens were used as outgroup. Chinese subspecies (tangi, insularis) could not be included in the data set.

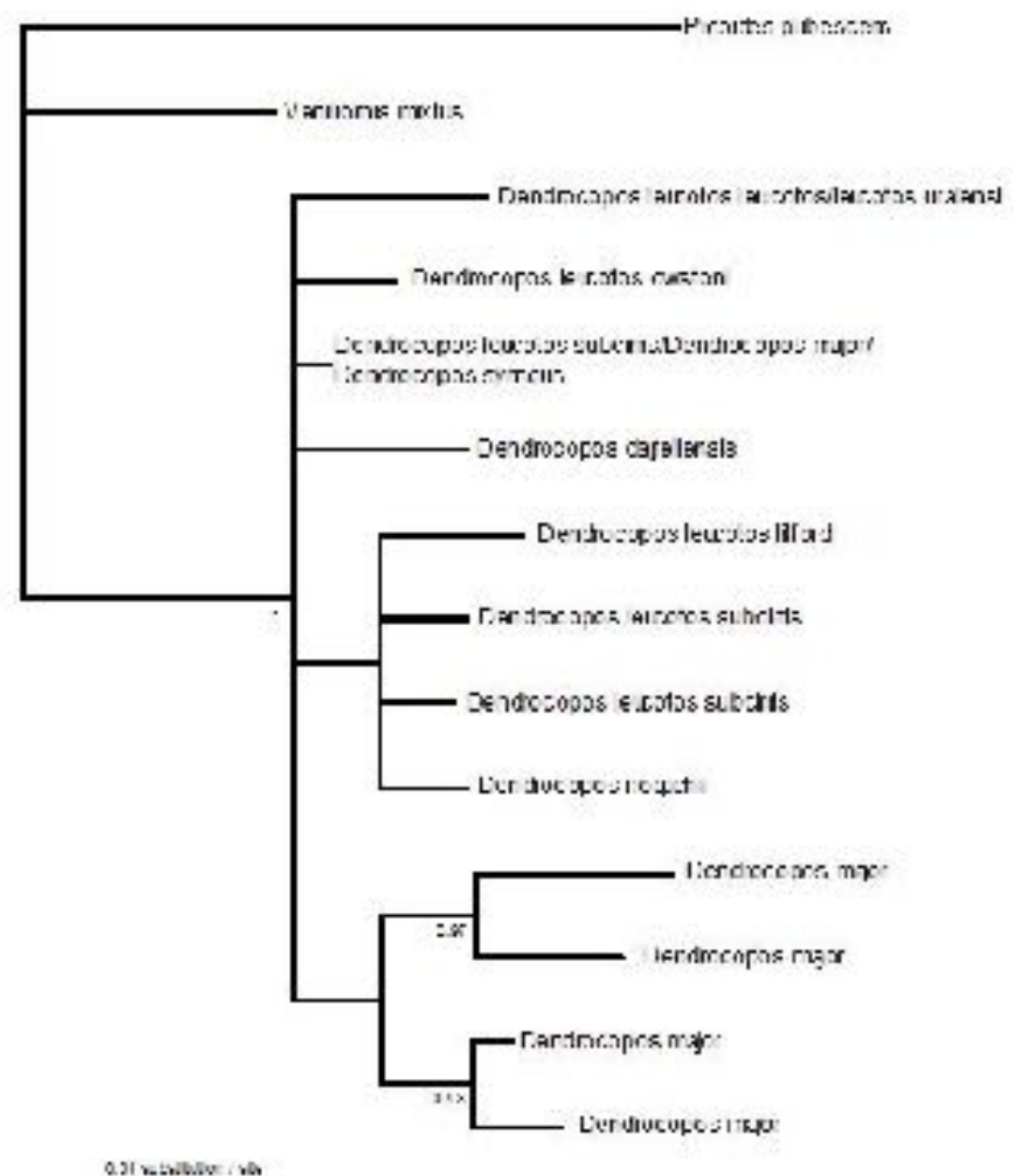


Figure S2: Fifty percent majority-rule consensus tree obtained from the Bayesian analyses of the TGFB marker using MR BAYES. Values close to nodes represent Bayesian posterior probabilities (PP). PP values $<0.95$ not shown. Veniliornis mixtus and Picoides pubescens were used as outgroup. Chinese subspecies (tangi, insularis) could not be included in the data set.

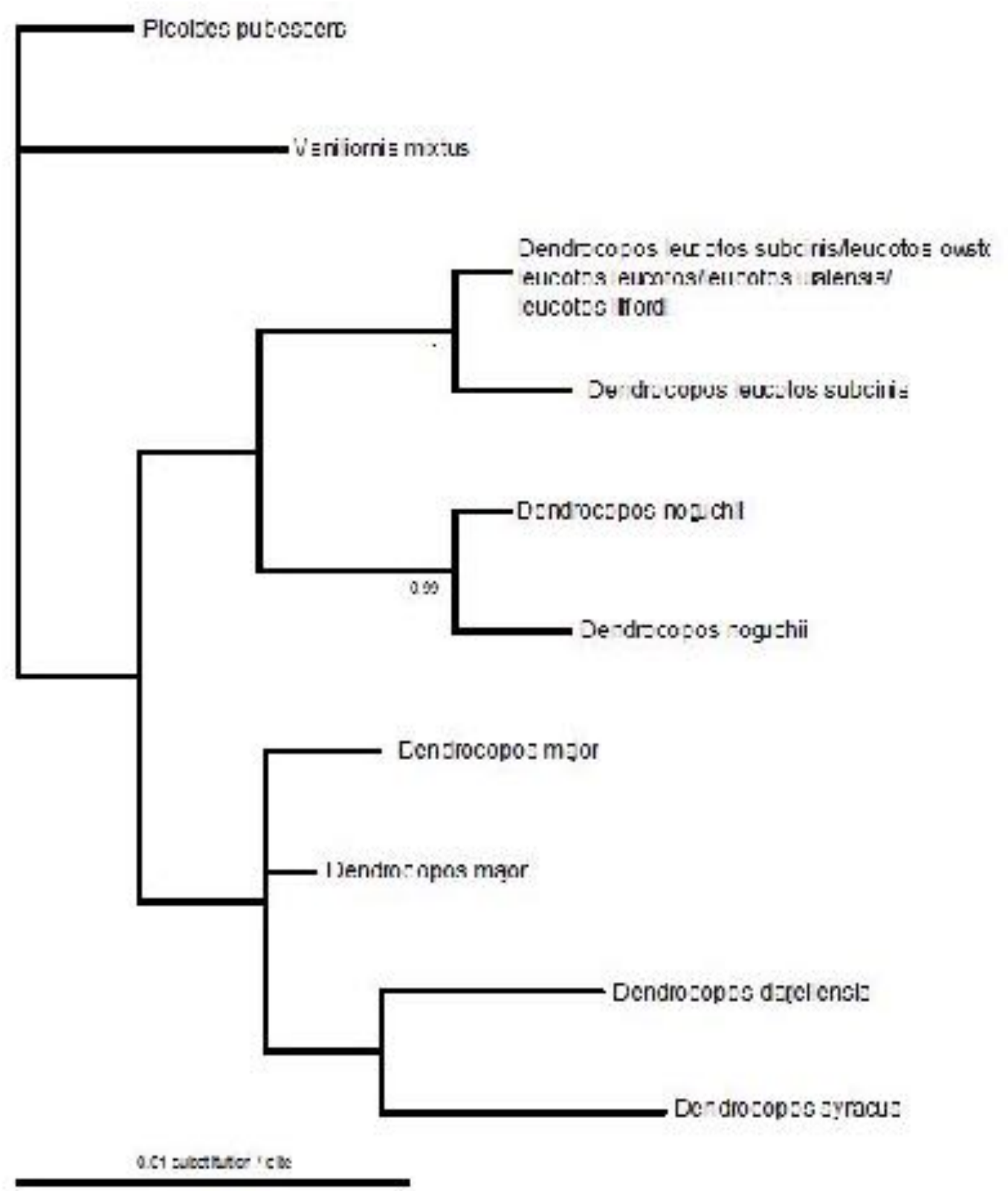


Figure S3: Fifty per cent majority-rule consensus tree obtained from the Bayesian analyses of the MB marker using MR BAYES. All PP values $<0.95$ (not shown).Veniliornis mixtus and Picoide spubescens were used as outgroup. Chinese subspecies (tangi, insularis) could not be included in the data set.

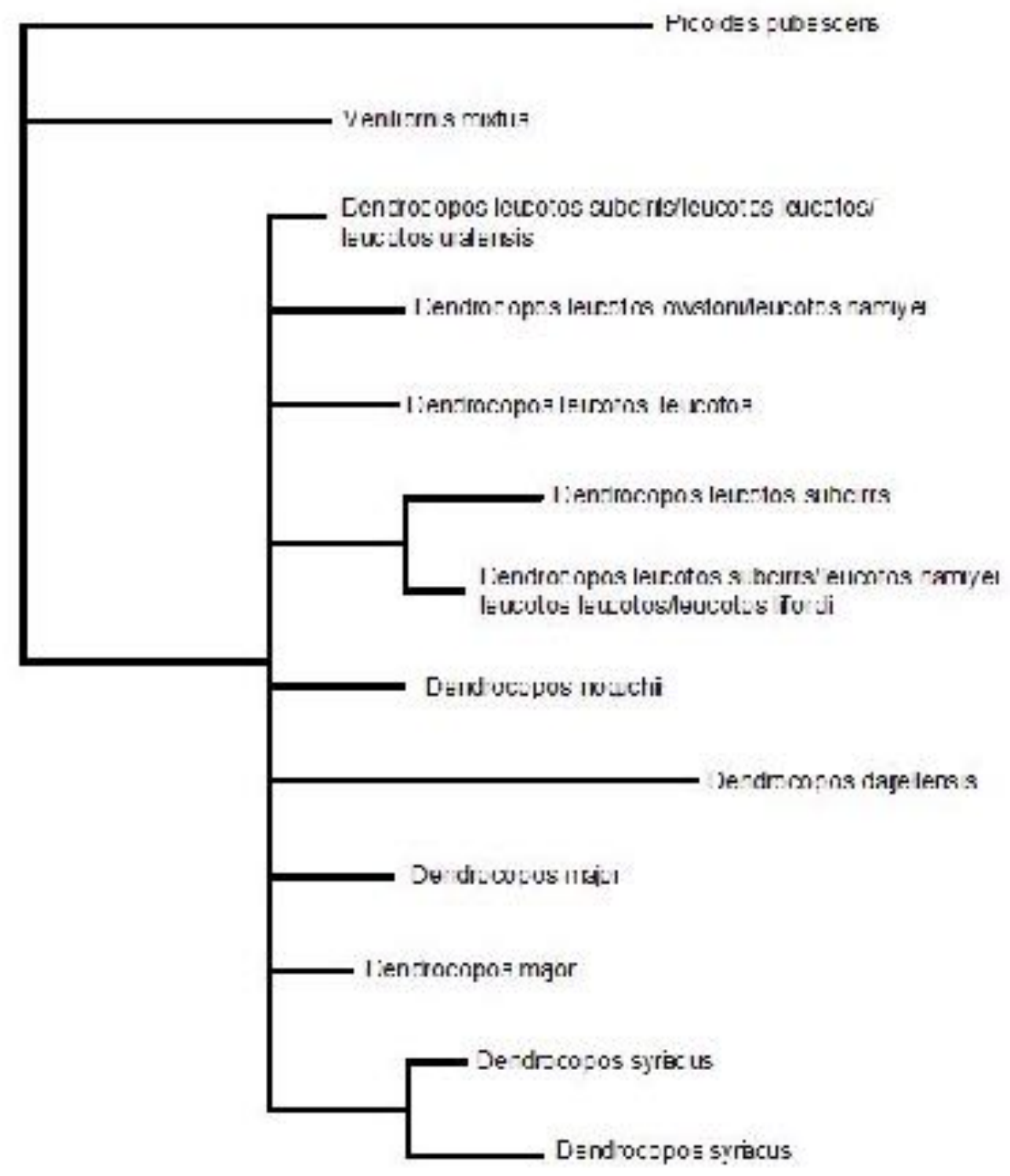


Figure $\mathrm{S} 4_{\mathrm{A}, \mathrm{B}, \mathrm{C}, \mathrm{D}, \mathrm{E}, \mathrm{F}, \mathrm{G}}$ : Predicted geographic distributions for Dendrocopos leucotos subspecies during the Mid-Holocene period ( $\mathrm{S} 4_{\mathrm{A}, \mathrm{B}, \mathrm{C}}$, see the Fig. 5 for the other time periods) with a focus on the potential distribution of $D$. leucotos lilfordi in Corsica $\left(\mathrm{S} 4_{\mathrm{D}, \mathrm{E}, \mathrm{F}, \mathrm{G}}\right)$. The present niche model was projected on paleoclimatic layers from three times periods: the Last Interglacial (about 130,000 years ago, Last Glacial Maximum (21,000 years ago) and the Mid-Holocene (8,326-4,200 years ago).

S4 $4_{\mathrm{A}}$ : Predicted Mid-Holocene distribution of Japanese subspecies clade

\section{Mid-Holocene Suitability}

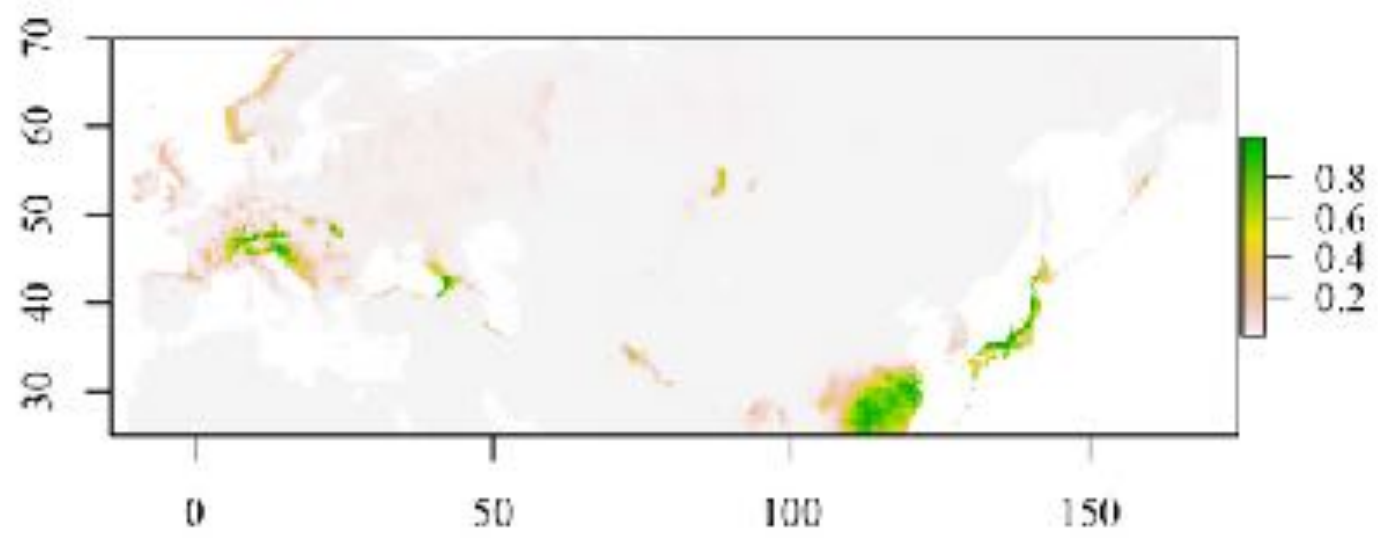


$\mathrm{S} 4_{\mathrm{B}}$ : Predicted Mid-Holocene distribution of D. leucotos/uralensis

mid-Holocene

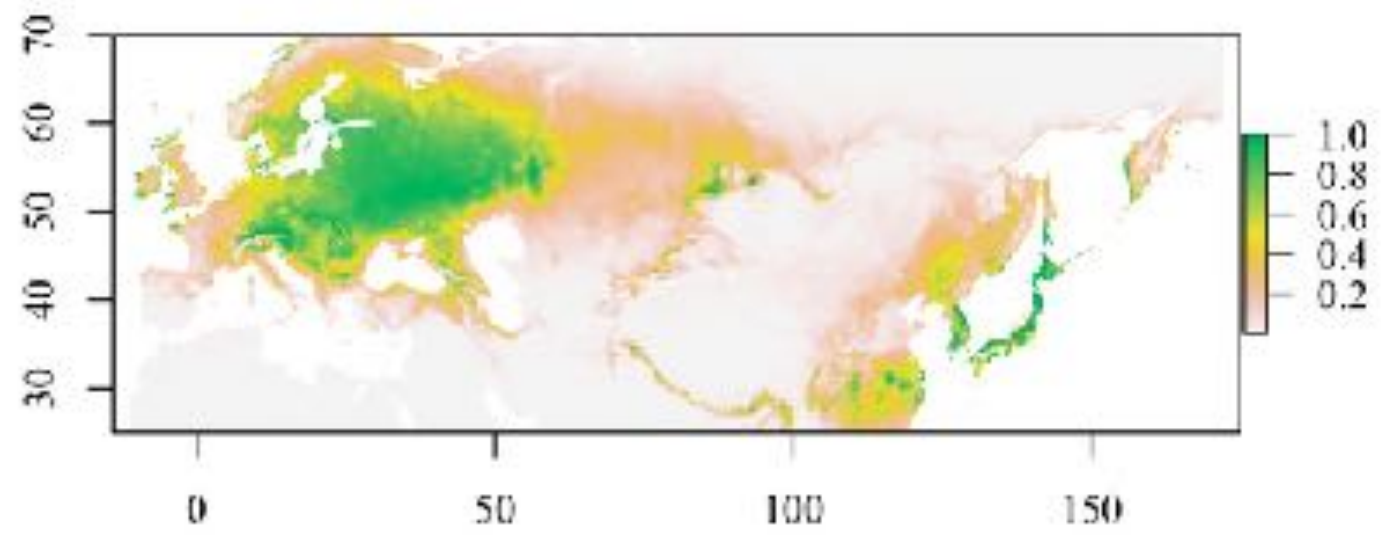

S4 ${ }_{C}$ : Predicted Mid-Holocene distribution of D. lilfordi 
mid-Holocene Suitability

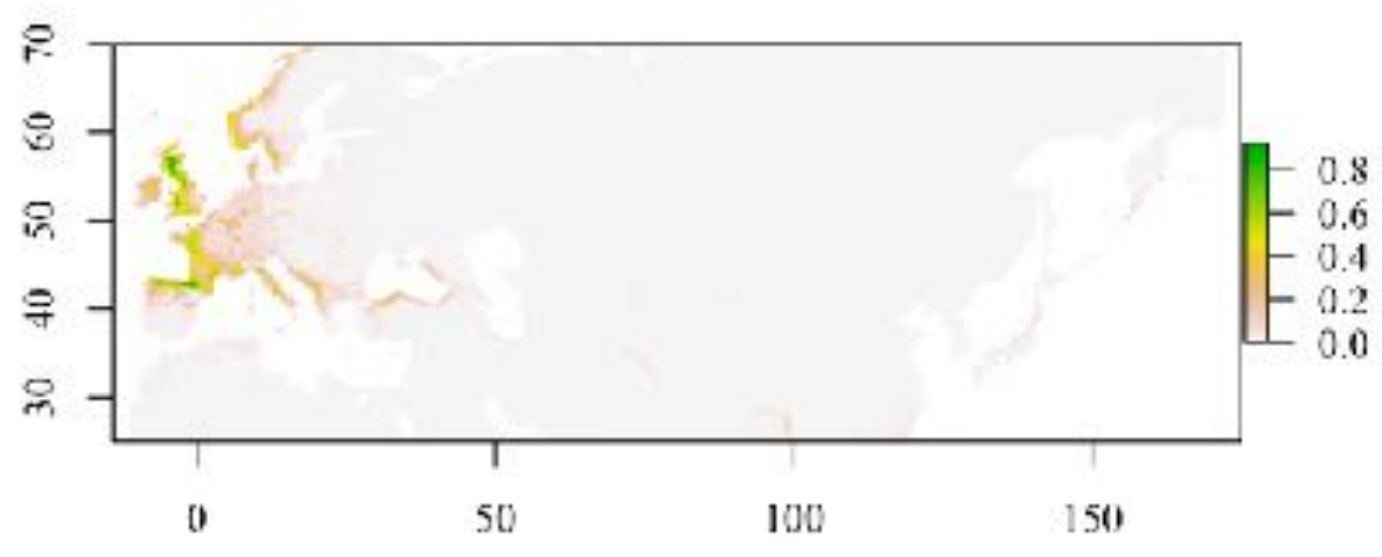

S4D: Prediction of the present distribution of $D$. lilfordi in Corsica

\section{Predicted Suitability}

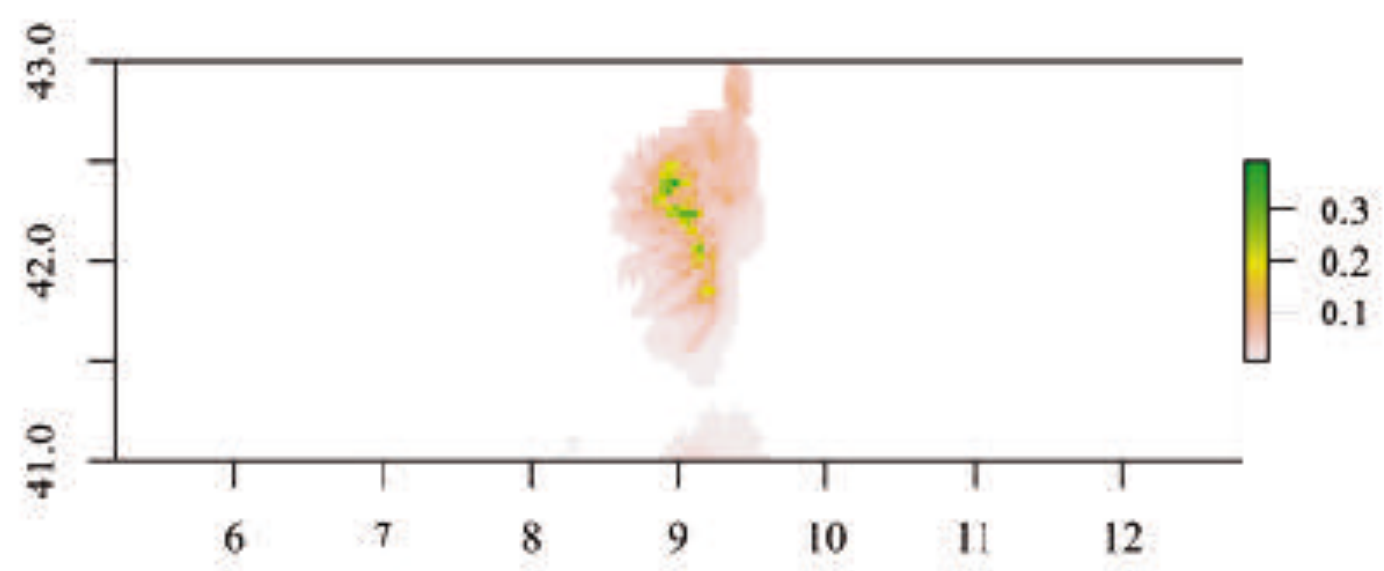


S4 $4_{\mathrm{E}}$ : Predicted Last interglacial distribution of $D$. lilfordi in Corsica

\section{LIG Suitability}

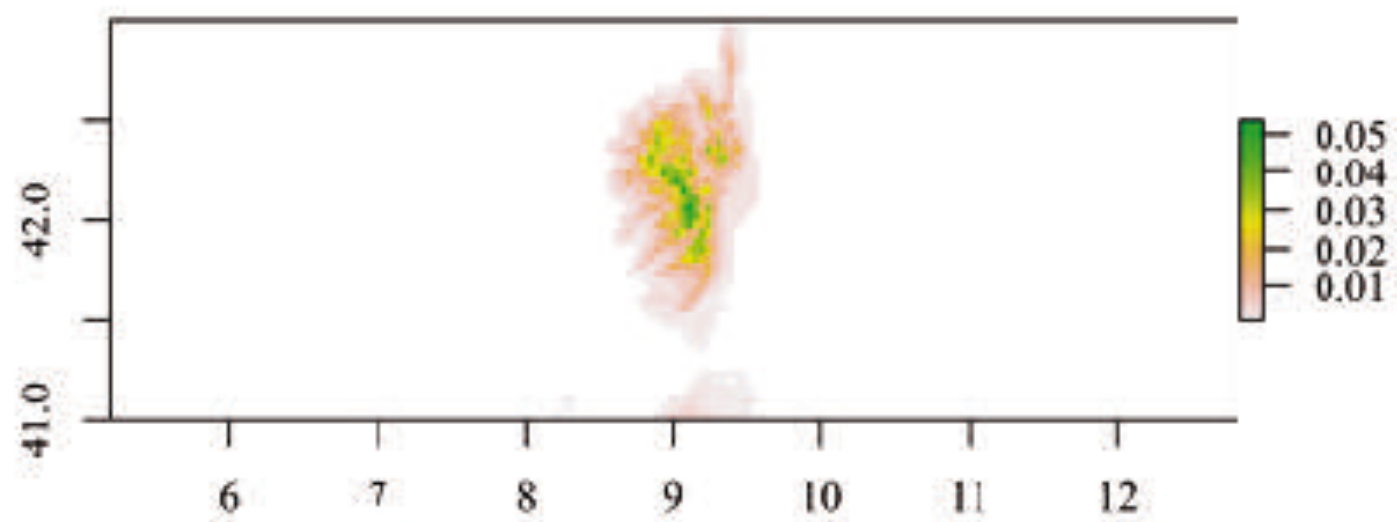

S4F: Predicted Mid-Holocene distribution of D. lilfordi in Corsica

mid-Holocene Suitability

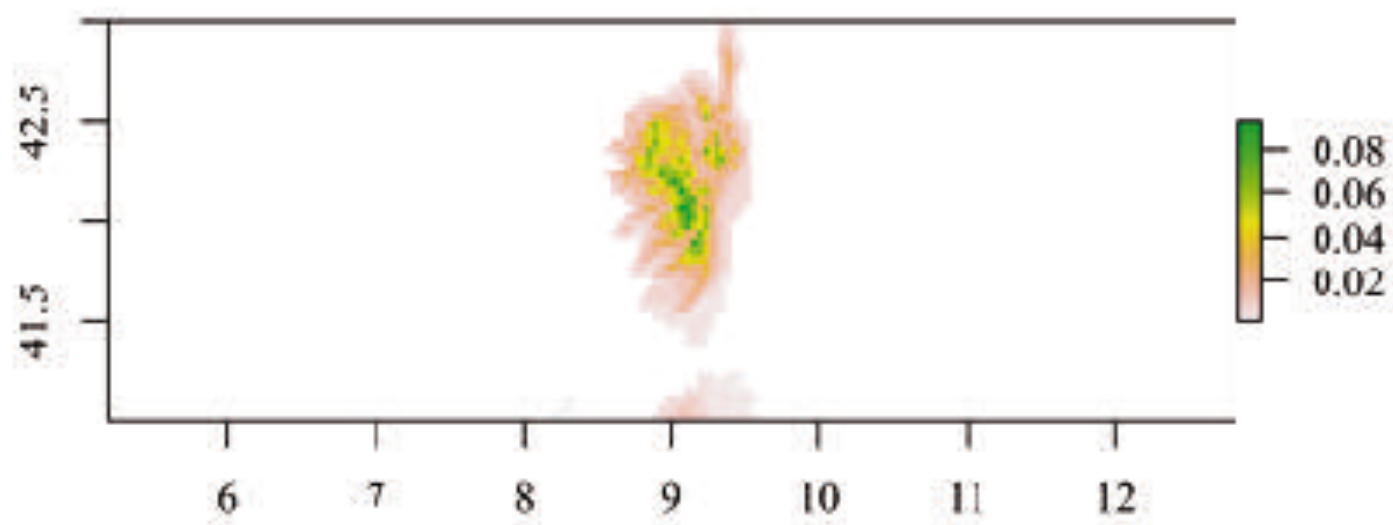


$\mathrm{S} 4_{\mathrm{G}}$ : Predicted Last glacial maximum distribution of $D$. lilfordi in Corsica

\section{LGM Suitability}

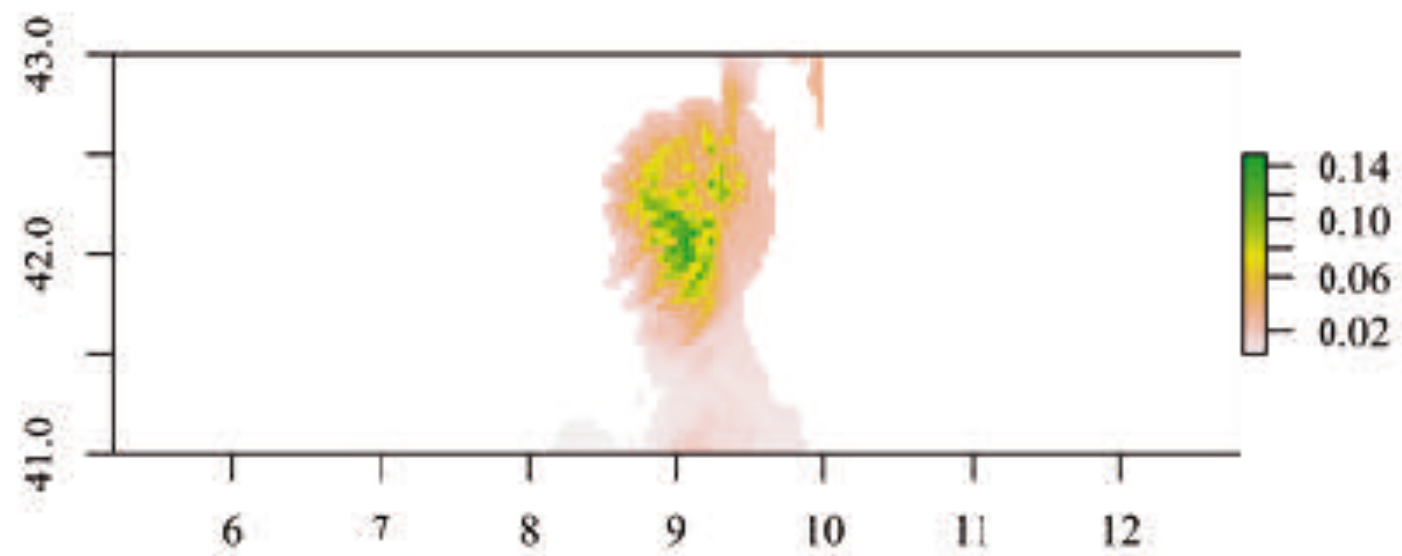




\begin{tabular}{|c|c|c|c|c|c|}
\hline Genus & species & subspecies & Country & locality & Lat, long \\
\hline Dendrocopos & leucotos & leucotos & Poland & Beskid Sądecki, Carpathians & $49.887,20.811$ \\
\hline Dendrocopos & leucotos & leucotos & Poland & Beskid Sądecki, Carpathians & $49.887,20.811$ \\
\hline Dendrocopos & leucotos & leucotos & Poland & Carpathians & $49.887,20.811$ \\
\hline Dendrocopos & leucotos & lilfordi & Spain & Navarra, Pyrenees & $42.872,-1.019$ \\
\hline Dendrocopos & leucotos & lilfordi & Spain & Navarra, Pyrenees & $42.872,-1.019$ \\
\hline Dendrocopos & leucotos & lilfordi & France & Arette, Pyrenees & $43.063,-0.726$ \\
\hline Dendrocopos & leucotos & lilfordi & France & Vallée d'Aspe, Urdos, Pyrenees & $42.872,-0.564$ \\
\hline Dendrocopos & leucotos & lilfordi & Serbia & & $44.173,21.469$ \\
\hline Dendrocopos & leucotos & lilfordi & Serbia & & $44.173,21.469$ \\
\hline Dendrocopos & leucotos & leucotos & Czech Republic & Moràvka, Trauny' Potok & $49.731,18.480$ \\
\hline Dendrocopos & leucotos & leucotos & Czech Republic & Dolni Lomna & $49.597,18.466$ \\
\hline Dendrocopos & leucotos & leucotos & Czech Republic & Moràvka, Ropiae & $49.829,18.495$ \\
\hline Dendrocopos & leucotos & leucotos & Czech Republic & Moràvka, Trauny' Potok & $49.829,18.495$ \\
\hline Dendrocopos & leucotos & leucotos & Czech Republic & Kosariska & $49.591,18.683$ \\
\hline Dendrocopos & leucotos & leucotos & Czech Republic & Horni Lomnà & $49.597,18.466$ \\
\hline Dendrocopos & leucotos & leucotos & Czech Republic & Dolni Lomna & $49.597,18.466$ \\
\hline Dendrocopos & leucotos & leucotos & Czech Republic & Kozubova & $49.580,18.672$ \\
\hline Dendrocopos & leucotos & lilfordi & France & Aussurucq, Pyrenees & $43.131,-0.947$ \\
\hline Dendrocopos & leucotos & lilfordi & France & Aussurucq, Pyrenees & $43.131,-0.947$ \\
\hline Dendrocopos & leucotos & lilfordi & France & Laruns, Pyrénées-Atlantiques & $42.987,-0.442$ \\
\hline Dendrocopos & leucotos & lilfordi & France & Borce, Pyrénées-Atlantiques & $42.908,-0.579$ \\
\hline Dendrocopos & leucotos & subcirris & Japan & Bankei 226, Chuo, Sapporo, Hokkaido & $43.035,141.287$ \\
\hline Dendrocopos & leucotos & subcirris & Japan & Takino 274, Minami, Sapporo, Hokkaido & $42.936,141.158$ \\
\hline Dendrocopos & leucotos & subcirris & Japan & Shikaoi, Kato, Hokkaido & $43.276,143.042$ \\
\hline Dendrocopos & leucotos & subcirris & Japan & Kitaurimaku, Shikaoi, Kato, Hokkaido & $43.276,143.042$ \\
\hline Dendrocopos & leucotos & stejnegeri & Japan & Towada, Aomori & $40.567,140.922$ \\
\hline Dendrocopos & leucotos & namiyei & Japan & Kakeaicho-Hata, Un-nan, Shimane & $35.205,132.890$ \\
\hline Dendrocopos & leucotos & owstoni & Japan & Naze-Itubugachi, Amami, Kagoshima & $28.370,129.482$ \\
\hline Dendrocopos & leucotos & lilfordi & Spain & Navarra, Pyrenees & $43.062,-1.790$ \\
\hline Dendrocopos & leucotos & lilfordi & France & Corsica? & $42.260,9.090$ \\
\hline Dendrocopos & leucotos & lilfordi & France & Corsica? & $42.260,9.090$ \\
\hline Dendrocopos & leucotos & lilfordi & Russia & Krasnodarskiy Kray & $43.50,40.19$ \\
\hline Dendrocopos & leucotos & leucotos & Russia & Avtonomnaya Respublika Buryatiya & $51.577,106.85$ \\
\hline Dendrocopos & major & mauritanus & Morocco & Azrou & $33.417,-5.174$ \\
\hline Dendrocopos & leucotos & leucotos & Russia & Kurskaya Oblast' & $51.687,34.912$ \\
\hline Dendrocopos & leucotos & leucotos & Russia & Khabarovskiy Kray & $49.75,137.12$ \\
\hline Dendrocopos & leucotos & leucotos & Russia & Primorskiy Kray & $43.87,131.42$ \\
\hline Dendrocopos & leucotos & leucotos & Russia & Kirovskaya Oblast' & $59.927,52.946$ \\
\hline Dendrocopos & leucotos & leucotos & Russia & Sakhalinskaya Oblast' & $46.37,141.87$ \\
\hline Dendrocopos & leucotos & leucotos & Romania & Rastolita & $46.967,24.992$ \\
\hline Dendrocopos & leucotos & tangi & China & Chin Tu Shi N.W. Of Kwanhsien W. Szechuan & \\
\hline Dendrocopos & leucotos & insularis & Taiwan & & $23.811,120.960$ \\
\hline Dendrocopos & leucotos & subcirris & Japan & Lake Tohya, Hokkaido & $42.597,140.769$ \\
\hline Dendrocopos & leucotos & lilfordi & Italy & Near Veroli, Central Italy & $41.813,13.387$ \\
\hline Dendrocopos & leucotos & lilfordi & France & Forêt d'Issaux, Pyrenees & $43.020,-0.706$ \\
\hline Dendrocopos & leucotos & lilfordi & Italy & Parco Abruzzi & $41.889,13.776$ \\
\hline Dendrocopos & leucotos & uralensis & Mongolia & Bulgan Gol & $46.224,91.098$ \\
\hline Dendrocopos & leucotos & uralensis & Mongolia & Bulgan Gol & $46.224,91.098$ \\
\hline Dendrocopos & leucotos & uralensis & Mongolia & Bulgan Gol & $46.224,91.092$ \\
\hline Dendrocopos & leucotos & uralensis & Mongolia & Bulgan Gol & $46.224,91.092$ \\
\hline Dendrocopos & leucotos & uralensis & Mongolia & Bulgan Gol & $46.224,91.092$ \\
\hline Dendrocopos & leucotos & uralensis & Mongolia & Bulgan Gol & $46.224,91.092$ \\
\hline Dendrocopos & leucotos & leucotos & Switzerland & & $46.961,9.707$ \\
\hline
\end{tabular}




\begin{tabular}{|c|c|c|c|c|c|}
\hline Dendrocopos & leucotos & leucotos & Switzerland & & $47.261,9.475$ \\
\hline Dendrocopos & leucotos & leucotos & Austria & & $47.210,9.795$ \\
\hline Dendrocopos & leucotos & leucotos & Austria & & $47.199,9.565$ \\
\hline Dendrocopos & leucotos & leucotos & Austria & & $47.306,9.720$ \\
\hline Dendrocopos & leucotos & leucotos & Austria & & $47.160,9.681$ \\
\hline Dendrocopos & leucotos & leucotos & Switzerland & & $46.946,9.608$ \\
\hline Dendrocopos & leucotos & lilfordi & France & Izeste, Pyenees, 64 & $43.079,-0.454$ \\
\hline Dendrocopos & leucotos & leucotos & Austria & & $47.196,9.601$ \\
\hline Dendrocopos & leucotos & lilfordi & Italy & Pescasser oli, La Difesa, Parco Abruzzi & $41.800,13.763$ \\
\hline Dendrocopos & leucotos & lilfordi & Italy & Pescasser oli, La Difesa, Parco Abruzzi & $41.800,13.763$ \\
\hline Dendrocopos & leucotos & lilfordi & Italy & Parco Abruzzi & $41.800,13.763$ \\
\hline Dendrocopos & leucotos & leucotos & Italy & Ferrera Erbognone, Lombardia & $45.118,8.869$ \\
\hline Dendrocopos & leucotos & lilfordi & France & Izeste, Pyrenees, 64 & $43.029,-0.760$ \\
\hline Dendrocopos & leucotos & lilfordi & France & Barétous, Pyrenees, 64 & $43.068,-0.780$ \\
\hline Dendrocopos & leucotos & leucotos & Poland & Białowieża Forest - Siemianówka & $52.734,23.876$ \\
\hline Dendrocopos & leucotos & leucotos & Poland & Białowieża Forest - Siemianówka & $52.734,23.876$ \\
\hline Dendrocopos & leucotos & leucotos & Poland & Bieszczady, Carpathians & $49.259,22.448$ \\
\hline Dendrocopos & major & numidus & Tunisia & Aïn Soltane & $36.525934,8.33746$ \\
\hline Dendrocopos & major & numidus & Tunisia & Aïn Soltane & $36.525934,8.33746$ \\
\hline Dendrocopos & major & numidus & Tunisia & Aïn Soltane & $36.525870,8.33744$ \\
\hline \multicolumn{6}{|c|}{ Sequences Genbank } \\
\hline Dendrocopos & leucotos & leucotos & Sweden & & \\
\hline Dendrocopos & leucotos & leucotos & Norway & Vest-Agder & $58.10,7.79$ \\
\hline Dendrocopos & leucotos & leucotos & Poland & & \\
\hline Dendrocopos & leucotos & leucotos & Russia & Khabarovskiy Kray & $50.93,137.45$ \\
\hline Dendrocopos & leucotos & leucotos & Russia & Rossiya, Moscovskaya Oblast & 54.917, 39.367 \\
\hline Dendrocopos & leucotos & leucotos & Russia & Primorskiy Kray & $46.017,135.25$ \\
\hline Dendrocopos & leucotos & leucotos & South Korea & near Seoul & $37.640,126.981$ \\
\hline Dendrocopos & leucotos & leucotos & Sweden & Norrbotten & $56.9165,18.1468$ \\
\hline Dendrocopos & leucotos & leucotos & Sweden & & \\
\hline Dendrocopos & leucotos & namiyei & Japan & Kyushu-chiho, Kagoshima & $32.69,130.77$ \\
\hline Dendrocopos & leucotos & namiyei & Japan & Kyushu-chiho, Kagoshima & $32.69,130.77$ \\
\hline \multicolumn{6}{|l|}{ Outgroup } \\
\hline Dendrocopos & \multicolumn{2}{|c|}{ darjellensis } & China & & \\
\hline Dendrocopos & \multicolumn{2}{|c|}{ darjellensis } & China & & \\
\hline Dendrocopos & noguchii & & Japan & & \\
\hline Dendrocopos & noguchii & & Japan & & \\
\hline Dendrocopos & noguchii & & Japan & & \\
\hline Dendrocopos & noguchii & & Japan & & \\
\hline Dendrocopos & noguchii & & Japan & & \\
\hline Dendrocopos & major & brevirostris & Russia & & \\
\hline Dendrocopos & major & brevirostris & Russia & & \\
\hline Dendrocopos & major & japonicus & Russia & & \\
\hline Dendrocopos & major & japonicus & Japan & & \\
\hline Dendrocopos & major & japonicus & Japan & & \\
\hline Dendrocopos & major & japonicus & Japan & & \\
\hline Dendrocopos & major & japonicus & Japan & & \\
\hline Dendrocopos & major & japonicus & Japan & & \\
\hline Dendrocopos & major & japonicus & Japan & & \\
\hline Dendrocopos & major & japonicus & Japan & & \\
\hline Dendrocopos & major & japonicus & Japan & & \\
\hline Dendrocopos & major & japonicus & Japan & & \\
\hline Dendrocopos & major & japonicus & South Korea & & \\
\hline Dendrocopos & major & major & Russia & & \\
\hline Dendrocopos & major & major & & & \\
\hline Dendrocopos & major & major & & & \\
\hline
\end{tabular}




\begin{tabular}{|l|l|l|l|l|l|}
\hline Dendrocopos & major & major & & & \\
\hline Dendrocopos & major & major & & & \\
\hline Dendrocopos & major & major & & & \\
\hline Dendrocopos & major & major & & & \\
\hline Dendrocopos & major & major & Denmark & & \\
\hline Dendrocopos & major & pinetorum & France & & \\
\hline Dendrocopos & major & pinetorum & Netherlands & & \\
\hline Dendrocopos & major & pinetorum & France & & \\
\hline Dendrocopos & major & pinetorum & France & & \\
\hline Dendrocopos & major & pinetorum & France & & \\
\hline Dendrocopos & major & pinetorum/m & Austria & & \\
\hline Dendrocopos & syriacus & & Iran & & \\
\hline Dendrocopos & syriacus & & Captive & & \\
\hline Dendrocopos & syriacus & & Captive & & \\
\hline Picoides & pubescens & USA & & \\
\hline Picoides & pubescens & USA & & \\
\hline Veniliornis & mixtus & & Paraguay & & \\
\hline \multicolumn{7}{|l|}{} & & & & \\
\hline 1 italics=sequences retrieved from Genbank, normal style=new sequences \\
\hline *sequences retrieved from BOLD & & & \\
\hline
\end{tabular}


Collector/Provider

Tomasz Baziak, Łukasz Kajtoch

Robert Kruszyk, Łukasz Kajtoch

tukasz Kajtoch

David Campion

David Campion

Patrick Urbina-Tobias, Jean-Louis Grangé

Jean-Louis Grangé/ Jeremy Bauwin

Marko Rakovic

Marko Rakovic

Robert Špilák

Eva Kolàrovà

Robert Špilák

Robert Špilák

Eva Kolàrovà

Eva Kolàrovà

Eva Kolàrovà

Daniel Kozubova

Jean-Louis Grangé/ Laurent Joubert

Jean-Louis Grangé/ Laurent Joubert

Jean-Louis Grangé/ P. Fontanilles

Jean-Louis Grangé/ P. Fontanilles

Sayaka Kobayashi

Sayaka Kobayashi

Sayaka Kobayashi

Sayaka Kobayashi

Sayaka Kobayashi

Sayaka Kobayashi

Sayaka Kobayashi

A. Senosian-S. Carcamo

Manuel Schweizer

Manuel Schweizer

Stein A. Saether

\section{Paul Harris}

Patrick Urbina-Tobias, Jean-Louis Grangé

Paul Harris

W. Stenzel, Jochen Martens

W. Stenzel, Jochen Martens

W. Stenzel, Jochen Martens

W. Stenzel, Jochen Martens

W. Stenzel, Jochen Martens

W. Stenzel, Jochen Martens

Antonia Ettwein
Institution

Specimen Voucher number

Institute of Systematics and Evolution of Animals Polish Academy of Sciences

Institute of Systematics and Evolution of Animals Polish Academy of Sciences

Institute of Systematics and Evolution of Animals Polish Academy of Sciences

Natural History Museum of Belgrade

Natural History Museum of Belgrade

Yamashina Institute for Ornithology

Yamashina Institute for Ornithology

Yamashina Institute for Ornithology

Yamashina Institute for Ornithology

Yamashina Institute for Ornithology

Yamashina Institute for Ornithology

Yamashina Institute for Ornithology

Natural History Museum, Bern, Switzerland

Natural History Museum, Bern, Switzerland

NHM 1035430

NHM 1035431

UWBM 64700

Burke Museum, University of Washington

UWBM 46354

University of Oslo, Norway

Burke Museum, University of Washington

UWBM 49418

UWBM 46919

UWBM 71785

UWBM 71369

UWBM 83093

NMW 72.920

Tring: 1954.59.34

Tring: 1965.M.6413

Institut für Zoologie, Johannes Gutenberg-Universität Institut für Zoologie, Johannes Gutenberg-Universität Institut für Zoologie, Johannes Gutenberg-Universität Institut für Zoologie, Johannes Gutenberg-Universität Institut für Zoologie, Johannes Gutenberg-Universität Institut für Zoologie, Johannes Gutenberg-Universität Schweizerische Vogelwarte 


\begin{tabular}{|c|c|c|}
\hline Antonia Ettwein & Schweizerische Vogelwarte & \\
\hline Antonia Ettwein & Schweizerische Vogelwarte & \\
\hline Antonia Ettwein & Schweizerische Vogelwarte & \\
\hline Antonia Ettwein & Schweizerische Vogelwarte & \\
\hline Antonia Ettwein & Schweizerische Vogelwarte & \\
\hline Antonia Ettwein & Schweizerische Vogelwarte & \\
\hline \multicolumn{3}{|c|}{ Patrick Urbina-Tobias, Jean-Louis Grangé } \\
\hline Antonia Ettwein & Schweizerische Vogelwarte & \\
\hline E.A. Di Carlo, Giorgio Chiozzi & Museo di Storia Naturale di Milano & MSNM Av 12765 \\
\hline E.A. Di Carlo, Giorgio Chiozzi & Museo di Storia Naturale di Milano & MSNM Av 12766 \\
\hline E.A. Di Carlo, Giorgio Chiozzi & Museo di Storia Naturale di Milano & MSNM Av 12767 \\
\hline E.A. Di Carlo, Giorgio Chiozzi & Museo di Storia Naturale di Milano & MSNM Av 35481 * \\
\hline \multicolumn{3}{|c|}{ Patrick Urbina-Tobias, Jean-Louis Grangé } \\
\hline \multicolumn{3}{|c|}{ Patrick Urbina-Tobias, Jean-Louis Grangé } \\
\hline Tomasz Mazgajski & \multicolumn{2}{|c|}{ Museum and Institute of Zoology Polish Academy of Sciences } \\
\hline Tomasz Mazgajski & \multicolumn{2}{|c|}{ Museum and Institute of Zoology Polish Academy of Sciences } \\
\hline Tomasz Mazgajski & \multicolumn{2}{|c|}{ Museum and Institute of Zoology Polish Academy of Sciences } \\
\hline G. Olioso, J.-M. Pons & Muséum national d'Histoire naturelle & \\
\hline G. Olioso, J.-M. Pons & Muséum national d'Histoire naturelle & \\
\hline \multirow[t]{3}{*}{ G. Olioso, J.-M. Pons } & Muséum national d'Histoire naturelle & \\
\hline & Swedish Museum of Natural History & NRM 996095 \\
\hline & UiO, Natural History Museum, Oslo & NHMO-BC126 \\
\hline \multirow[t]{15}{*}{ Łukasz Kajtoch } & \multicolumn{2}{|c|}{ Institute of Systematics and Evolution of Animals Polish Academy of Sciences } \\
\hline & Burke Museum, University of Washington & UWBM 47343 \\
\hline & Burke Museum, University of Washington & UWBM 57279 \\
\hline & Burke Museum, University of Washington & UWBM 72175 \\
\hline & Kongju National University & \\
\hline & Swedish Museum of Natural History & BISE-Aves14 \\
\hline & Swedish Museum of Natural History & BISE-Aves 425 \\
\hline & Yamashina Institute for Ornithology & YIO-65613 \\
\hline & Yamashina Institute for Ornithology & YIO-65543 \\
\hline & & \\
\hline & & CAS 96030 \\
\hline & & YIO64602 \\
\hline & & USNM 385204 \\
\hline & & YIO 2009-0963 \\
\hline & & YIO 2012-0352 \\
\hline & & \\
\hline & & \\
\hline & & \\
\hline & & \\
\hline & & \\
\hline & & \\
\hline & & \\
\hline & & \\
\hline & & \\
\hline & & \\
\hline & & \\
\hline & & \\
\hline & & \\
\hline
\end{tabular}




\begin{tabular}{|l|l|l|}
\hline & & \\
\hline & & \\
\hline & & \\
\hline & & ZMUC 128973 \\
\hline & & MNHN Uncat. 27-47 \\
\hline & & ZMA58803 \\
\hline & & MNHN ZO 2015-015 \\
\hline & MNHN Z0 2016-578 \\
\hline & MNHN Z0 2017-162 \\
\hline & & MNHN Uncat. 36-H05 \\
\hline & & NRM 2001-6743 \\
\hline & NRM 2003-6318 \\
\hline & CAS 95942 \\
\hline & & \\
\hline & & \\
\hline & NRM 937175 \\
\hline & \\
\hline
\end{tabular}




\begin{tabular}{|c|c|c|c|c|c|}
\hline Ring Number & tissue/DNA & tissue number & Collecting date & DNA extract MNHN num & $\mathrm{COI}$ \\
\hline & fresh & DL-CM1 & 02-06-2012 & D101 & MW042330 \\
\hline & fresh & DL-CM2 & 2013 & D103 & MW042331 \\
\hline & fresh & DL-CM6 & & D104 & MW042332 \\
\hline & fresh & MNHN105 & & D105 & MW042333 \\
\hline & fresh & MNHN106 & & D106 & MW042334 \\
\hline GH134919 & fresh & MNHN107 & $12 / 05 / 19$ & D107 & MW042335 \\
\hline \multirow[t]{3}{*}{ GH108101 } & fresh & MNHN11 & $27 / 05 / 15$ & D11 & MW042269 \\
\hline & fresh & MNHN12 & & D12 & MW042270 \\
\hline & fresh & MNHN14 & & D14 & MW042271 \\
\hline K531504 & fresh & MNHN15 & $28 / 05 / 15$ & D15 & MW042272 \\
\hline K531565 & fresh & MNHN16 & $16 / 05 / 15$ & D16 & MW042273 \\
\hline KB531566 & fresh & MNHN17 & $29 / 05 / 15$ & D17 & MW042274 \\
\hline K531568 & fresh & MNHN18 & $11 / 07 / 15$ & D18 & MW042275 \\
\hline K525905 & fresh & MNHN19 & $15 / 05 / 15$ & D19 & MW042276 \\
\hline K531563 & fresh & MNHN2O & $16 / 05 / 15$ & D20 & MW042277 \\
\hline K531564 & fresh & MNHN21 & $16 / 05 / 15$ & D21 & MW042278 \\
\hline K340747 & fresh & MNHN22 & $02 / 05 / 15$ & D22 & MW042279 \\
\hline GF29461 & fresh & MNHN23 & $21 / 05 / 16$ & D23 & MW042280 \\
\hline GF29462 & fresh & MNHN24 & $22 / 05 / 16$ & D24 & MW042281 \\
\hline GH48969 & fresh & MNHN25 & $30 / 05 / 16$ & D25 & MW042282 \\
\hline \multirow[t]{24}{*}{ GH92002 } & fresh & MNHN27 & $31 / 05 / 16$ & D27 & MW042283 \\
\hline & DNA & GEN06-06I & 05/11/99 & D28 & MW042284 \\
\hline & DNA & GEN06-05I & $25 / 04 / 03$ & D29 & MW042285 \\
\hline & DNA & GEN37-02B & $20 / 11 / 11$ & D30 & MW042286 \\
\hline & DNA & GEN37-03B & 29/04/12 & D31 & MW042287 \\
\hline & DNA & GEN33-06F & $07 / 05 / 08$ & D32 & MW042288 \\
\hline & DNA & GEN33-07F & $16 / 06 / 12$ & D33 & MW042289 \\
\hline & DNA & GEN37-01B & 07/07/06 & D34 & MW042290 \\
\hline & fresh & MNHN35 & $16 / 05 / 16$ & D35 & MW042291 \\
\hline & historical & MNHN36 & second half 19 th century & D36 & MW042292 \\
\hline & historical & MNHN37 & second half 19th century & D37 & MW042293 \\
\hline & fresh & MNHN38 & $6 / 20 / 99$ & D38 & MW042294 \\
\hline & fresh & MNHN39 & 6/19/93 & D39 & MW042295 \\
\hline & fresh & MNHN4 & May 2008 & D4 & \\
\hline & fresh & MNHN40 & $6 / 7 / 94$ & D40 & MW042296 \\
\hline & fresh & MNHN41 & $6 / 30 / 93$ & D41 & MW042297 \\
\hline & fresh & MNHN42 & $7 / 23 / 01$ & D42 & MW042298 \\
\hline & fresh & MNHN43 & 7/5/98 & D43 & MW042299 \\
\hline & fresh & MNHN44 & $6 / 29 / 03$ & D44 & MW042300 \\
\hline & historical & Dleu6 & & D49 & MW042301 \\
\hline & historical & Dleutan1 & $30 / 06 / 38$ & D50 & MW042302 \\
\hline & dry & Dleuins 5 & & D51 & MW042303 \\
\hline & fresh & Dleusub 1 & & D52 & MW042304 \\
\hline & fresh & MNHN54 & $26 / 05 / 06$ & D54 & MW042305 \\
\hline \multirow[t]{9}{*}{ GH134912 } & fresh & MNHN56 & $29 / 04 / 17$ & D56 & MW042306 \\
\hline & fresh & MNHN61 & around 2006 & D61 & MW042307 \\
\hline & fresh & 410 & mid-August 2002 & D66 & MW042308 \\
\hline & fresh & 432 & mid-August 2002 & D67 & MW042309 \\
\hline & fresh & 433 & mid-August 2002 & D68 & MW042310 \\
\hline & fresh & 453 & mid-August 2002 & D69 & MW042311 \\
\hline & fresh & 11.384 & mid-August 2002 & D70 & MW042312 \\
\hline & fresh & 11.387 & mid-August 2002 & D71 & MW042313 \\
\hline & fresh & WBW7 & $3 / 3 / 17$ & D72 & MW042314 \\
\hline
\end{tabular}




\begin{tabular}{|c|c|c|c|c|c|}
\hline & fresh & WBW8 & $8 / 25 / 17$ & D73 & MW042315 \\
\hline & fresh & WBW10 & 7/15/17 & D75 & MW042316 \\
\hline & fresh & WBW12 & $6 / 2 / 17$ & D76 & MW042317 \\
\hline & fresh & WBW13 & $8 / 30 / 17$ & D77 & MW042318 \\
\hline & fresh & WBW14 & $8 / 14 / 17$ & D78 & MW042319 \\
\hline & fresh & WBW20 & $5 / 13 / 17$ & D79 & MW042320 \\
\hline \multirow[t]{6}{*}{ GH134903 } & fresh & MNHN8 & $01 / 05 / 14$ & D8 & MW042267 \\
\hline & fresh & WBW22 & $5 / 18 / 17$ & D80 & MW042321 \\
\hline & historical & D81 & $11 / 1 / 63$ & D81 & MW042322 \\
\hline & historical & D84 & $11 / 1 / 63$ & D84 & MW042323 \\
\hline & historical & D85 & $25 / 10 / 60$ & D85 & MW042324 \\
\hline & historical & D86 & $31 / 03 / 72$ & D86 & MW042325 \\
\hline GH134904 & fresh & MNHN9 & $01 / 05 / 14$ & D9 & MW042268 \\
\hline \multirow[t]{42}{*}{ GH134916 } & fresh & MNHN92 & $02 / 06 / 18$ & D92 & MW042326 \\
\hline & fresh & DL-BF1 & & D93 & MW042327 \\
\hline & fresh & DL-BF6 & $30 / 06 / 05$ & D95 & MW042328 \\
\hline & fresh & DL-CM4 & & D97 & MW042329 \\
\hline & fresh & JMP350 & 12 May 2012 & JMP350 & MW042338 \\
\hline & fresh & JMP352 & 12 May 2012 & JMP352 & MW042339 \\
\hline & fresh & JMP383 & 17 May 2012 & JMP383 & MW042340 \\
\hline & & & & & \\
\hline & fresh & & & 03 & GU566412 \\
\hline & & BON126 & & & GU571366 \\
\hline & & & & & \\
\hline & & & & & KBPBU474 \\
\hline & & & & & KBPBU476 \\
\hline & & & & & KBPBU477 \\
\hline & & & & & KU131555 \\
\hline & & BISE014 & & & GU571860 \\
\hline & & BISE406 & & & GU571859 \\
\hline & & & & & YIO571-17* \\
\hline & & & & & YIO572-17* \\
\hline & & & & & NC042683 \\
\hline & & & & & \\
\hline & & & & & $A B 843125$ \\
\hline & & & & & $A B 843742$ \\
\hline & & & & & \\
\hline & & & & & \\
\hline & & & & & \\
\hline & & & & & GQ481709 \\
\hline & & & & & GQ481711 \\
\hline & & & & & GQ481708 \\
\hline & & & & & $A B 843467$ \\
\hline & & & & & $A B 843466$ \\
\hline & & & & & $A B 842723$ \\
\hline & & & & & $A B 842722$ \\
\hline & & & & & $A B 842721$ \\
\hline & & & & & $A B 842720$ \\
\hline & & & & & $A B 842719$ \\
\hline & & & & & $A B 842718$ \\
\hline & & & & & $A B 842717$ \\
\hline & & & & & NCO28174 \\
\hline & & & & & GQ481710 \\
\hline & & & & & GQ481712 \\
\hline & & & & & GU571863 \\
\hline
\end{tabular}




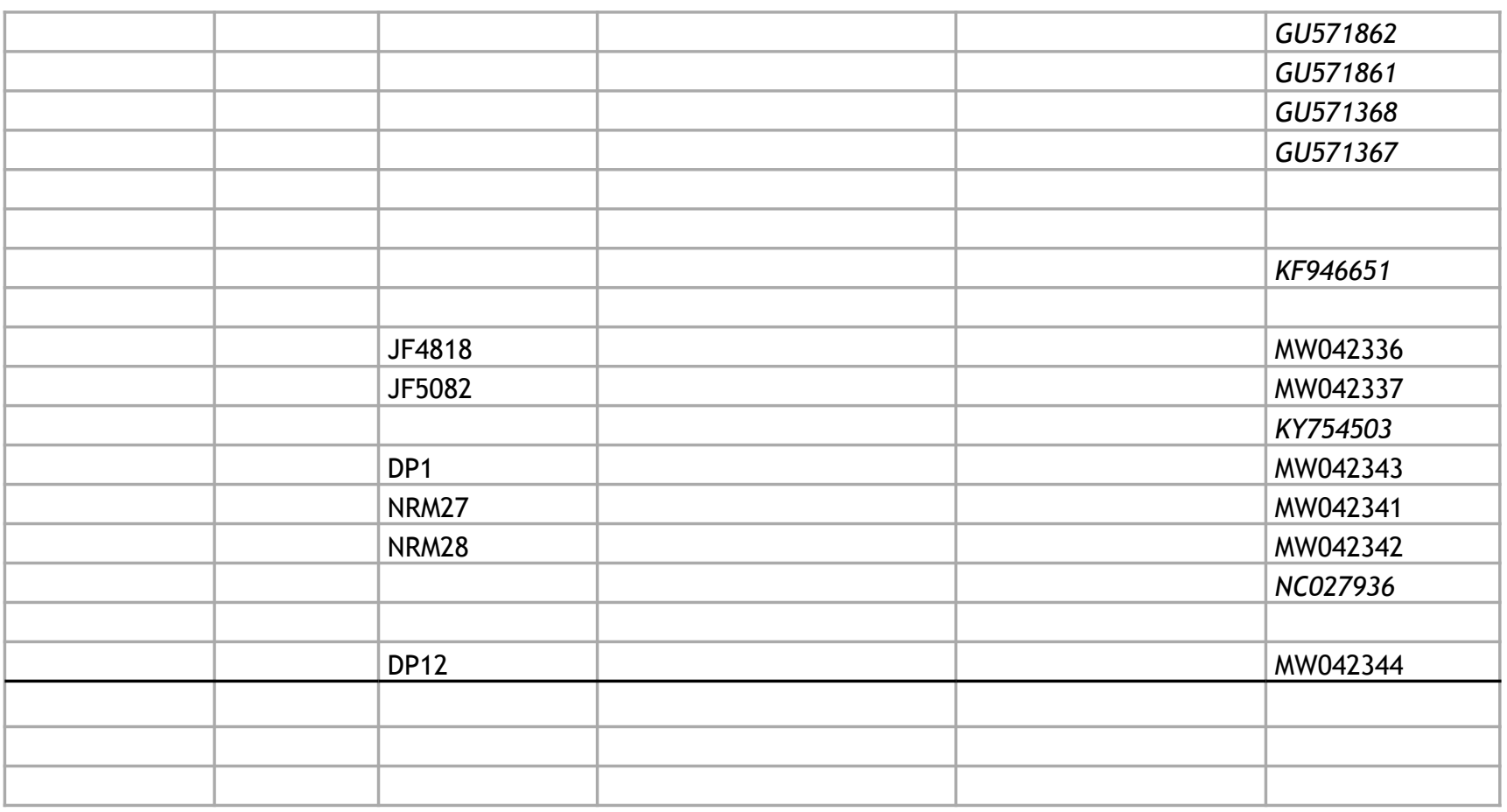


Genbank numbers ${ }^{1}$

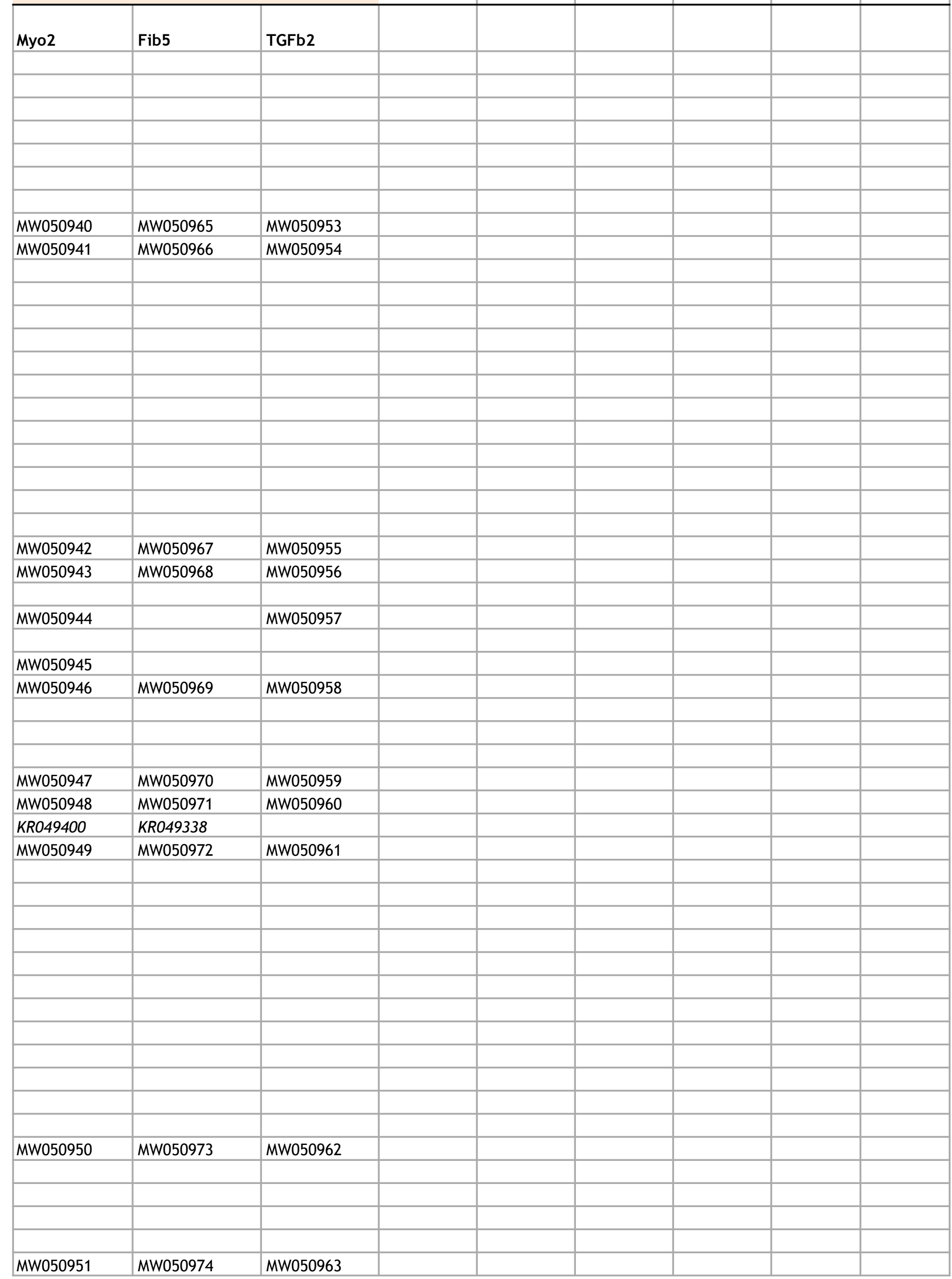




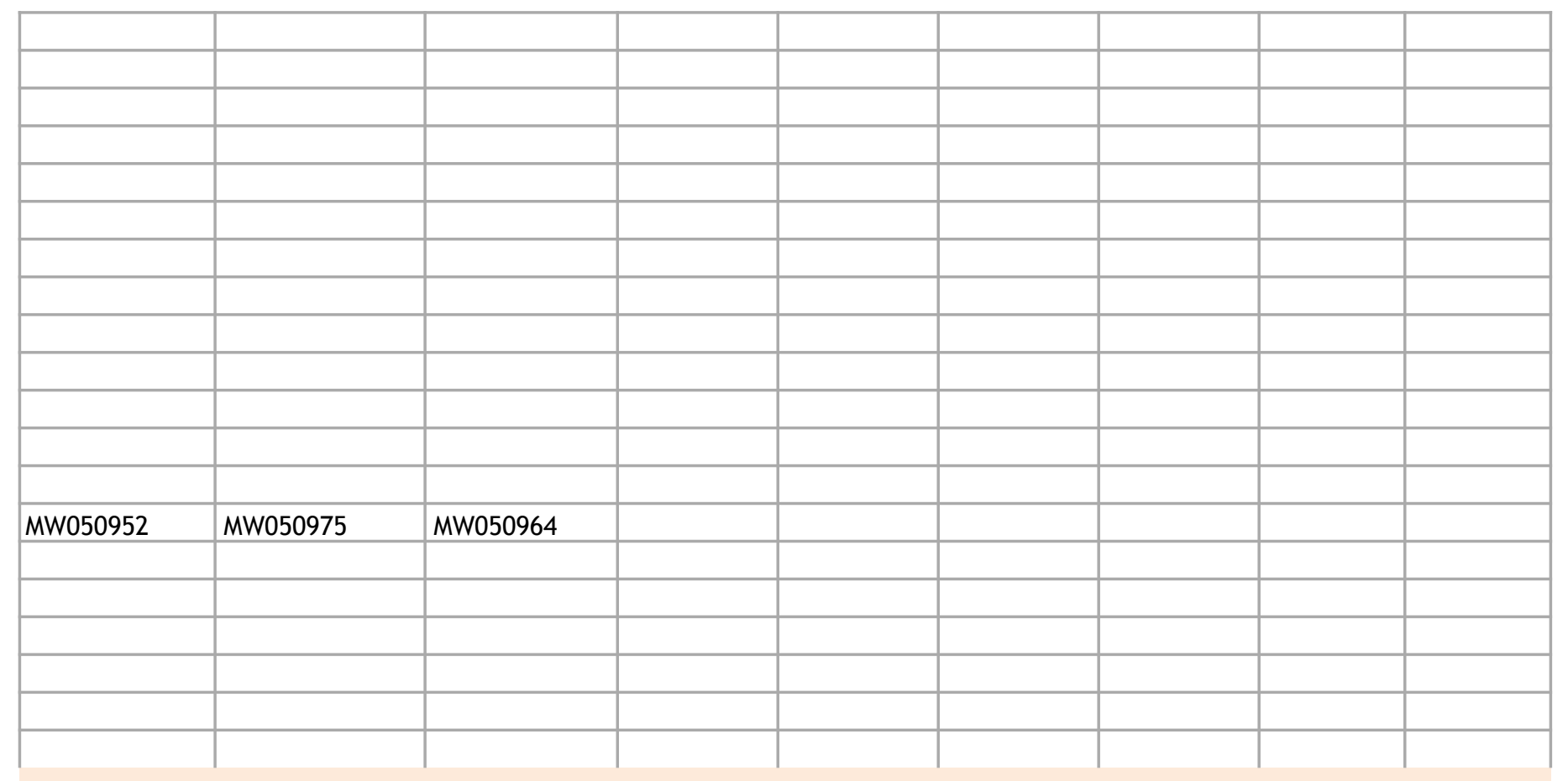

\begin{tabular}{|l|l|l|l|l|l|l|l|l|} 
DQ188142 & KC813370 & GU566576 & & & & & & \\
\hline & & & & & & & & \\
\hline & & KF445359 & & & & & & \\
\hline & & & & & & & & \\
\hline & & & & & & & & \\
\hline & & & & & & & & \\
\hline & & & & & & & & \\
\hline & & & & & & & & \\
\hline & & & & & & & &
\end{tabular}

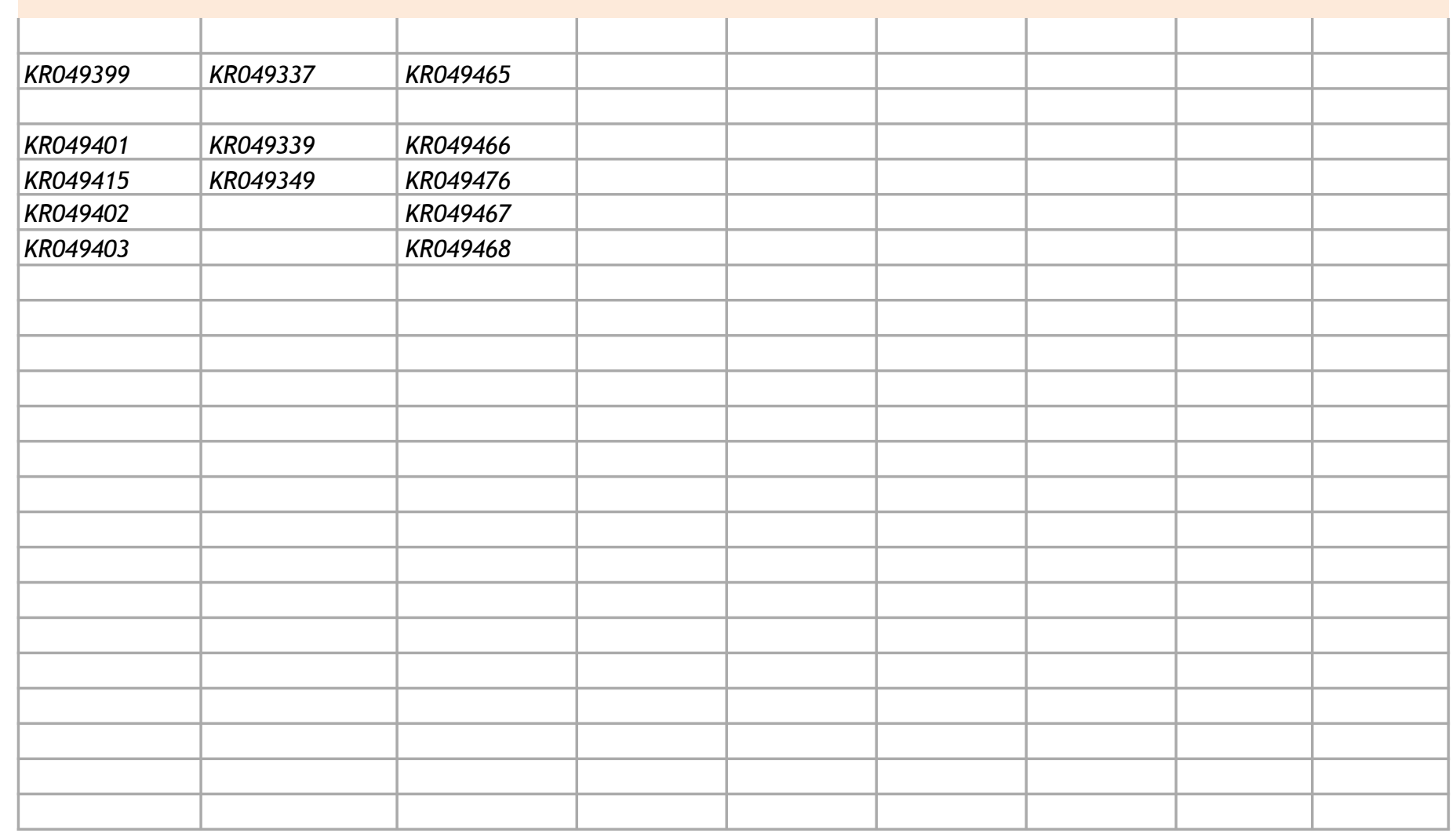




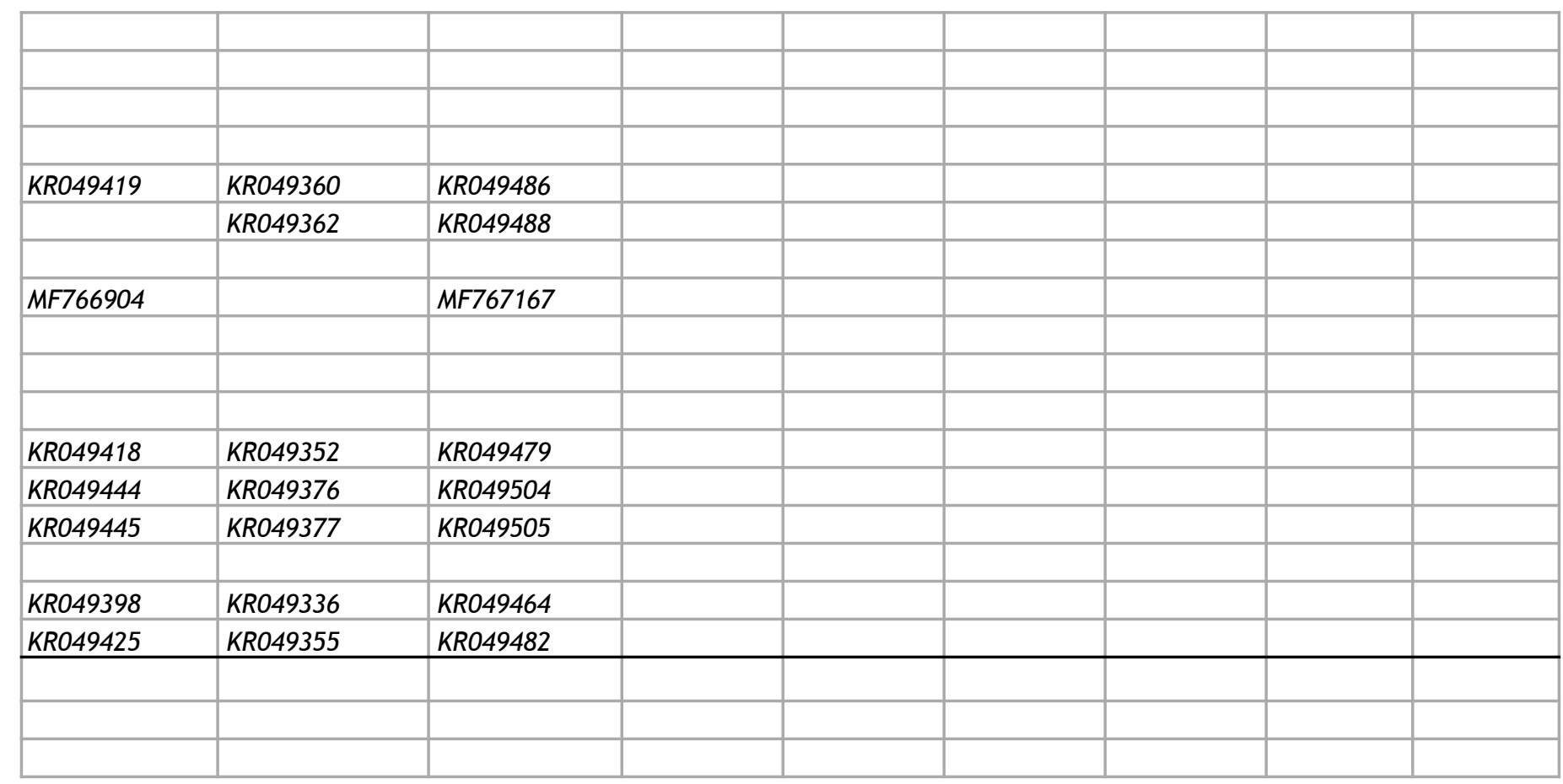




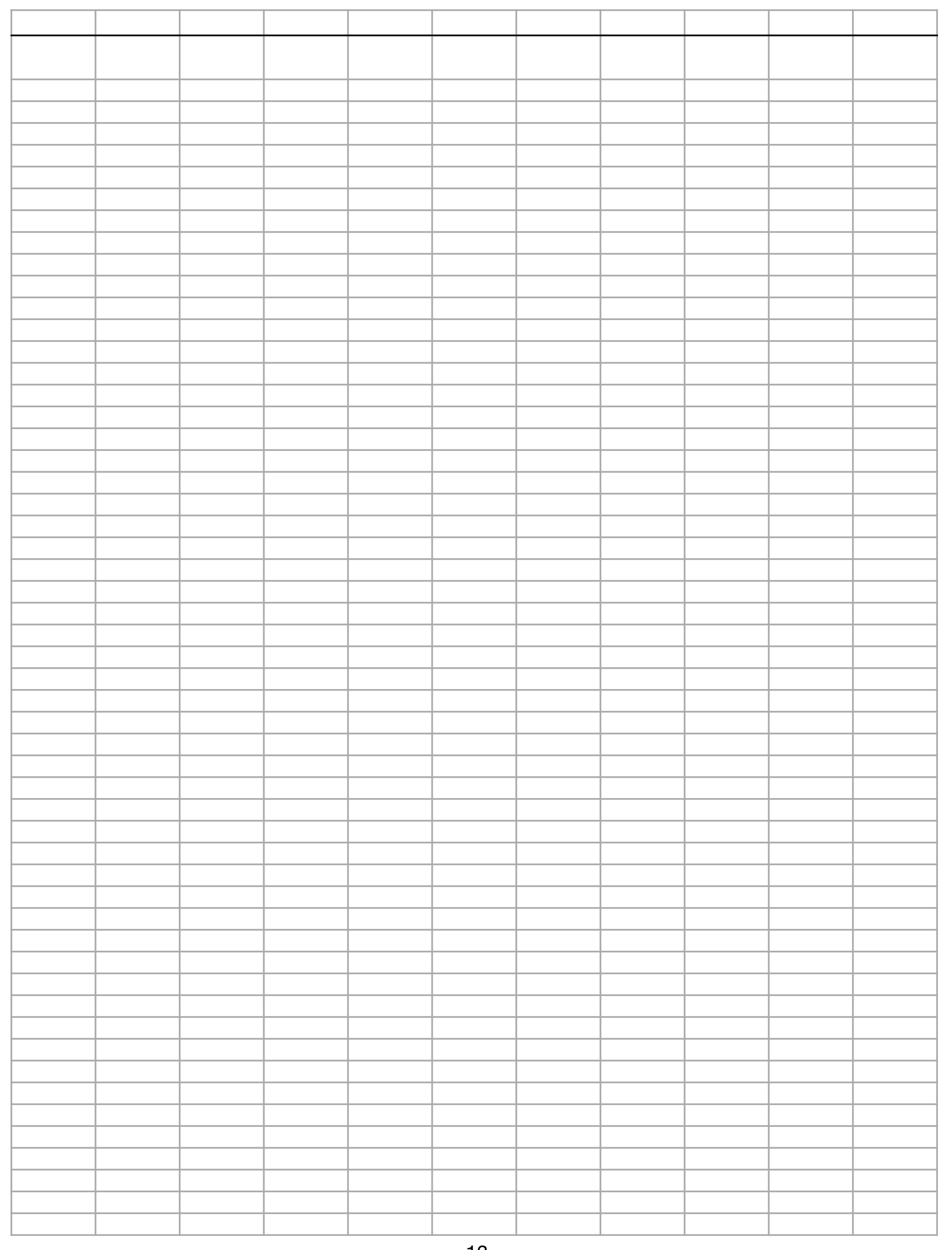



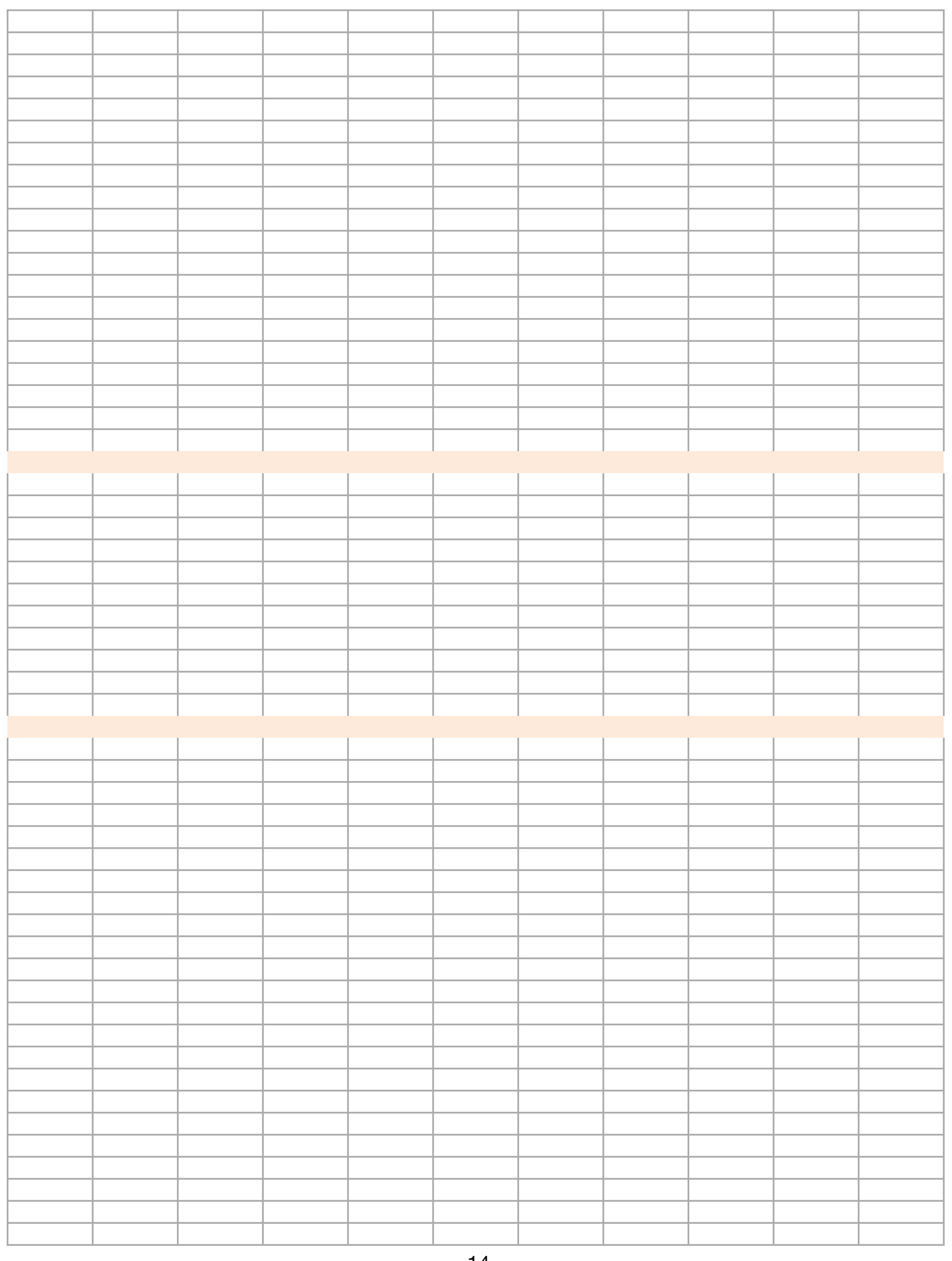


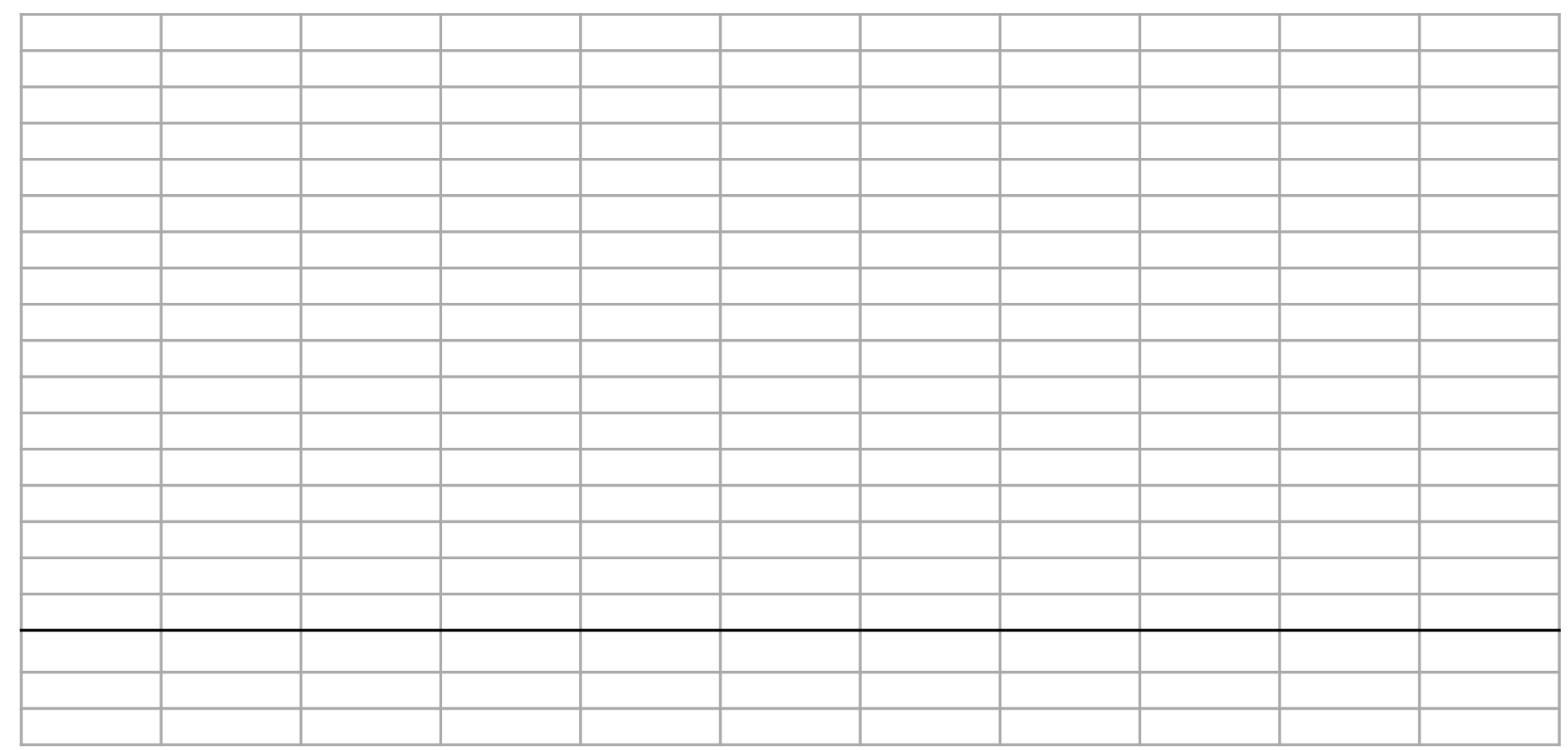




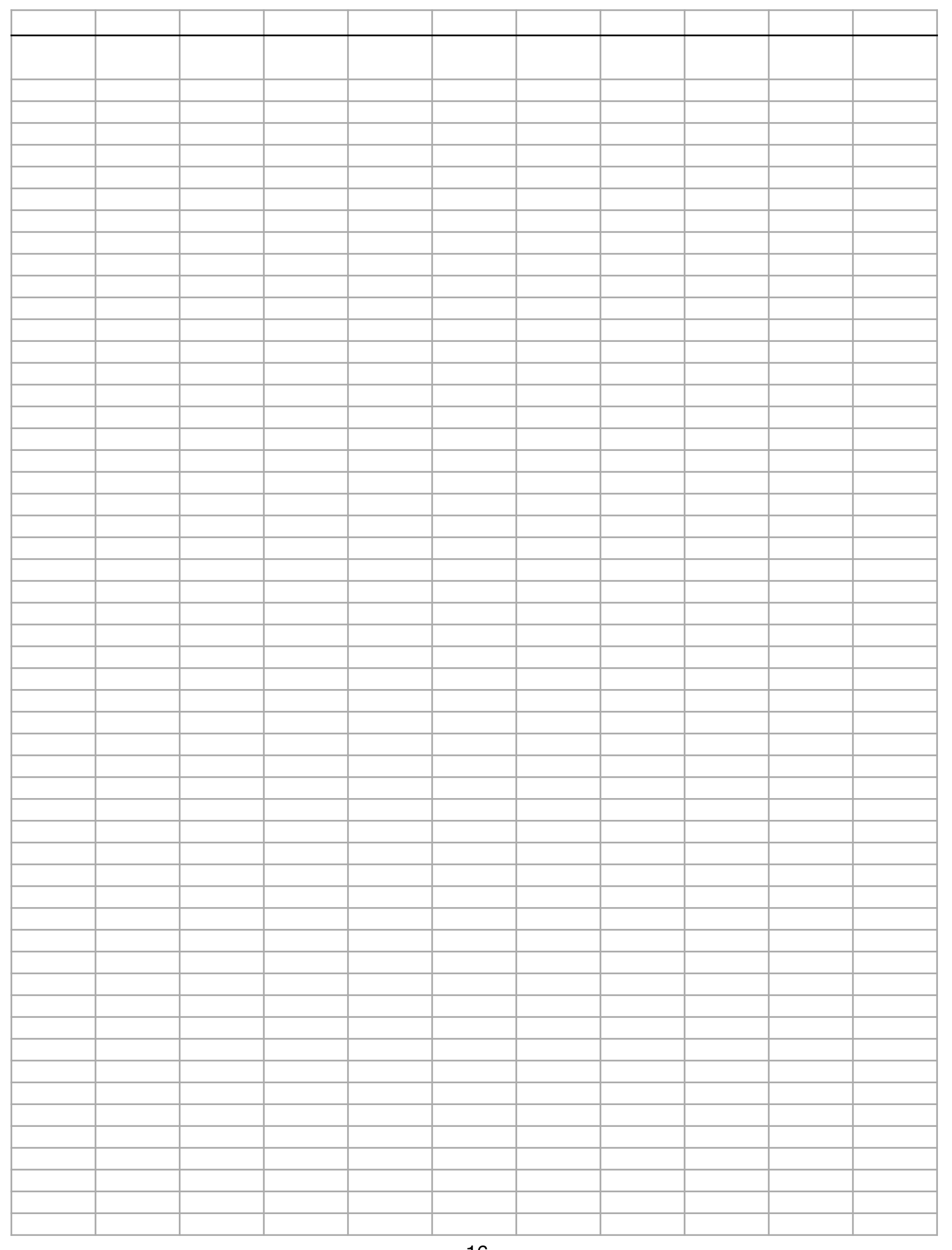



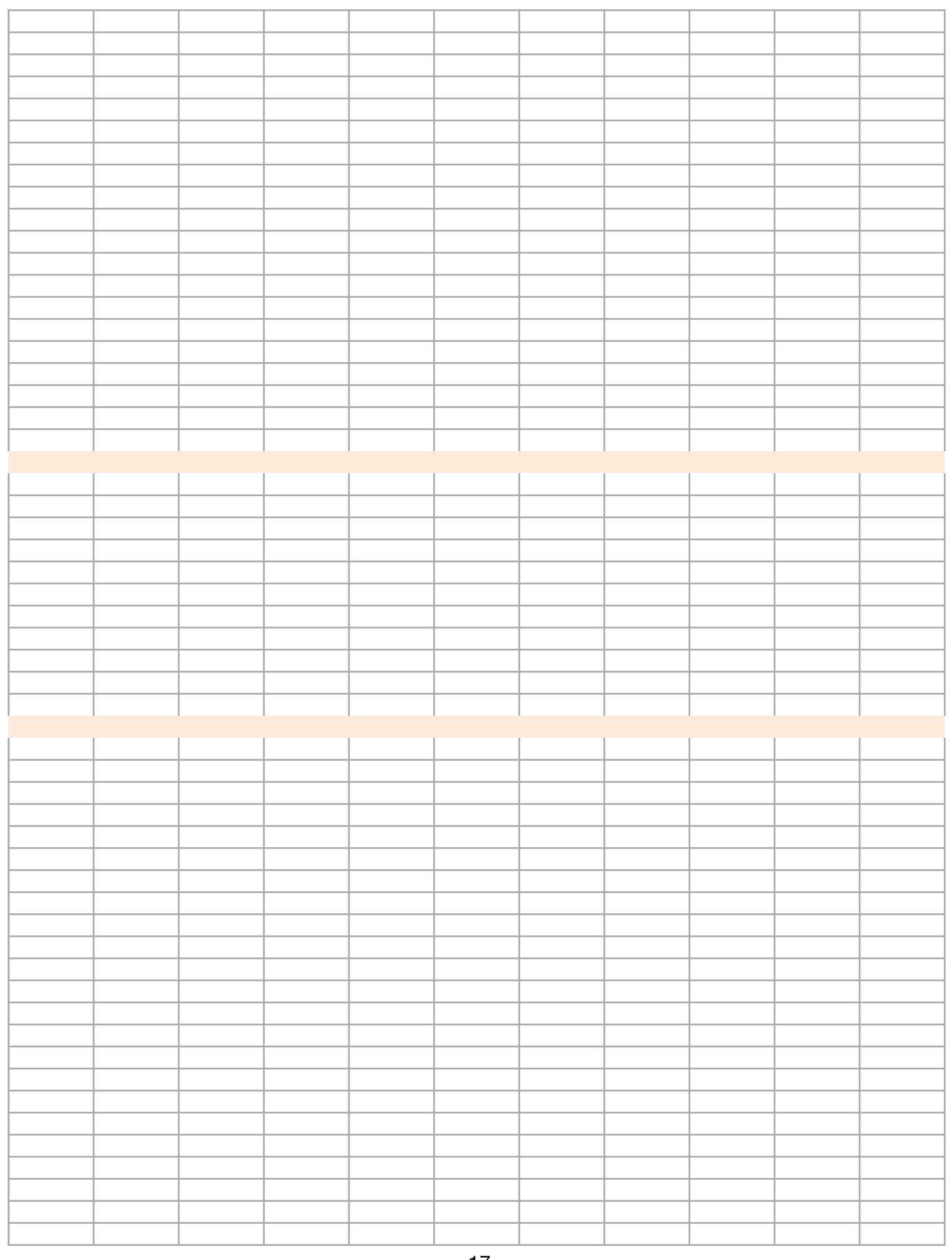


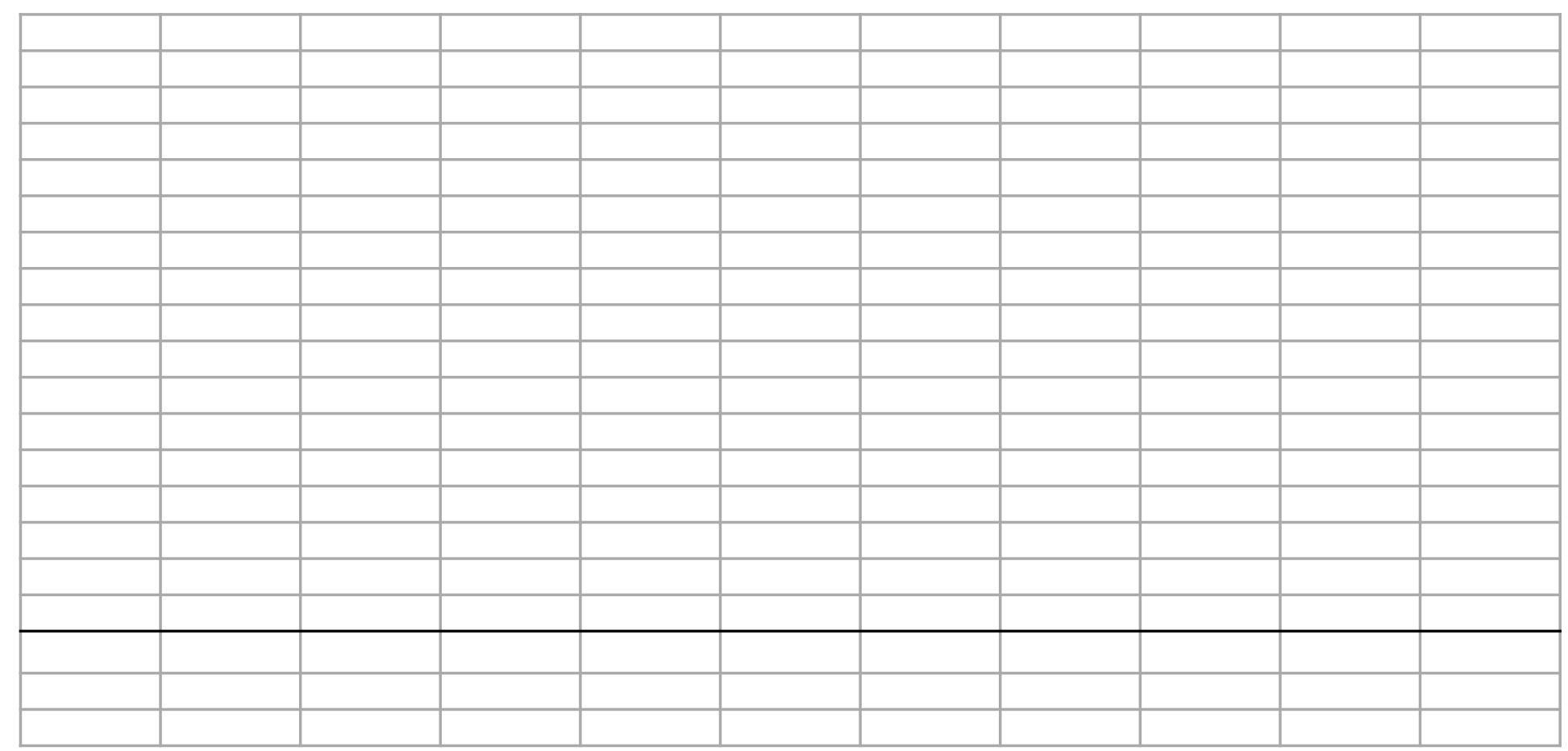




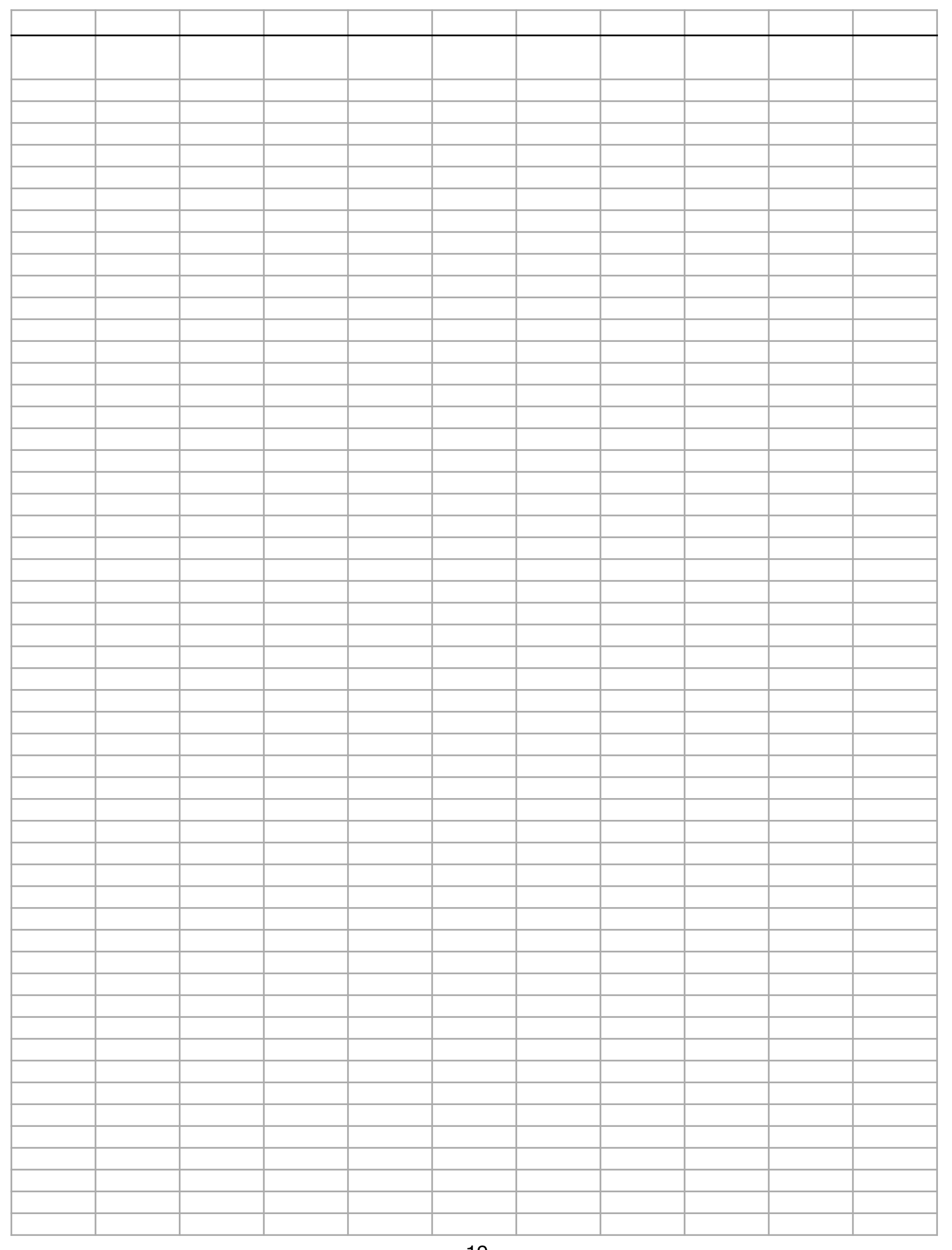



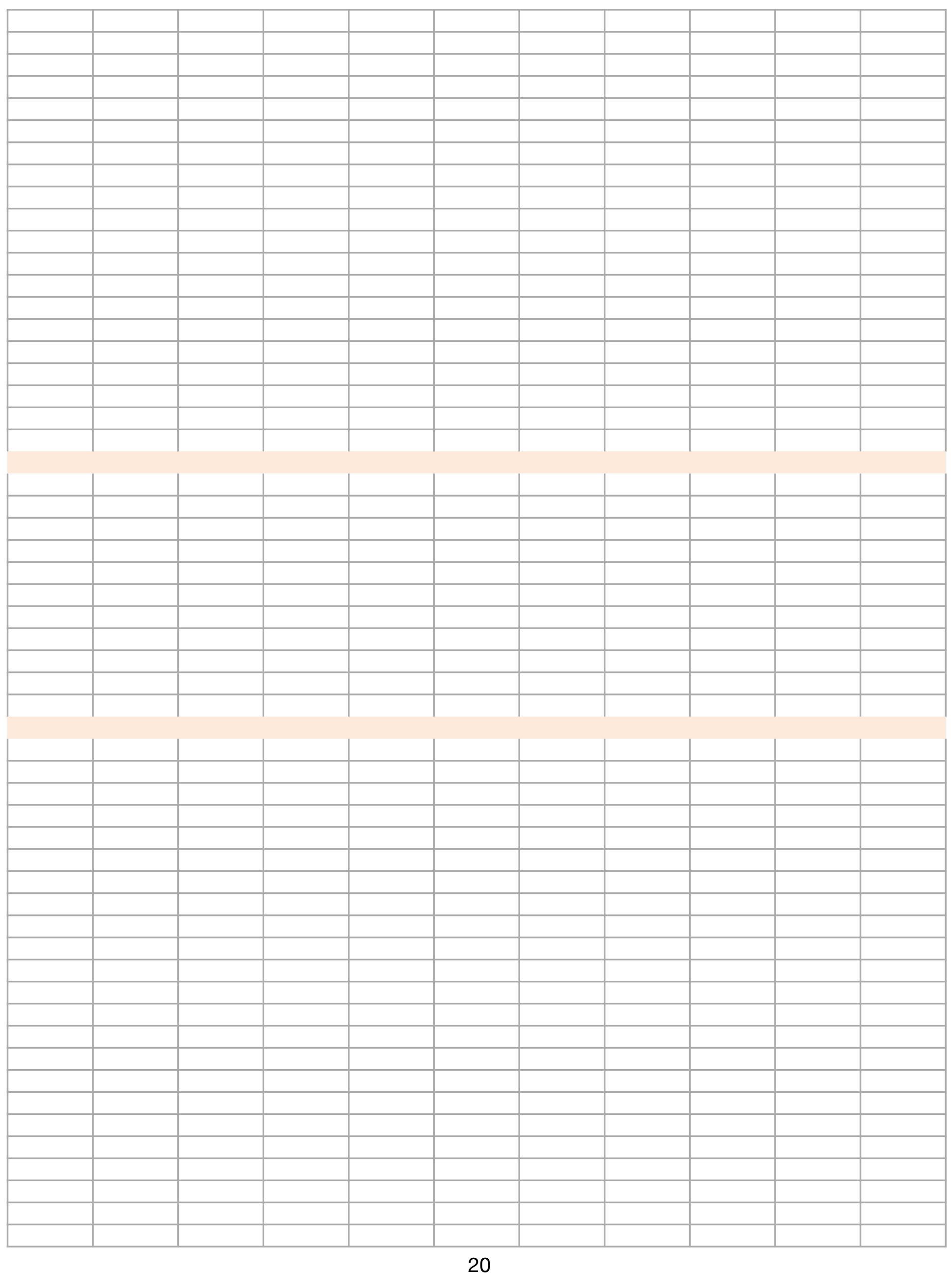


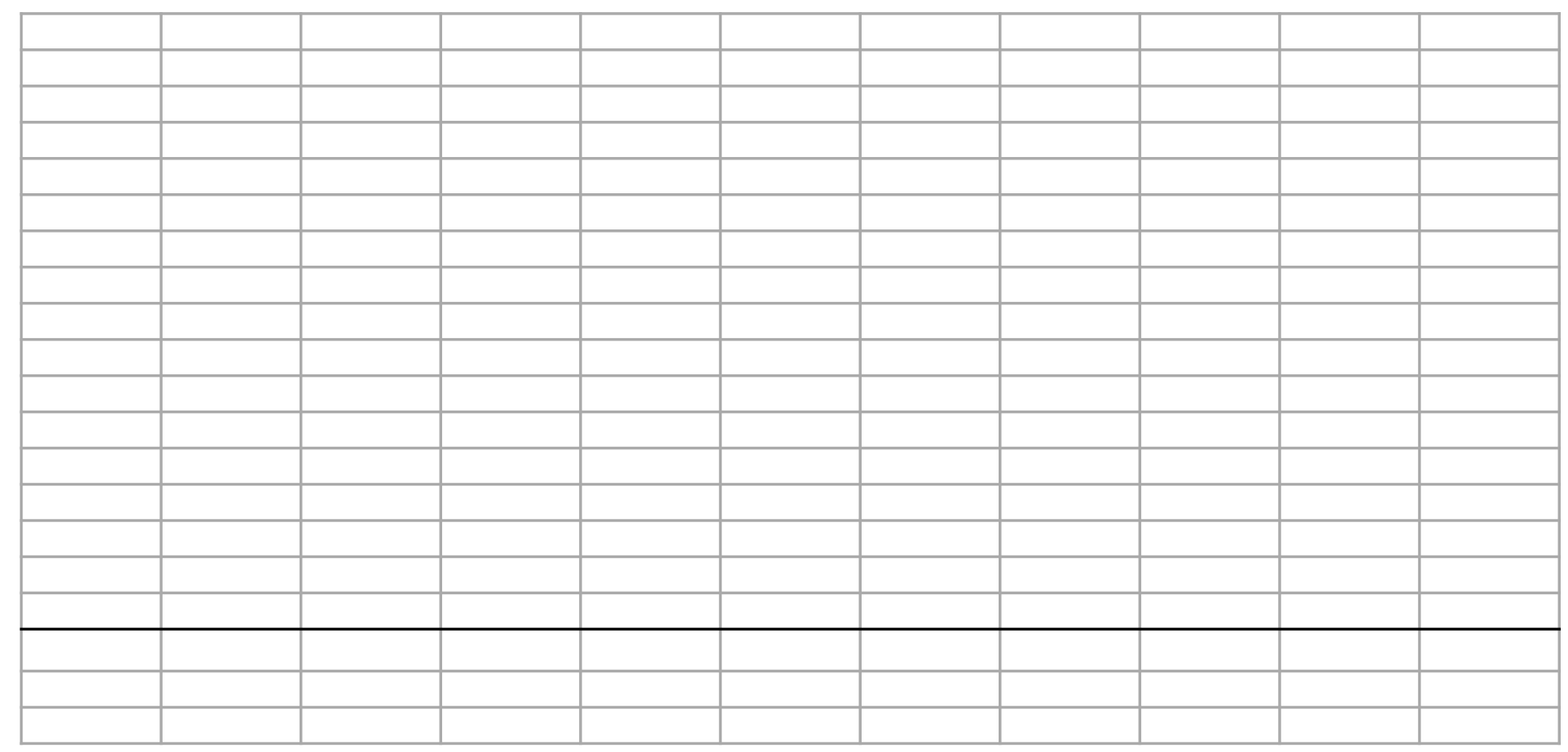




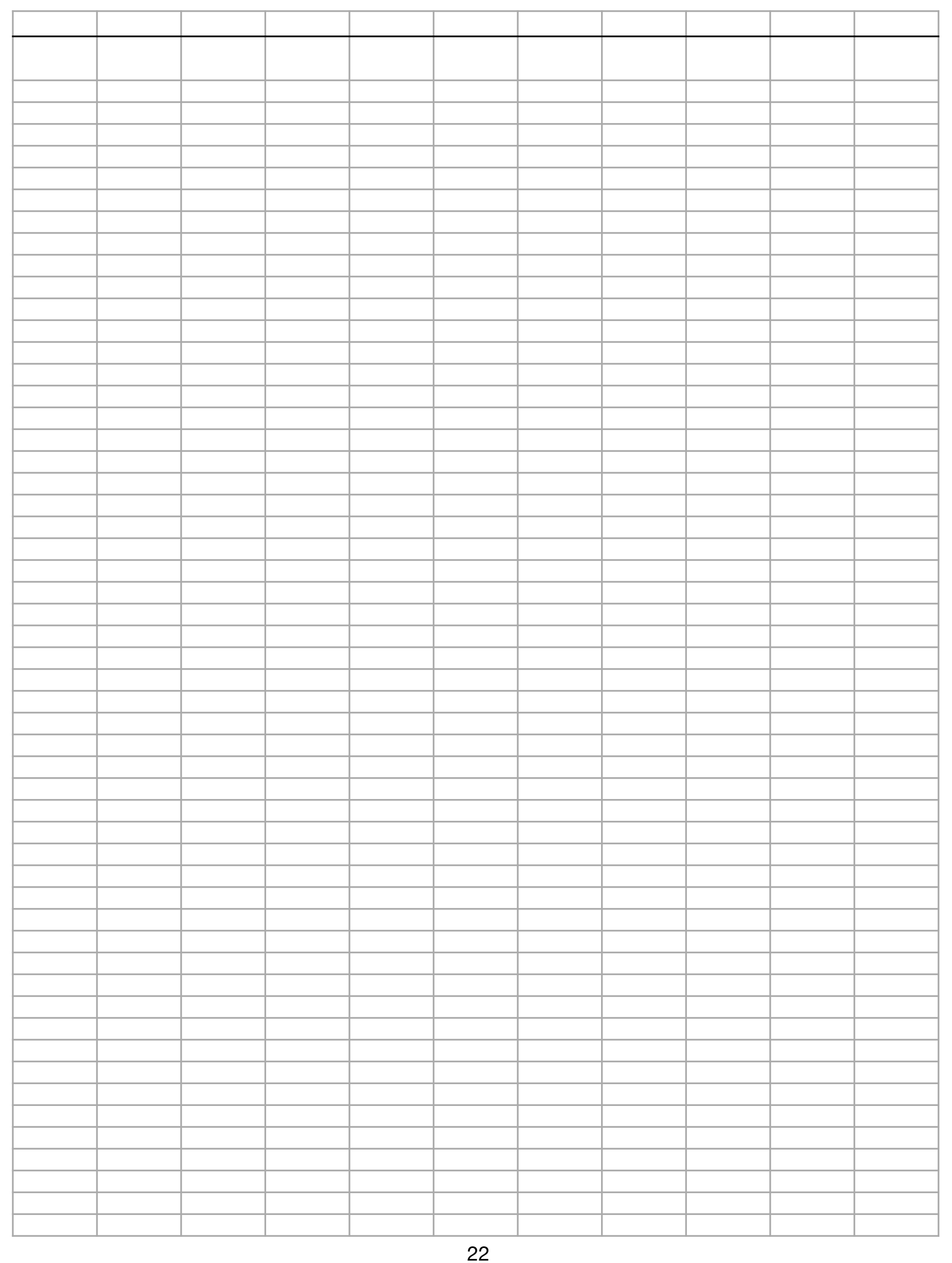



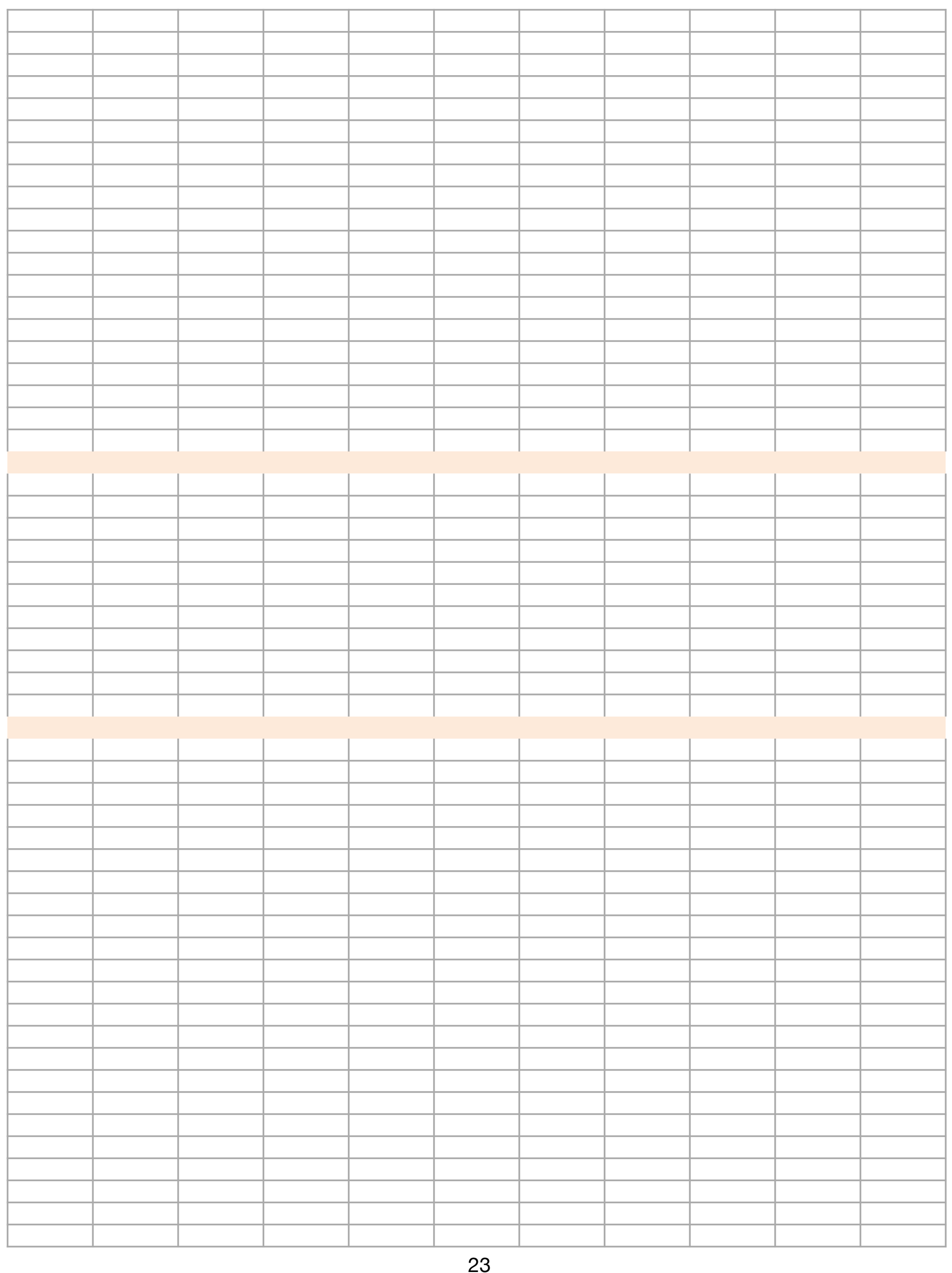


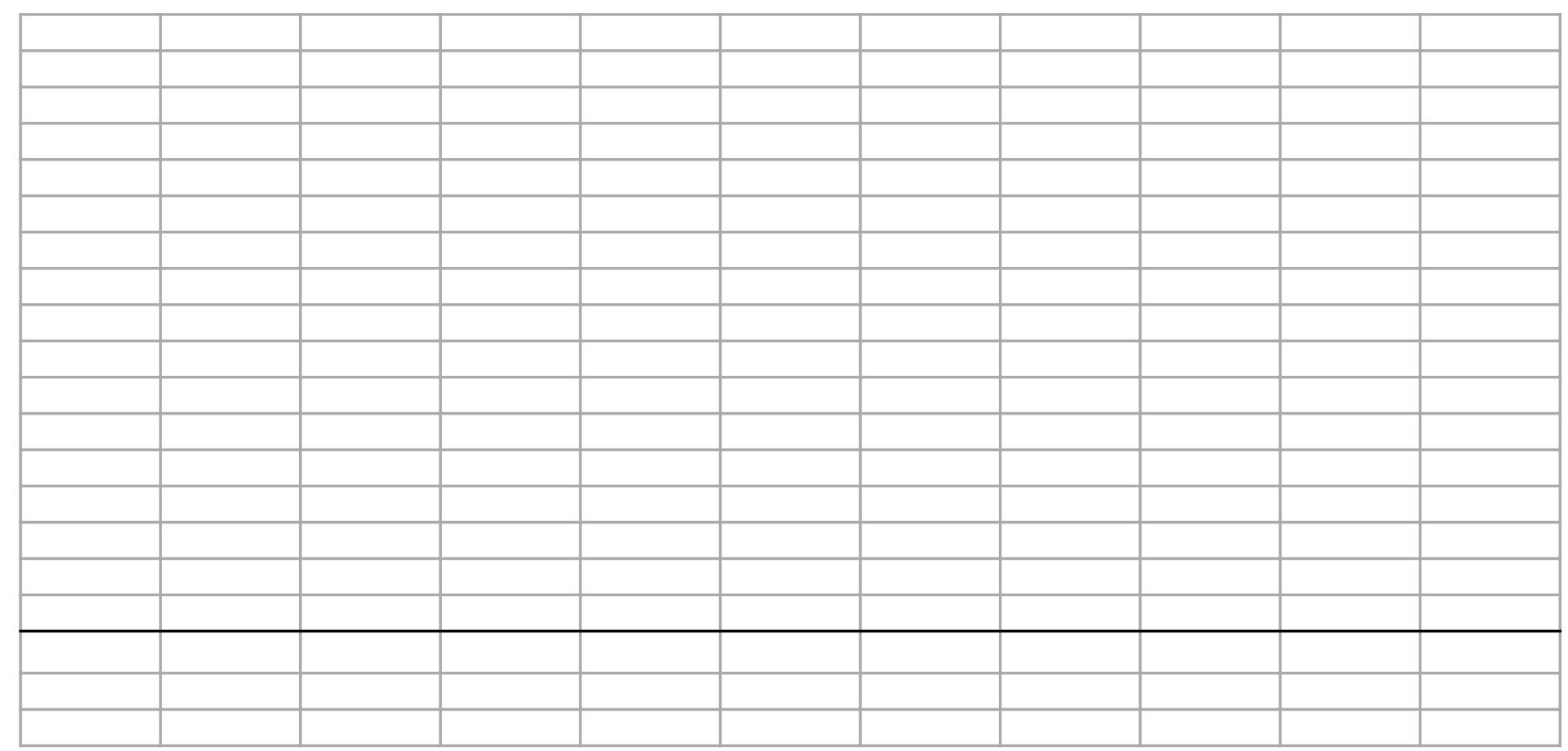




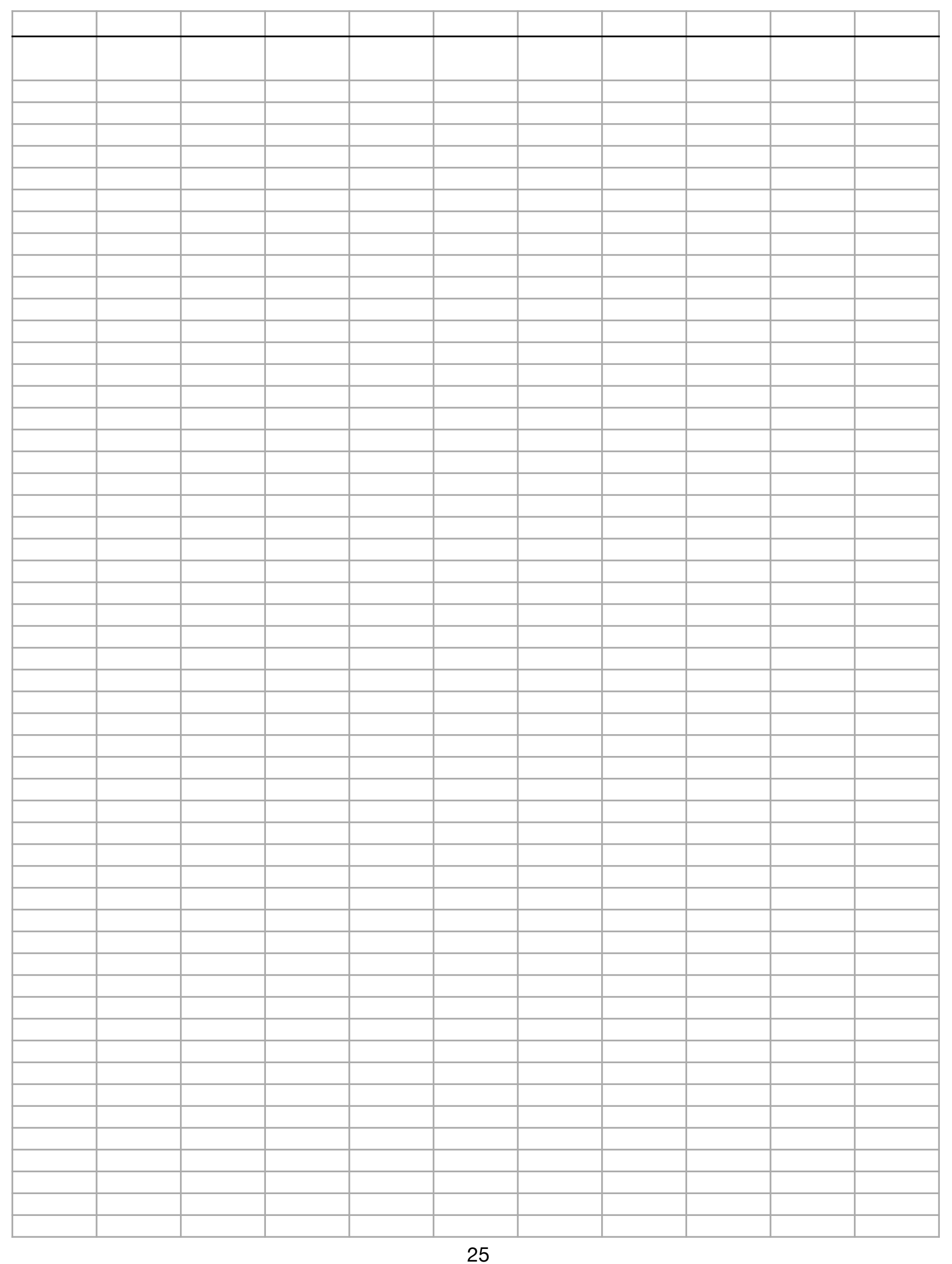



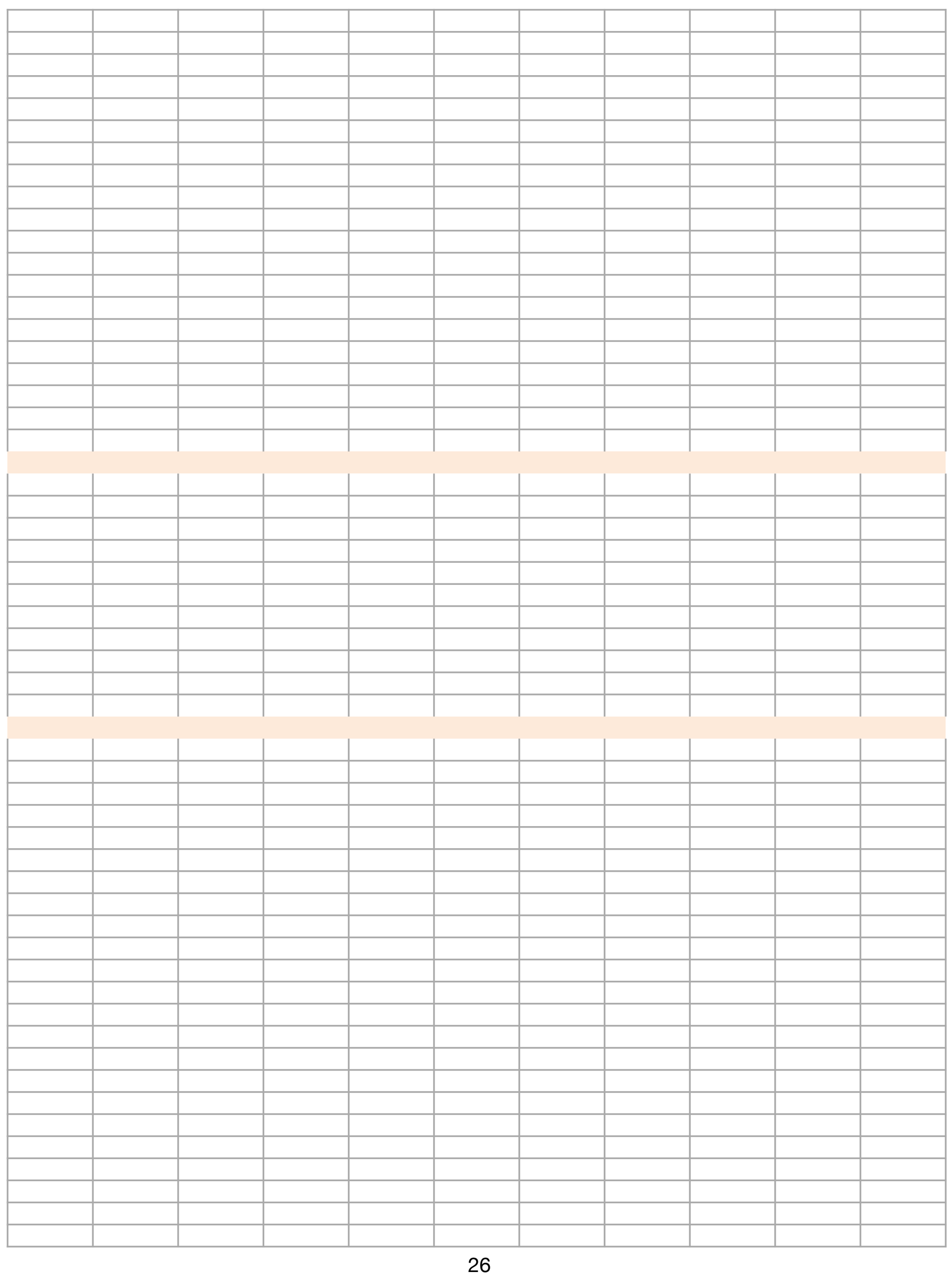


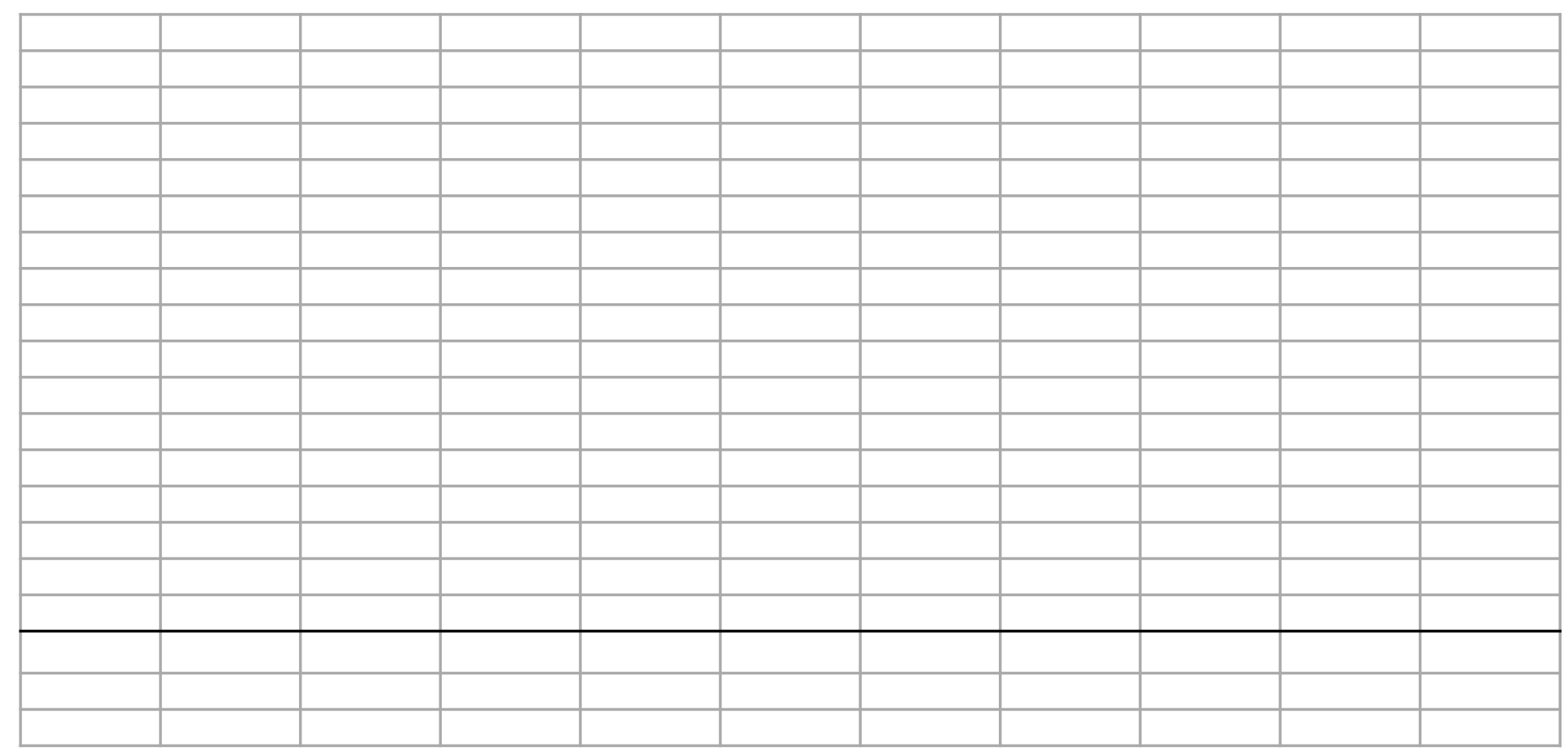




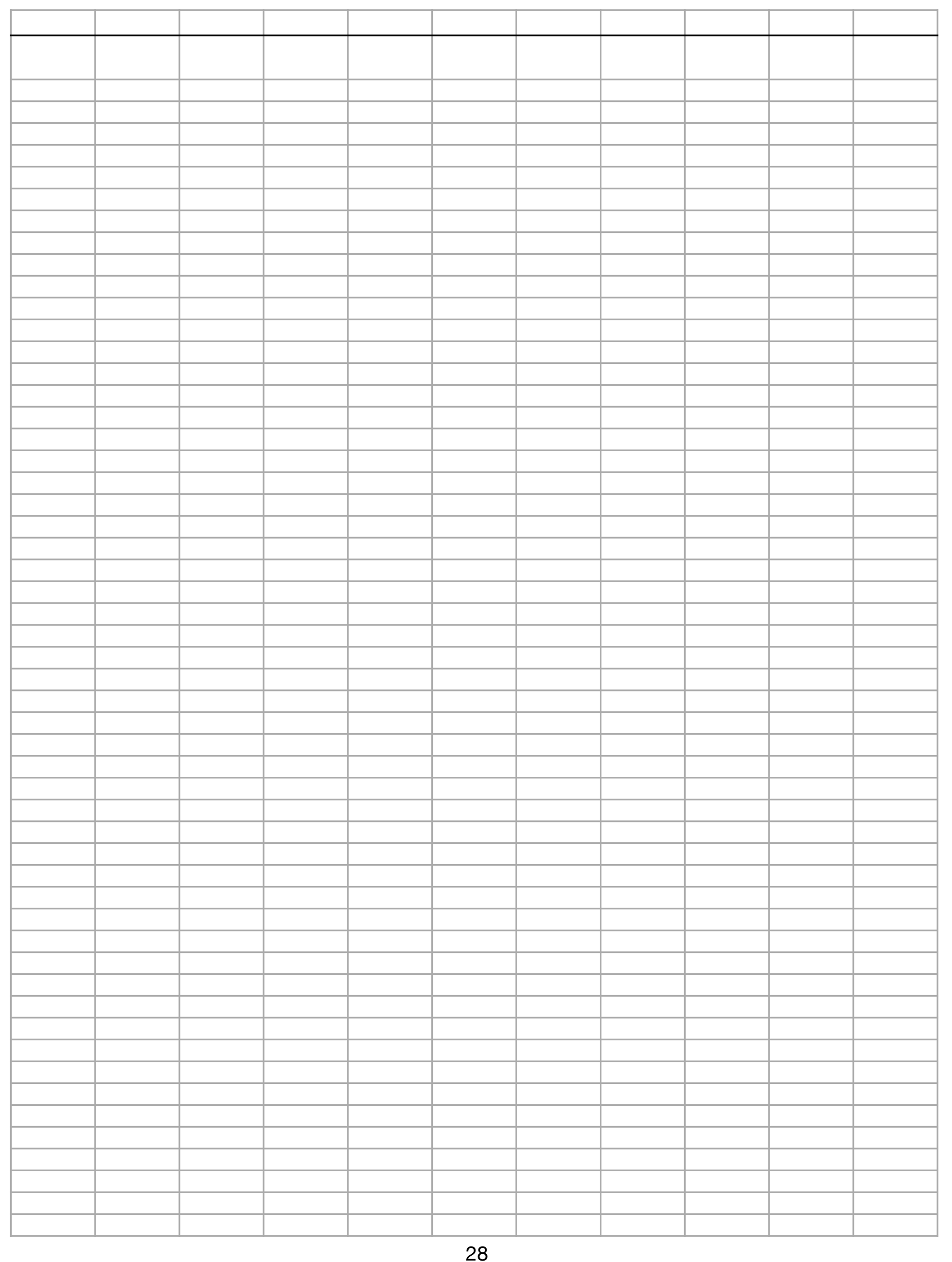



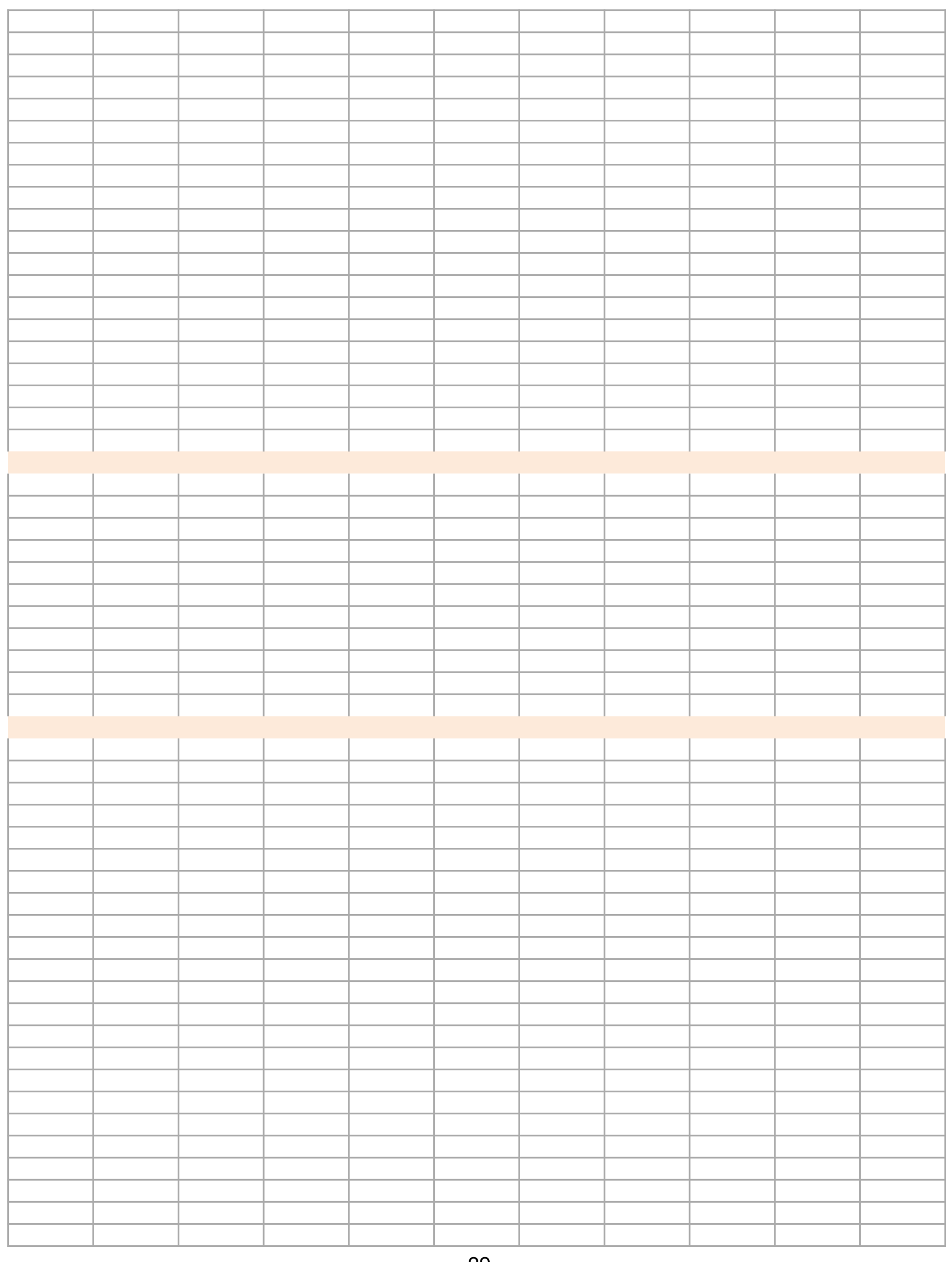


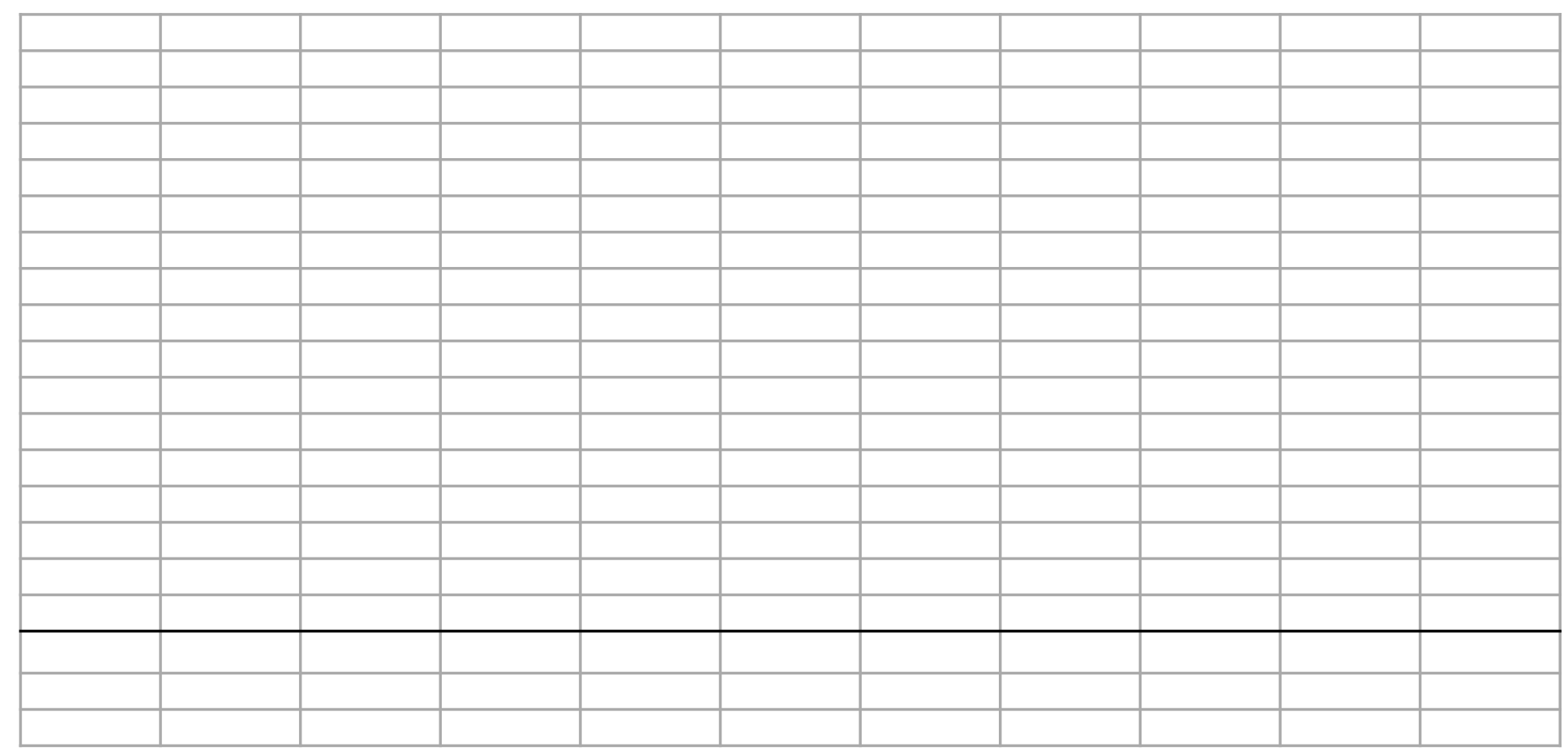




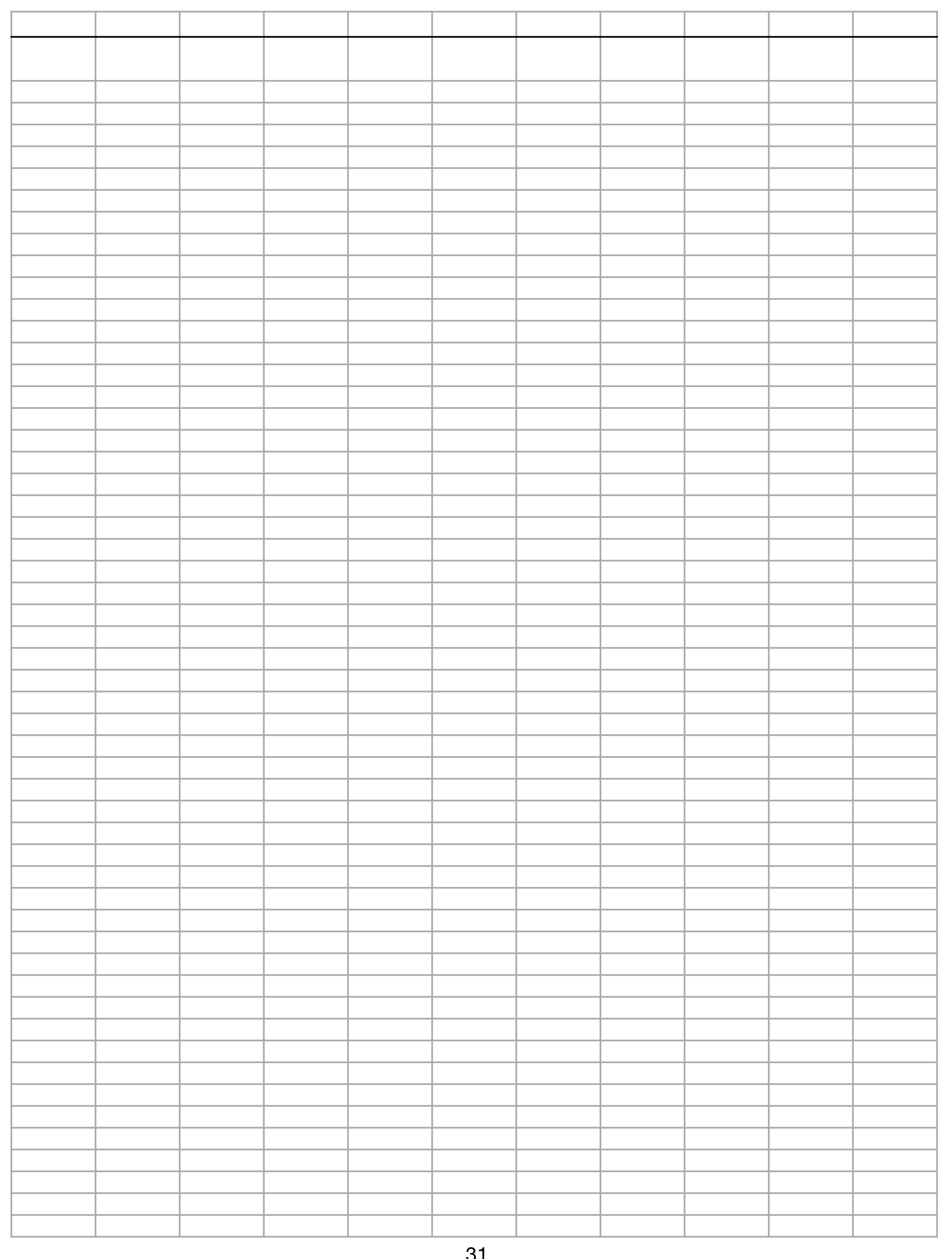



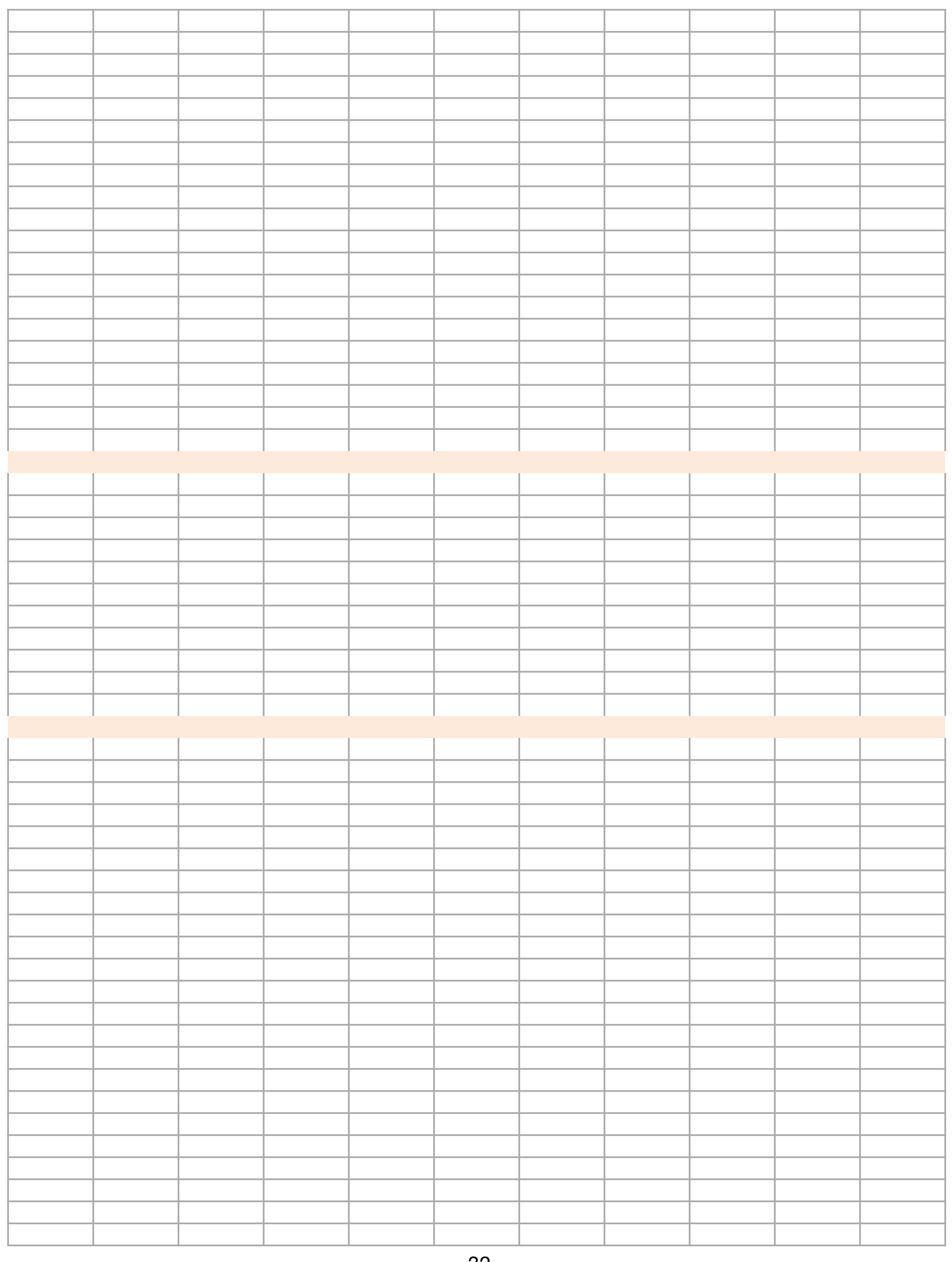


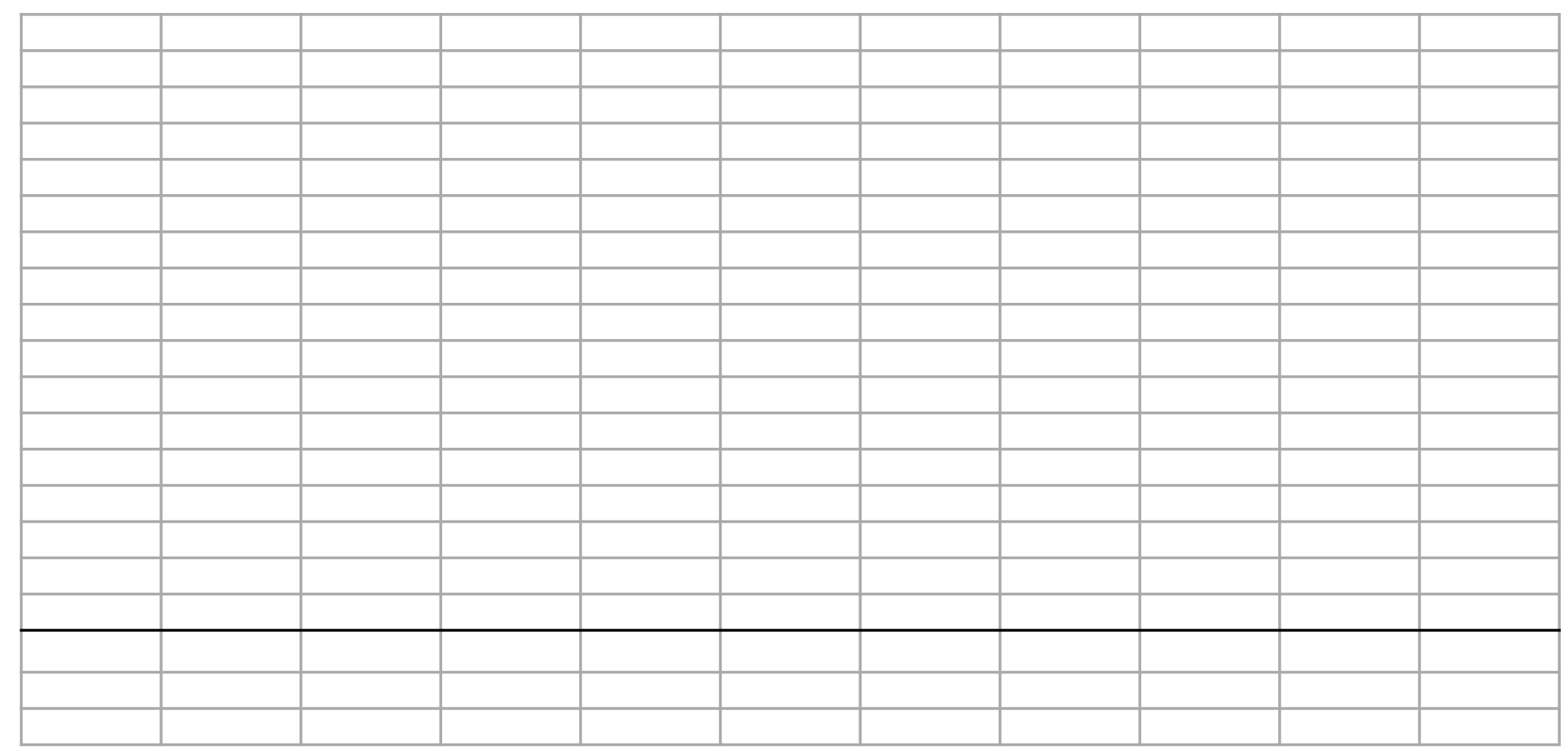




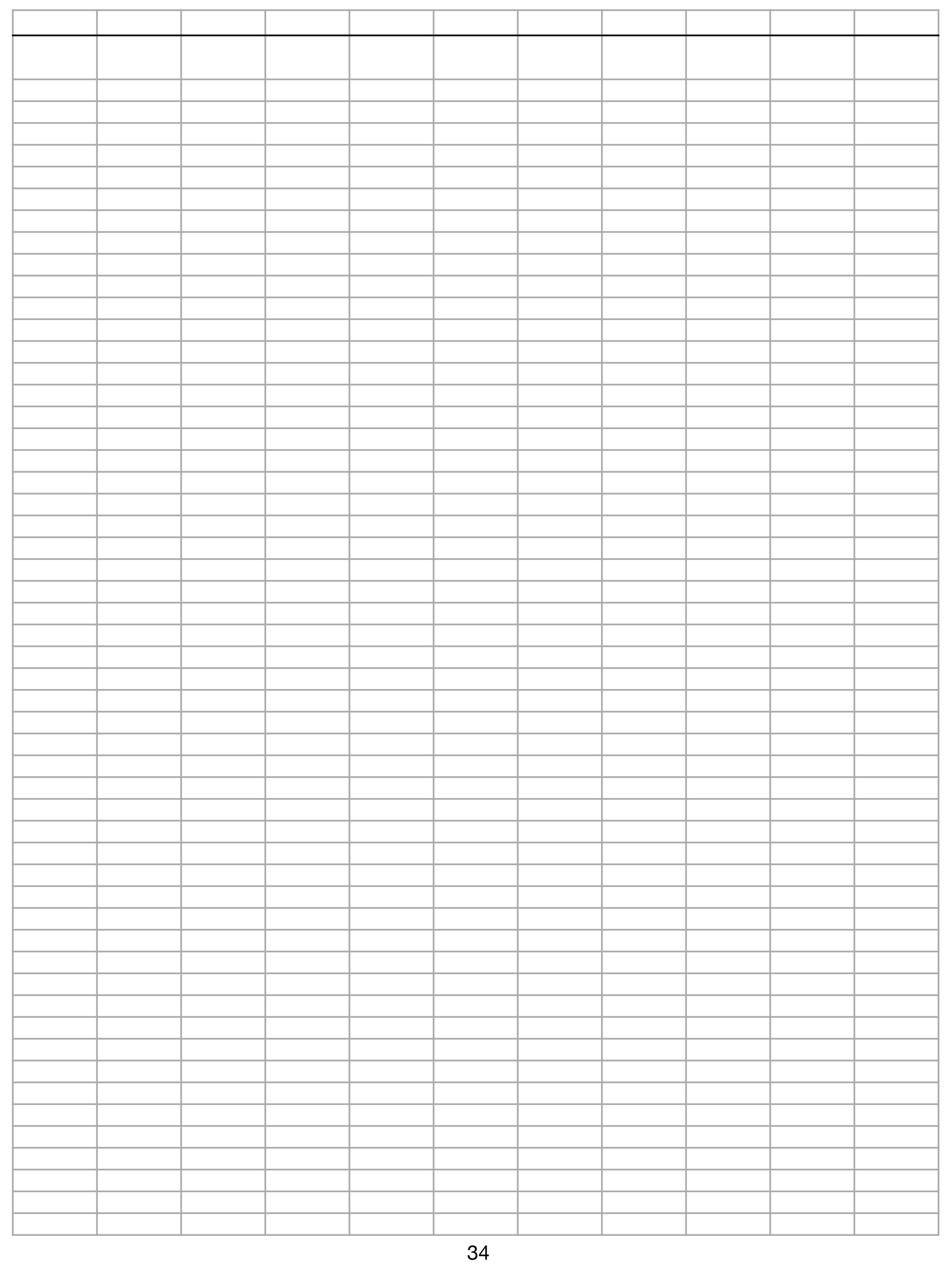



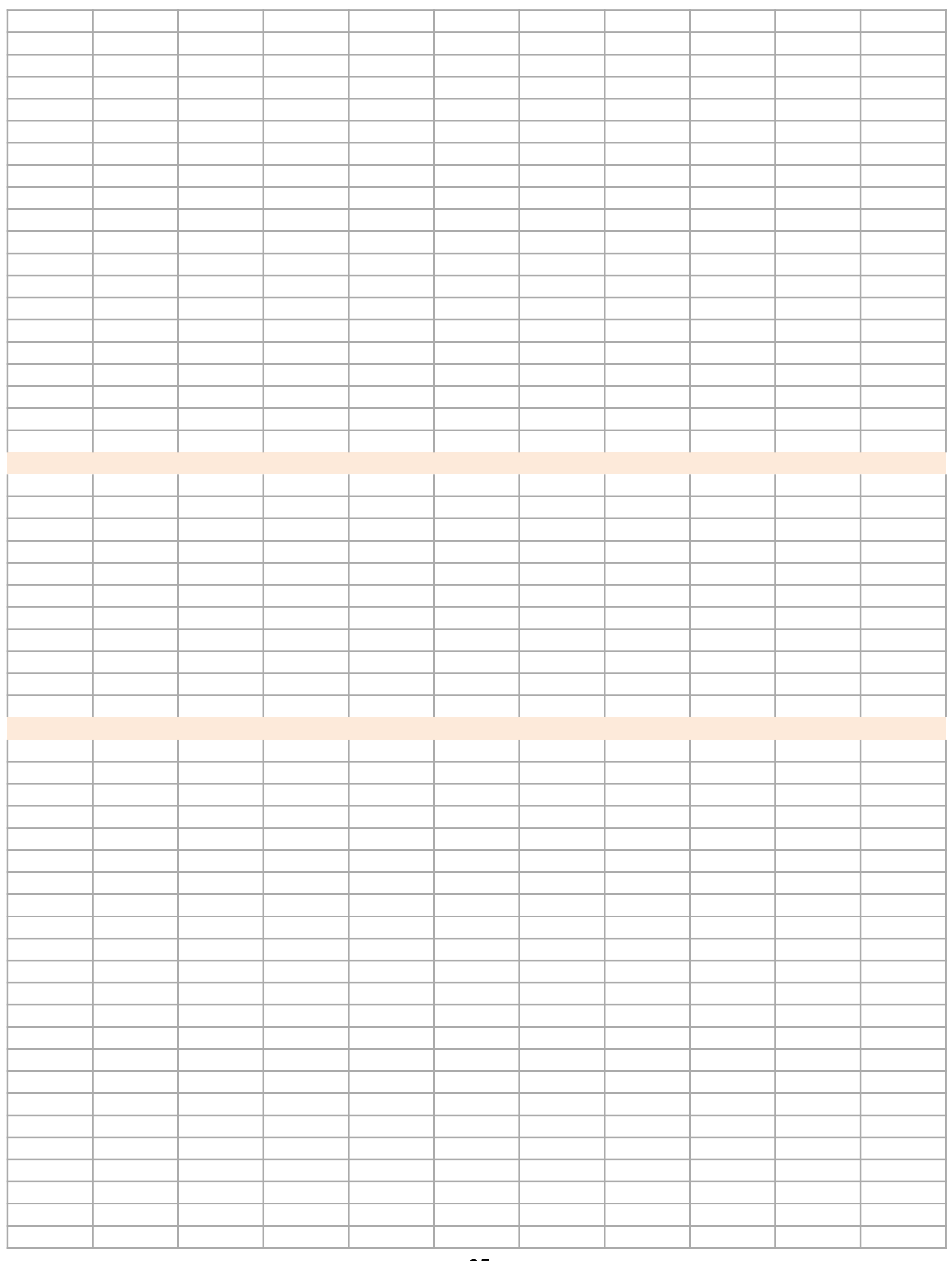


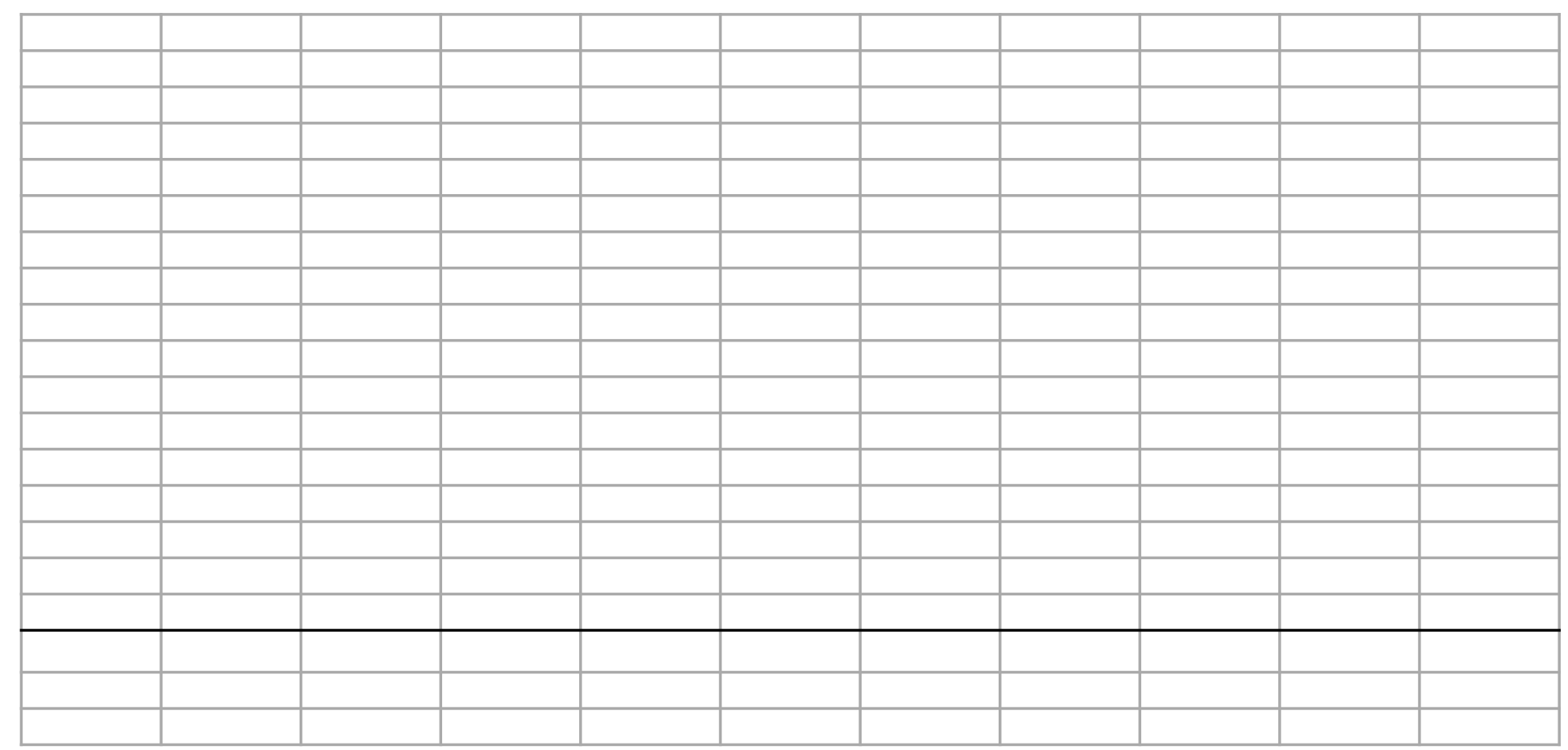




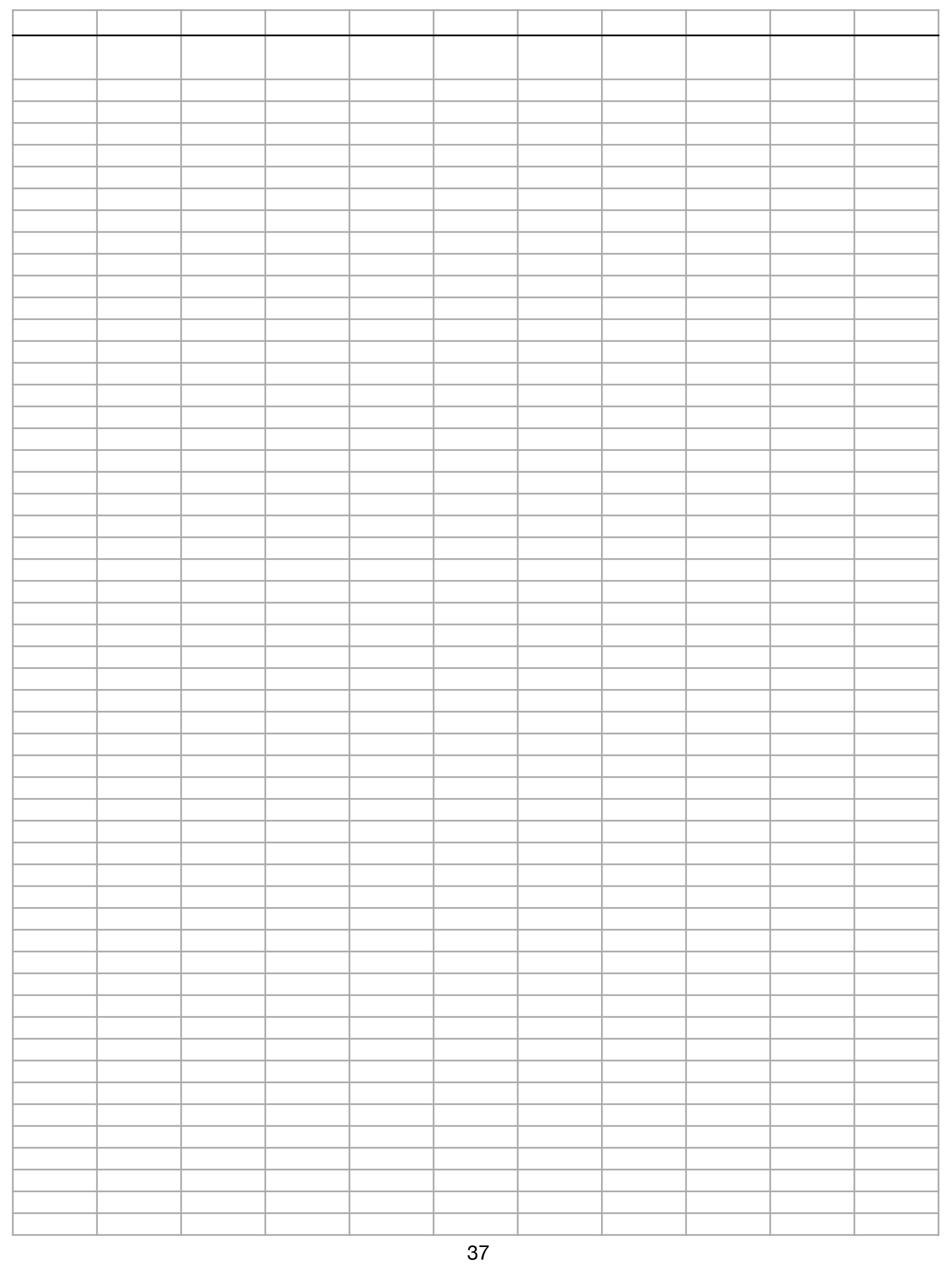



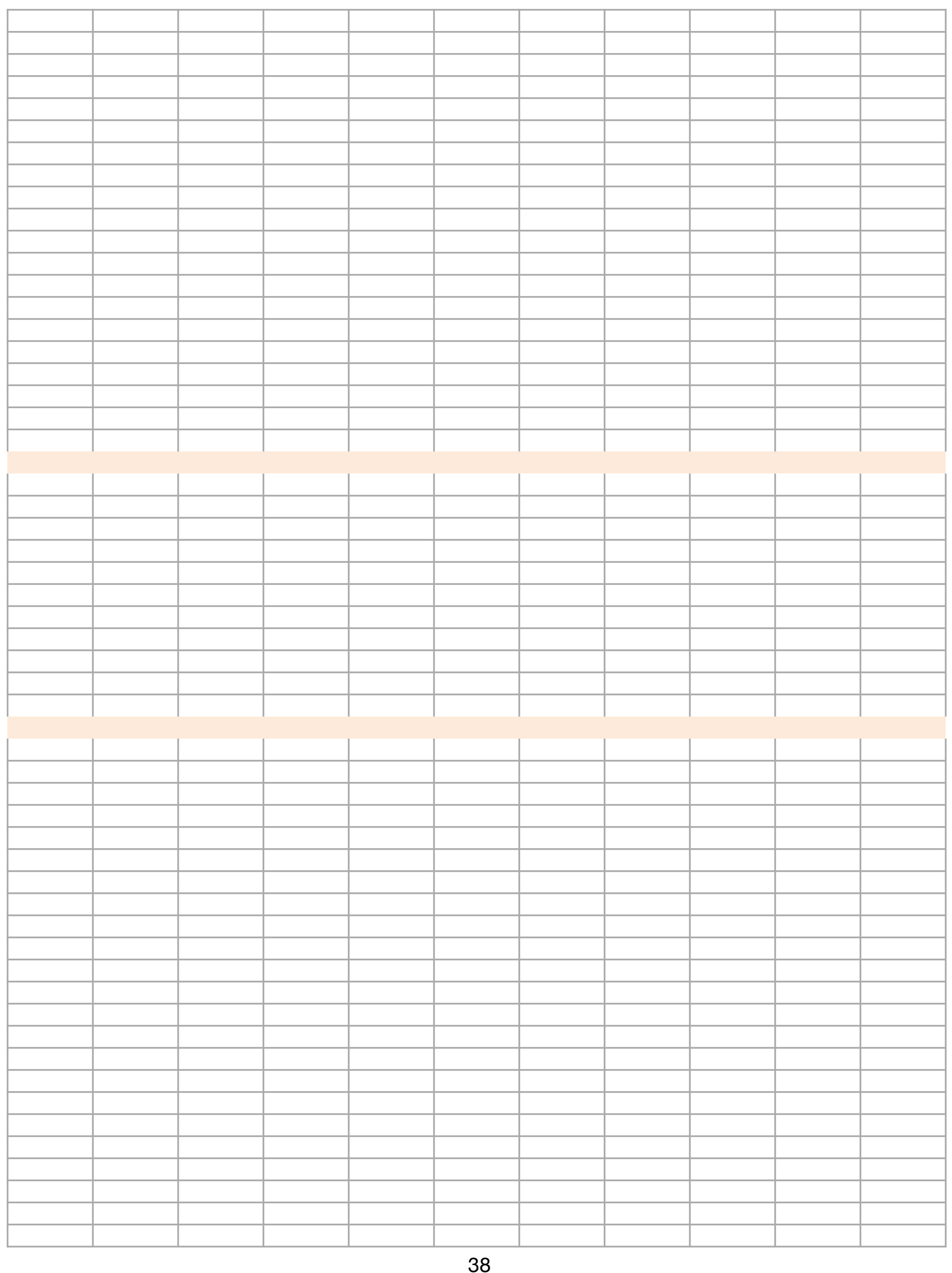


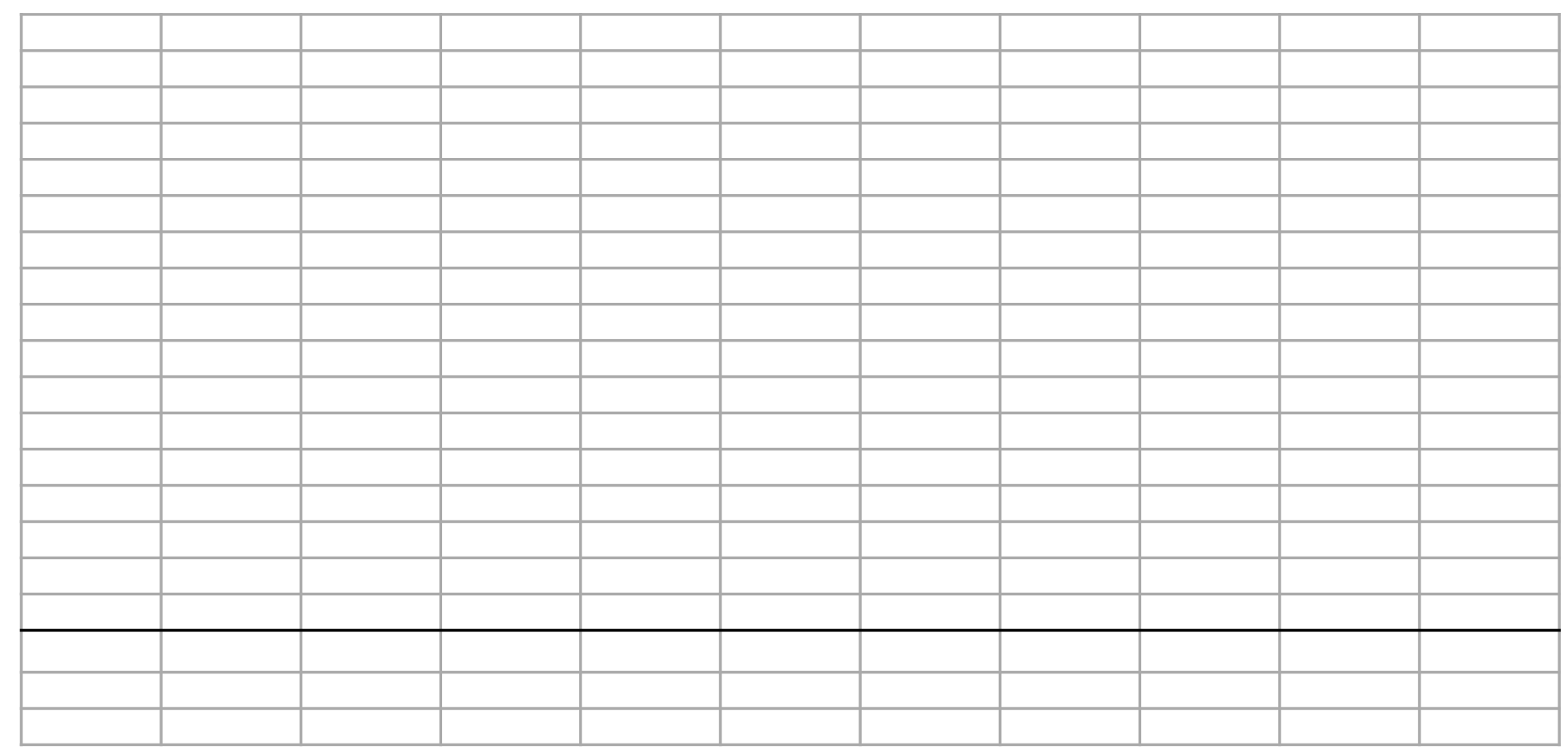




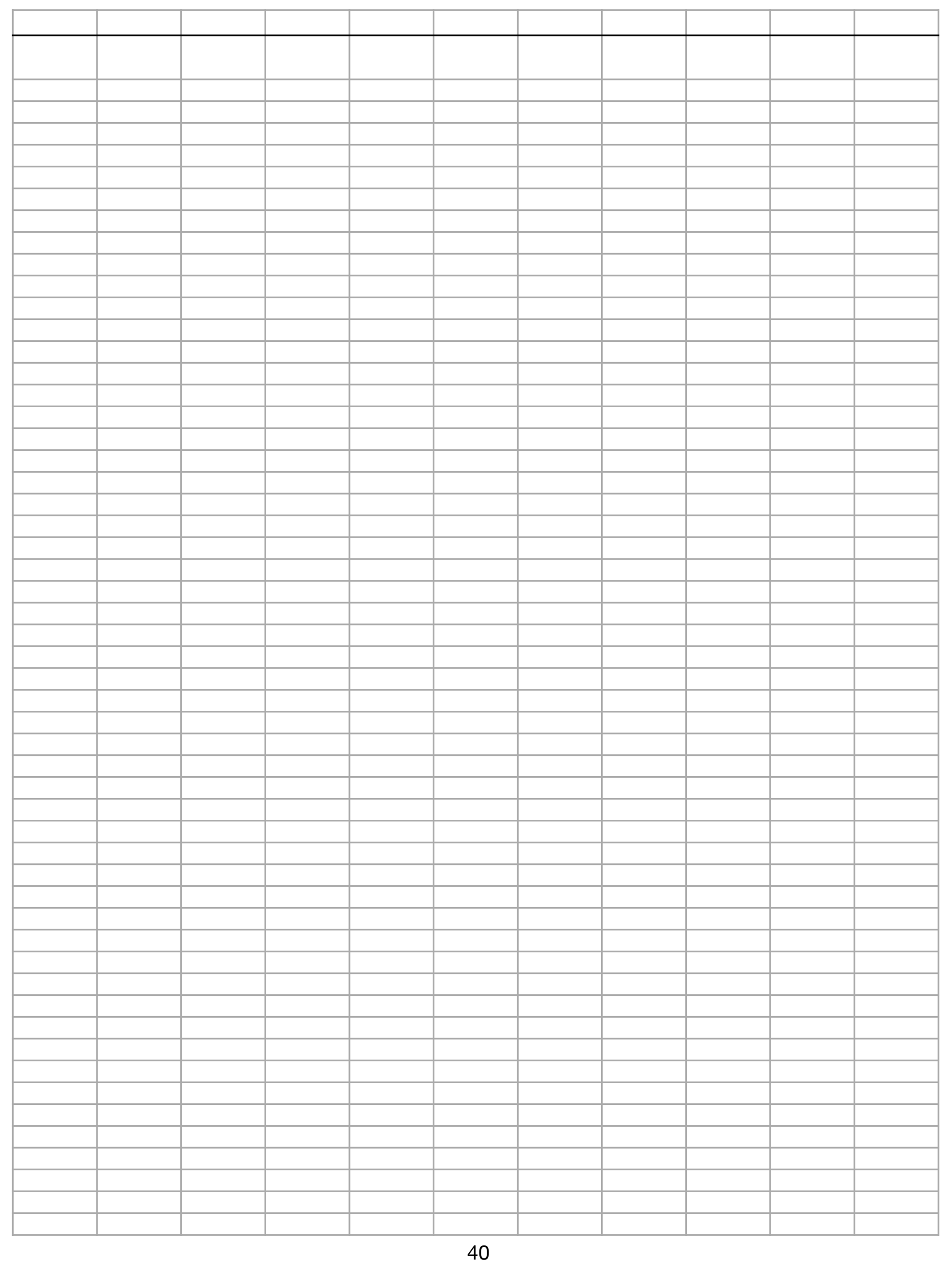



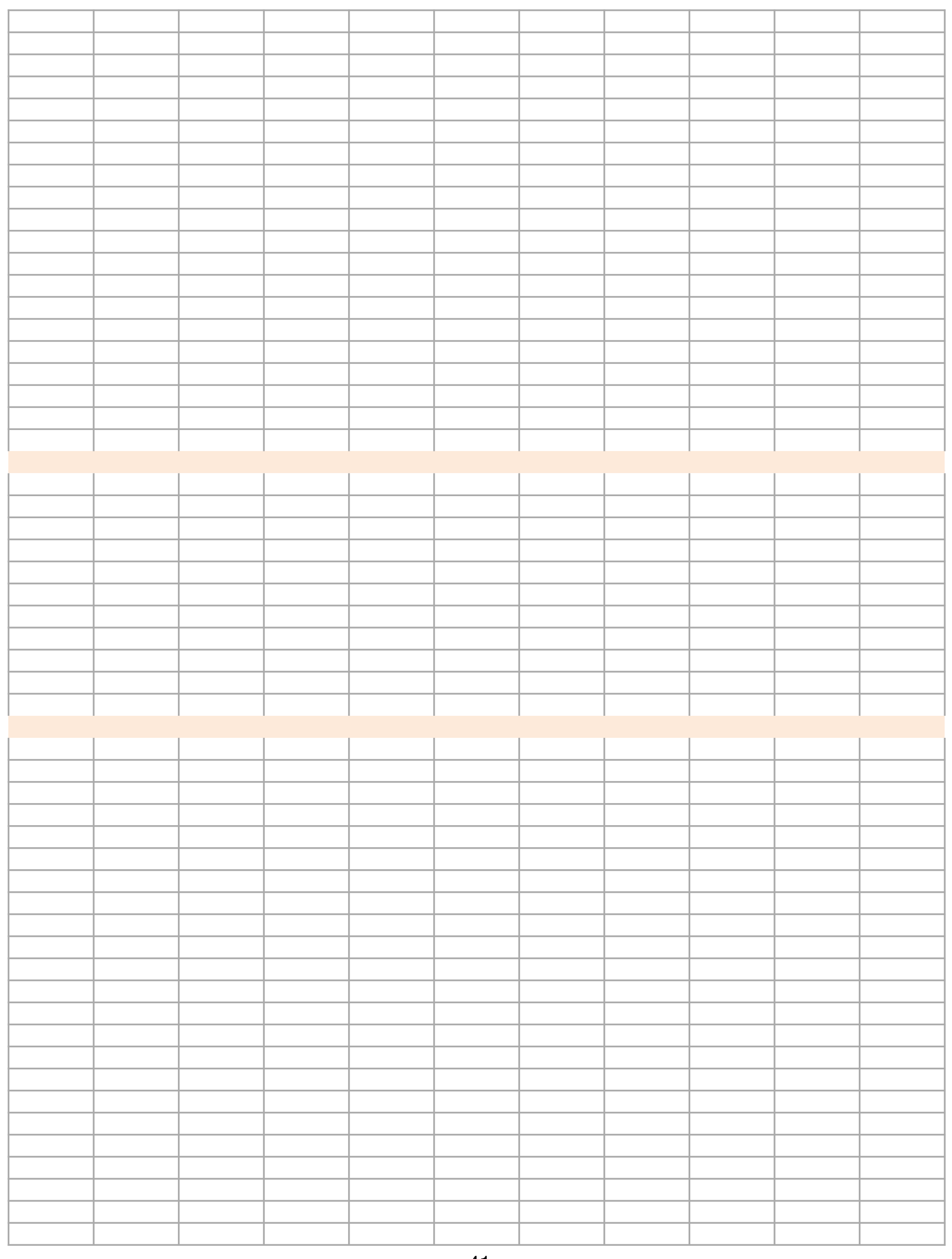

41 


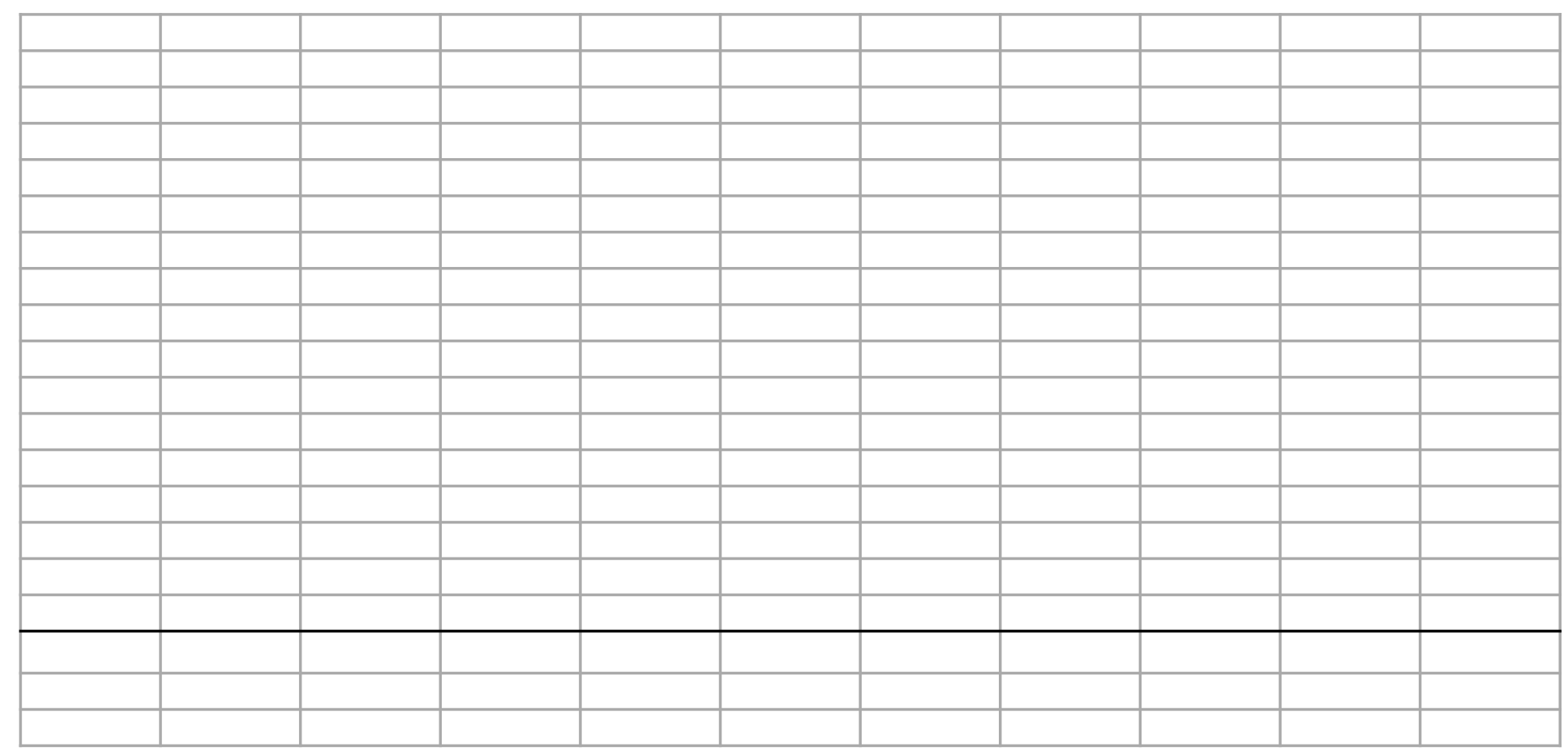




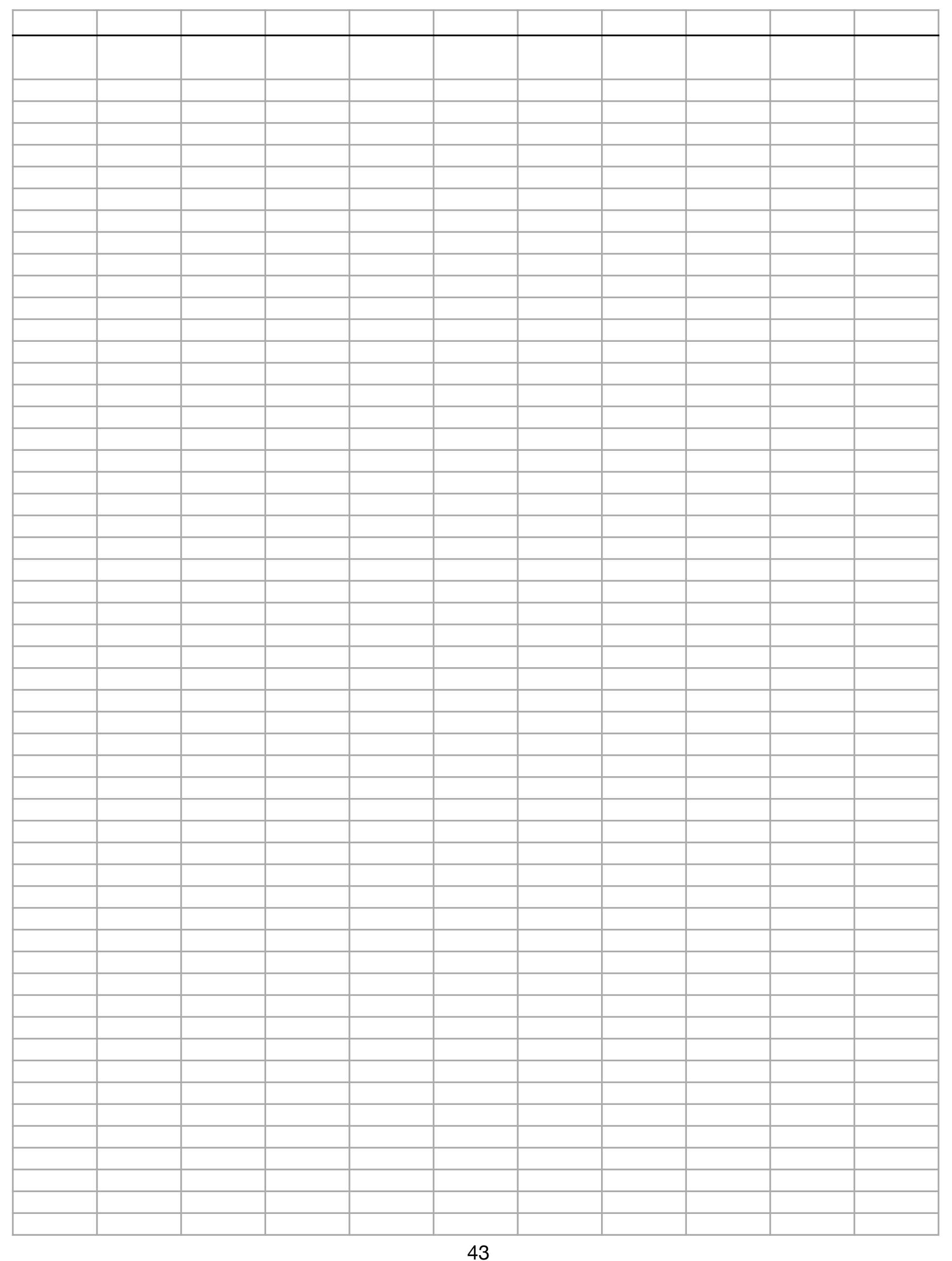



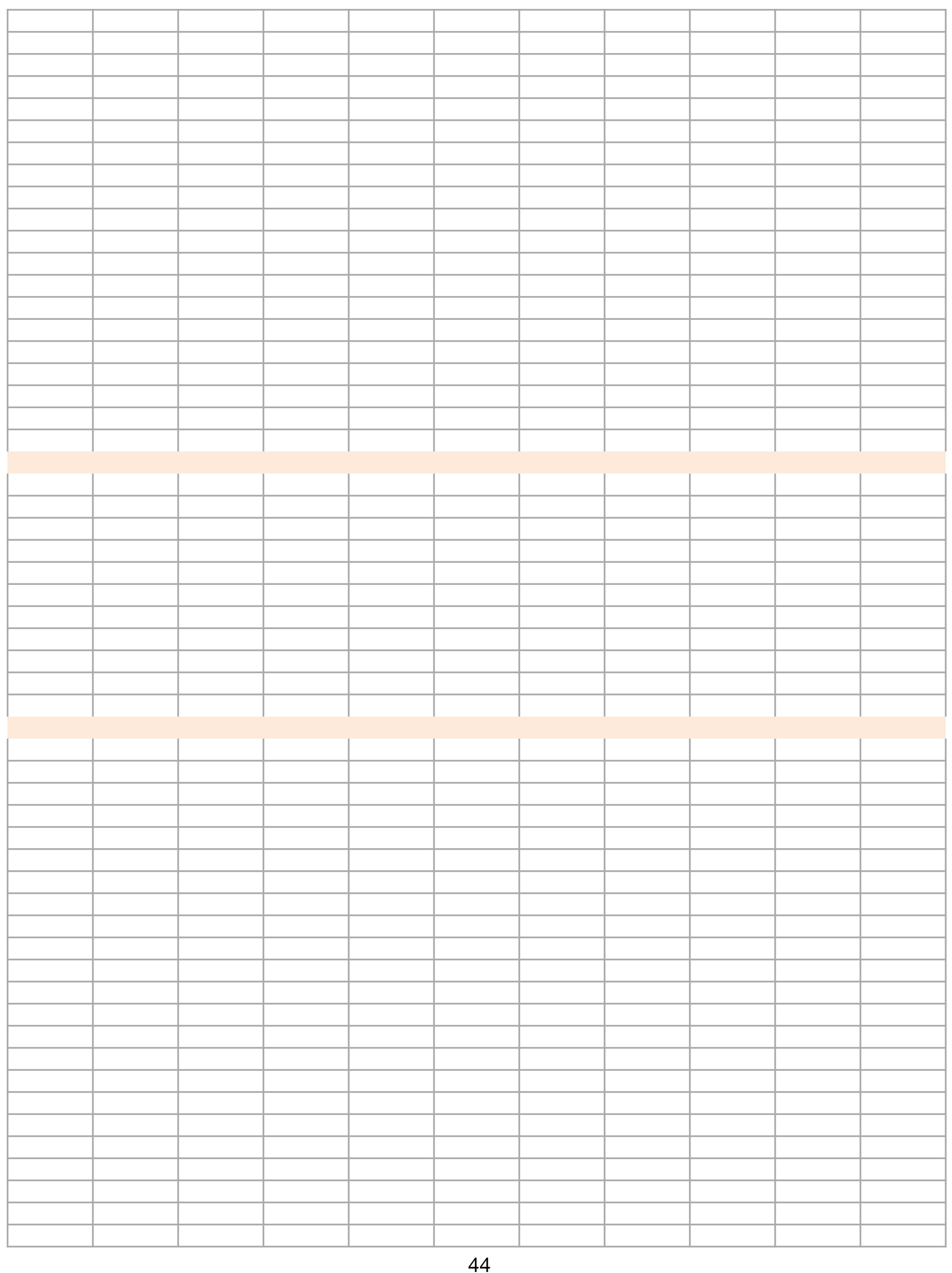


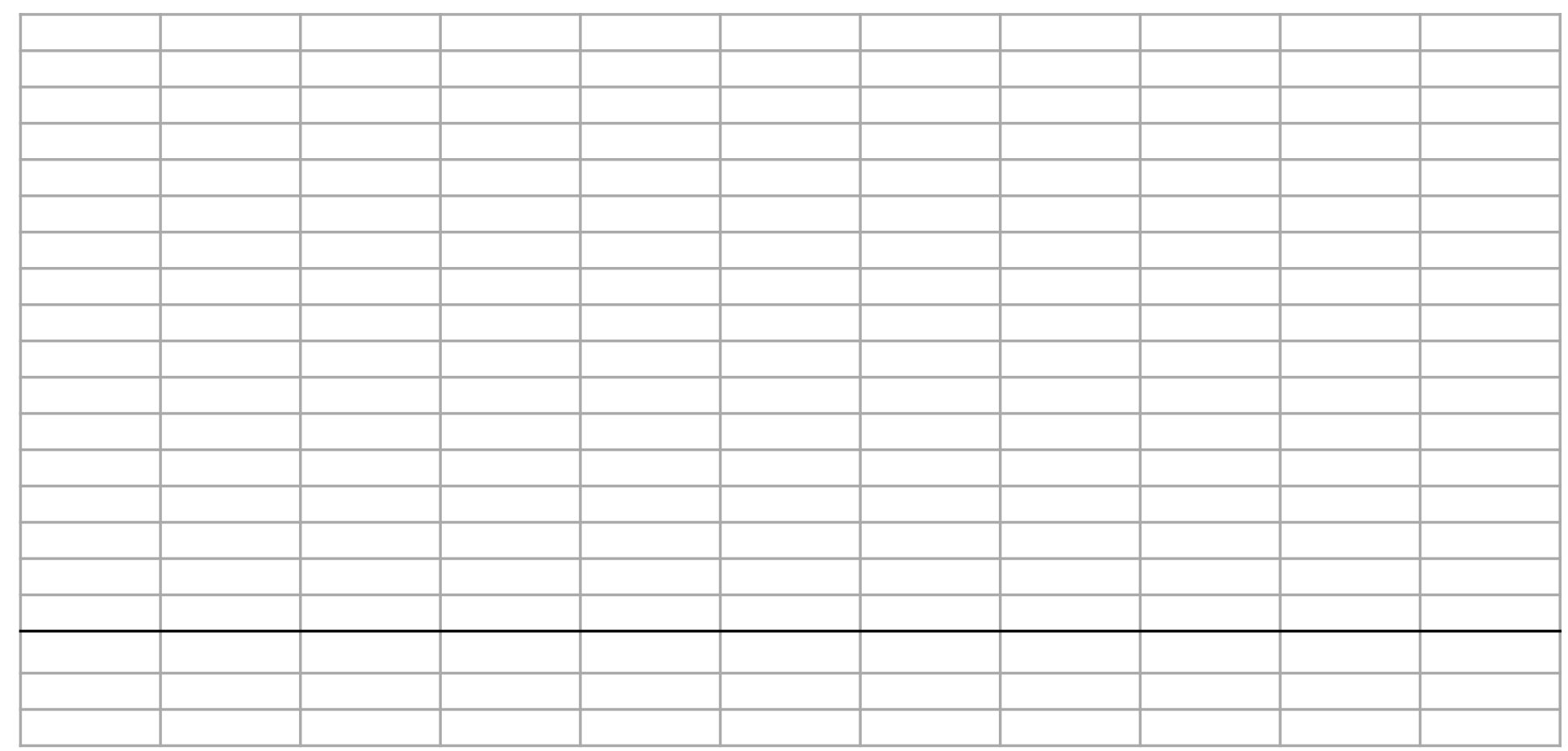




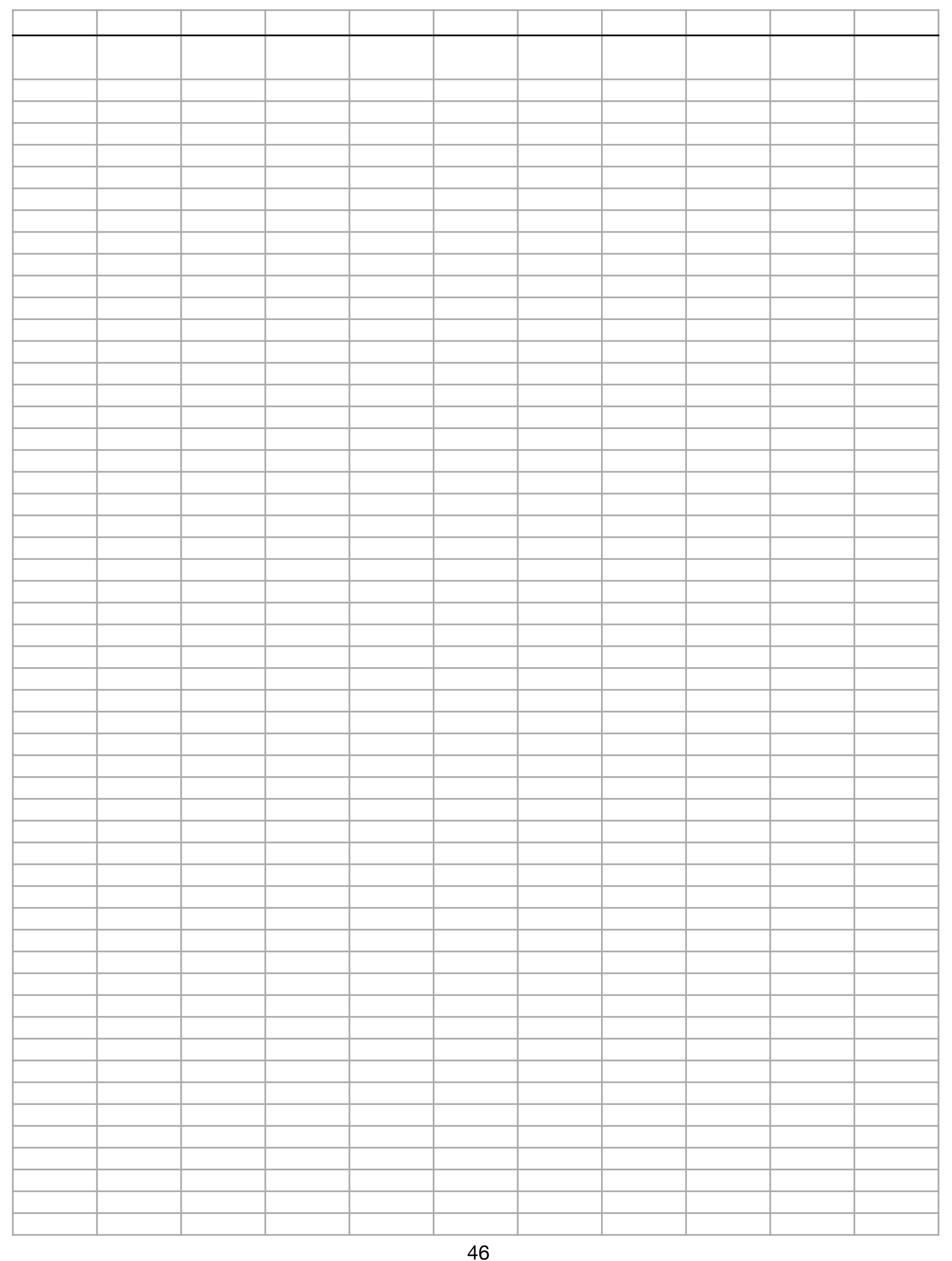



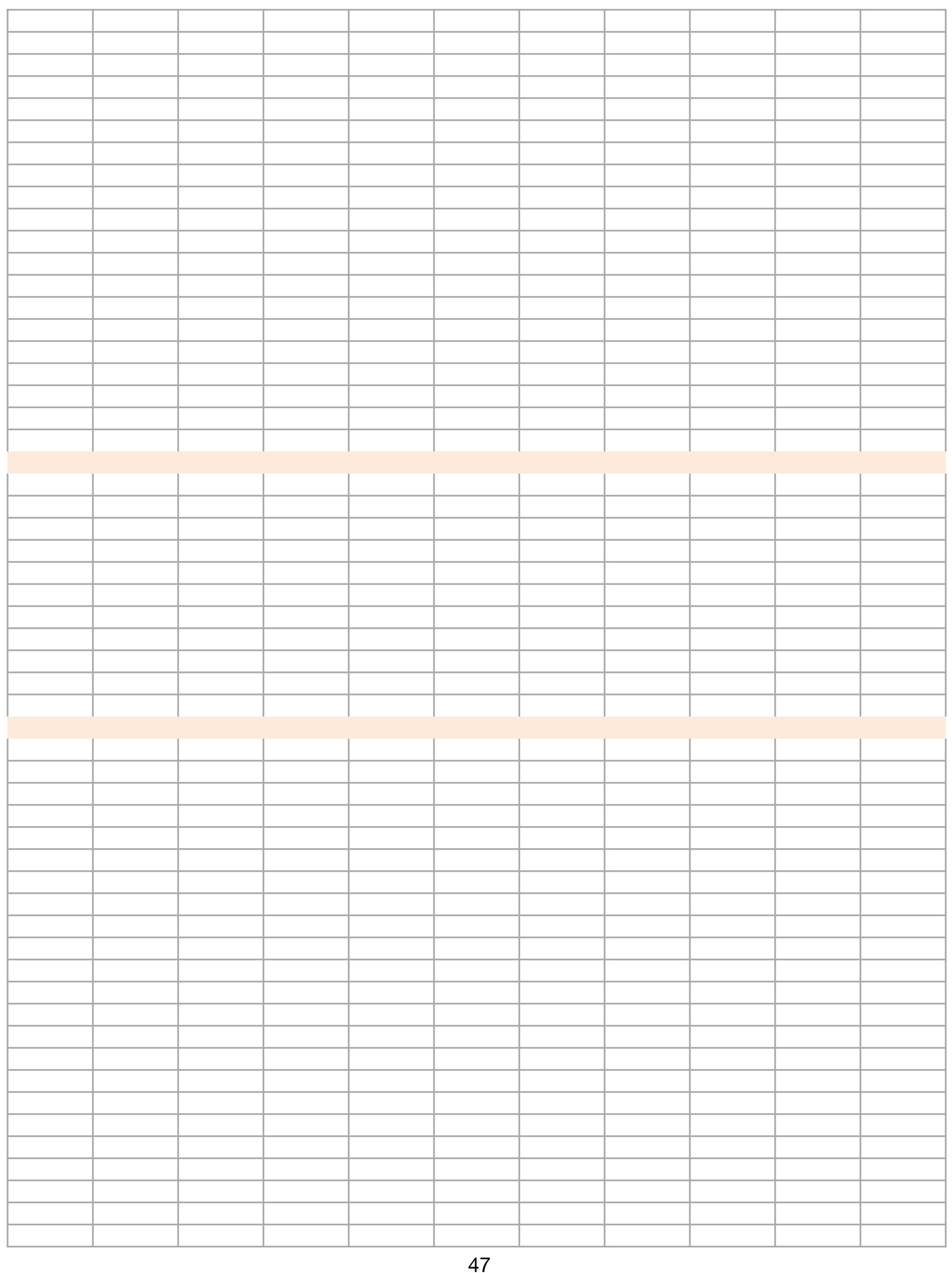


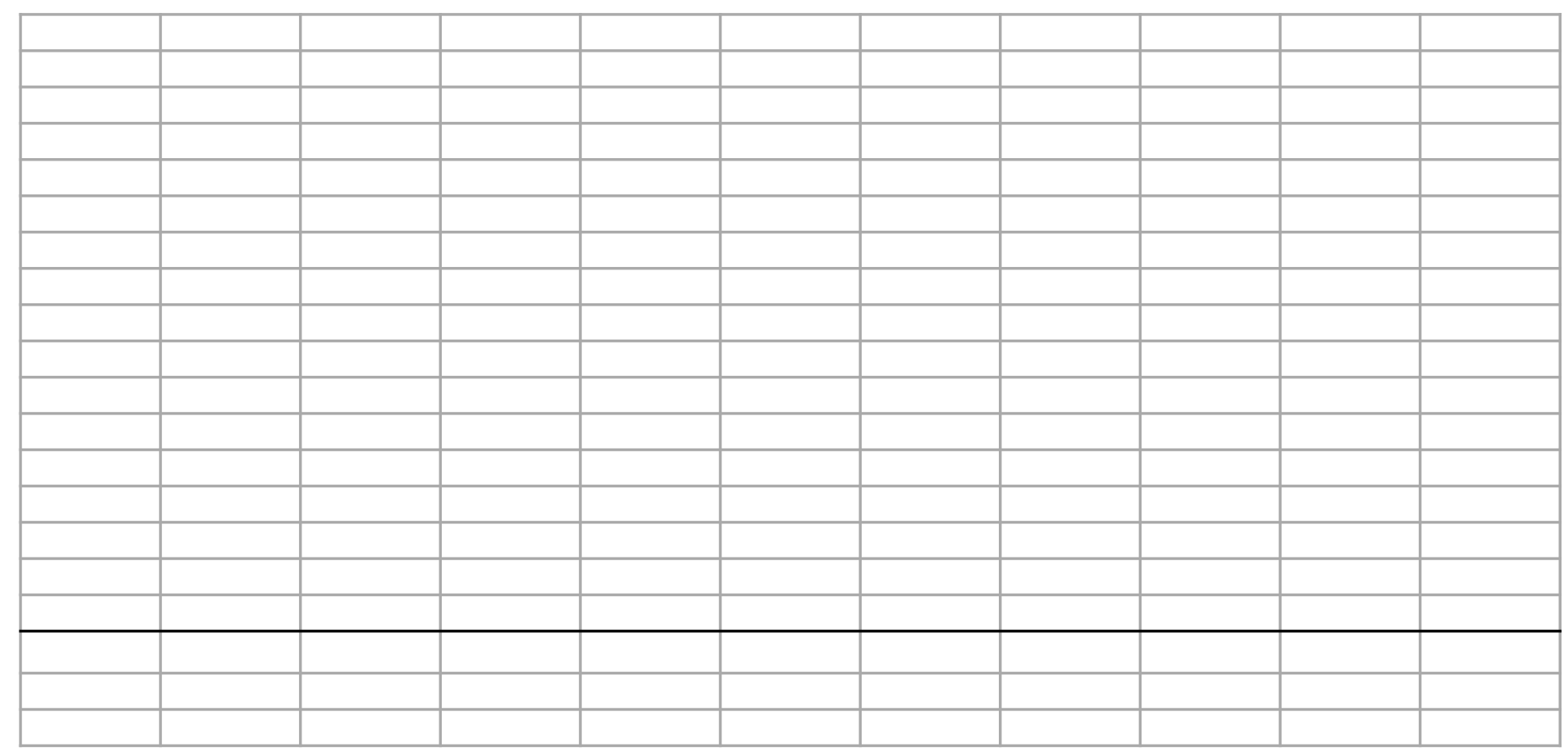




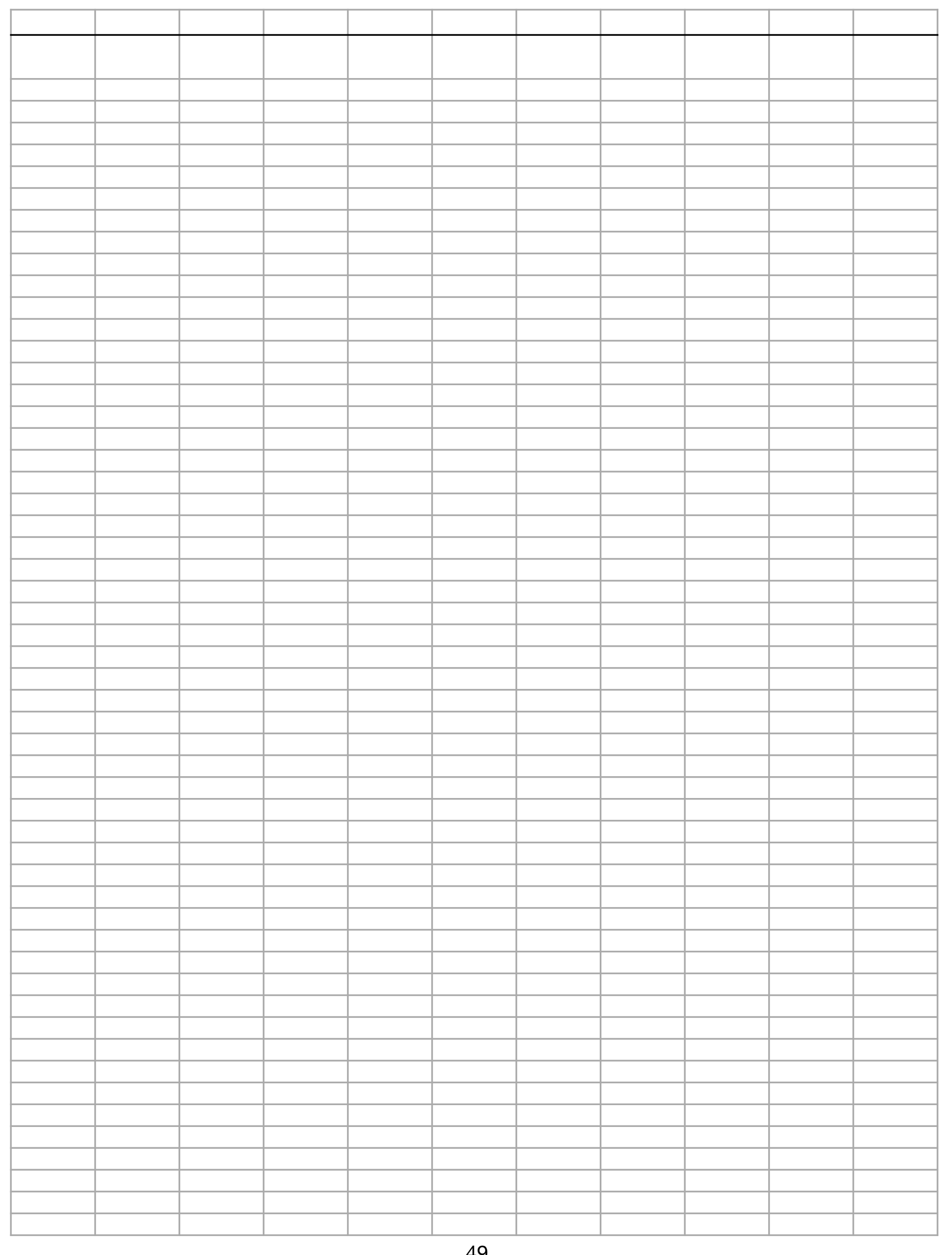



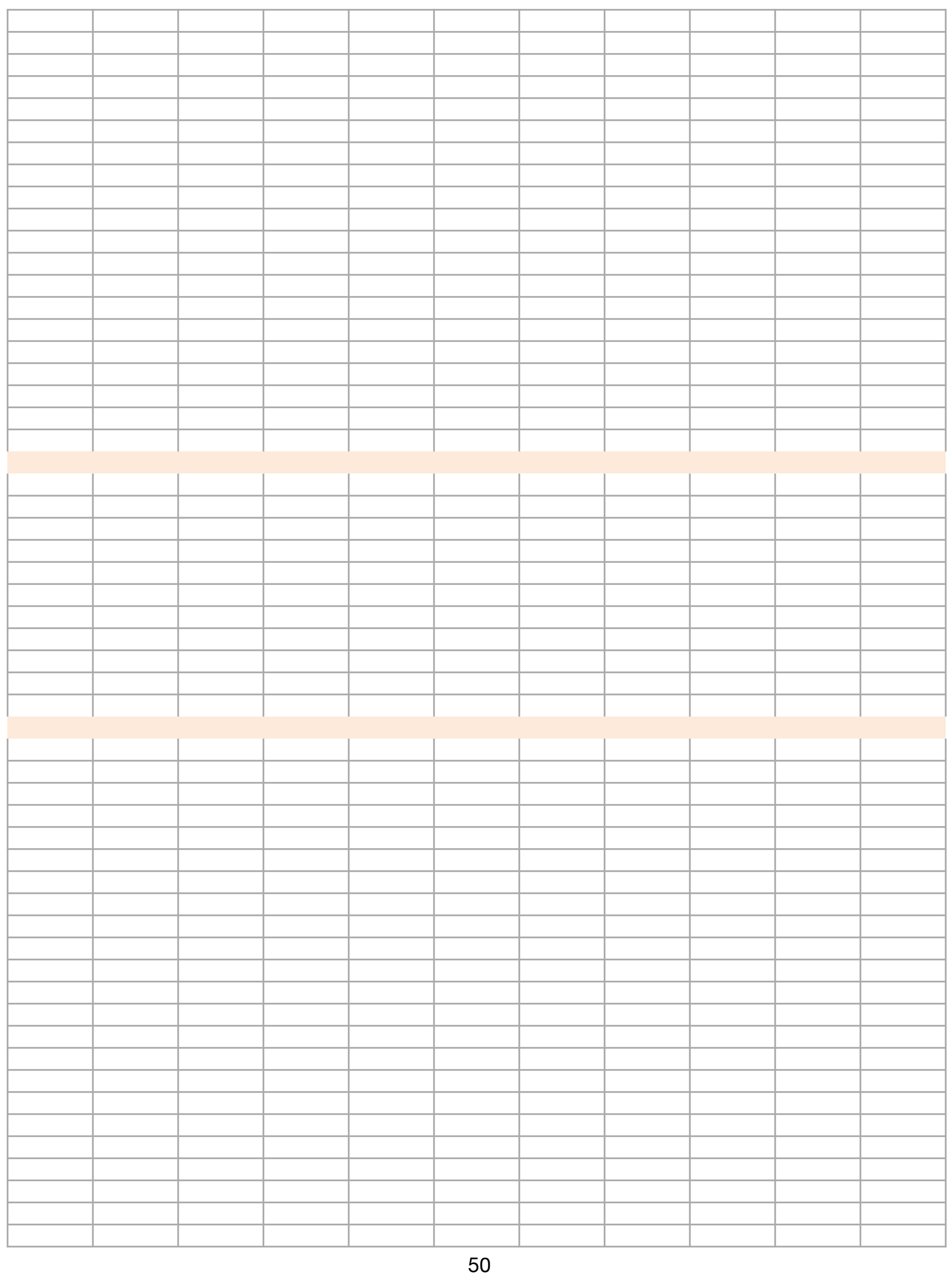


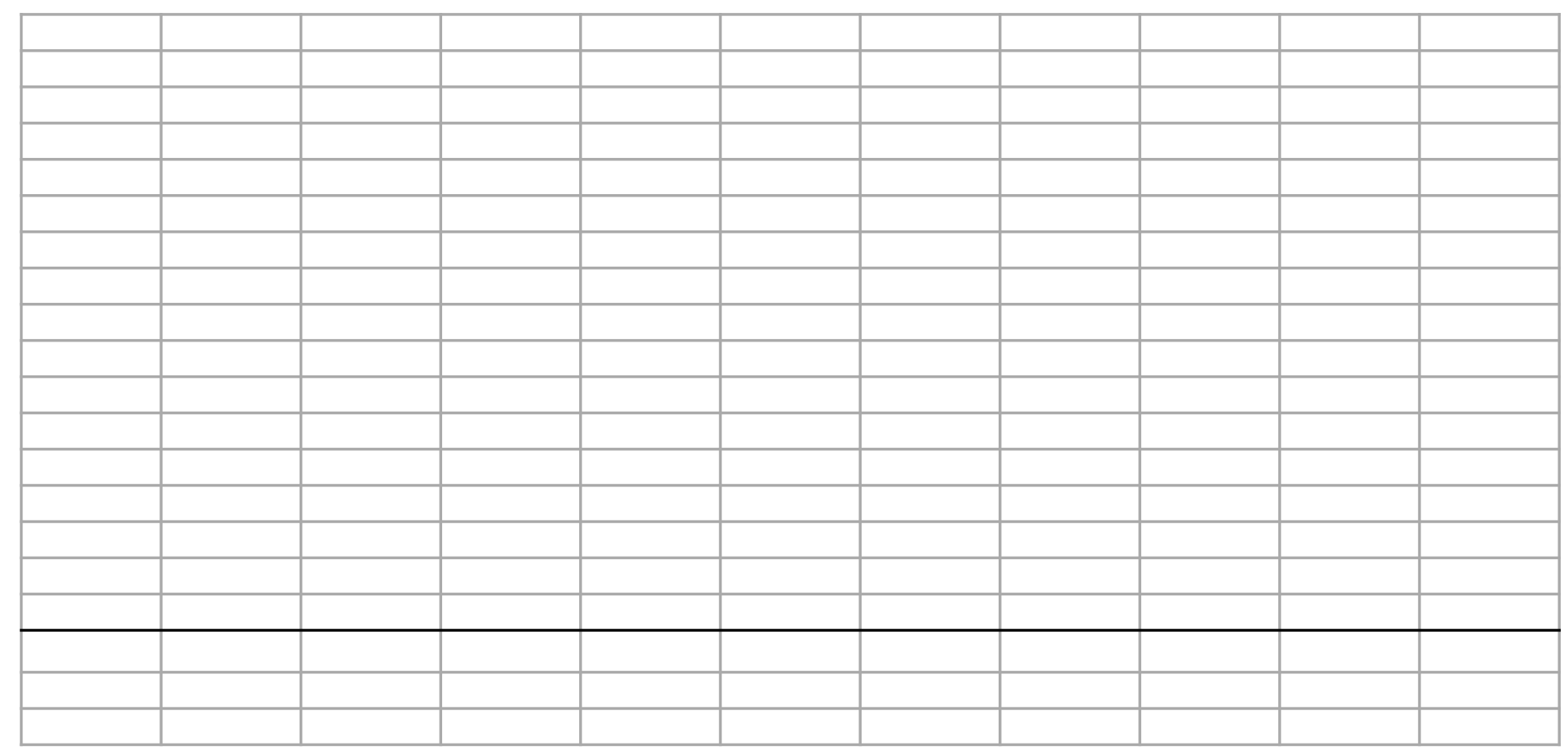




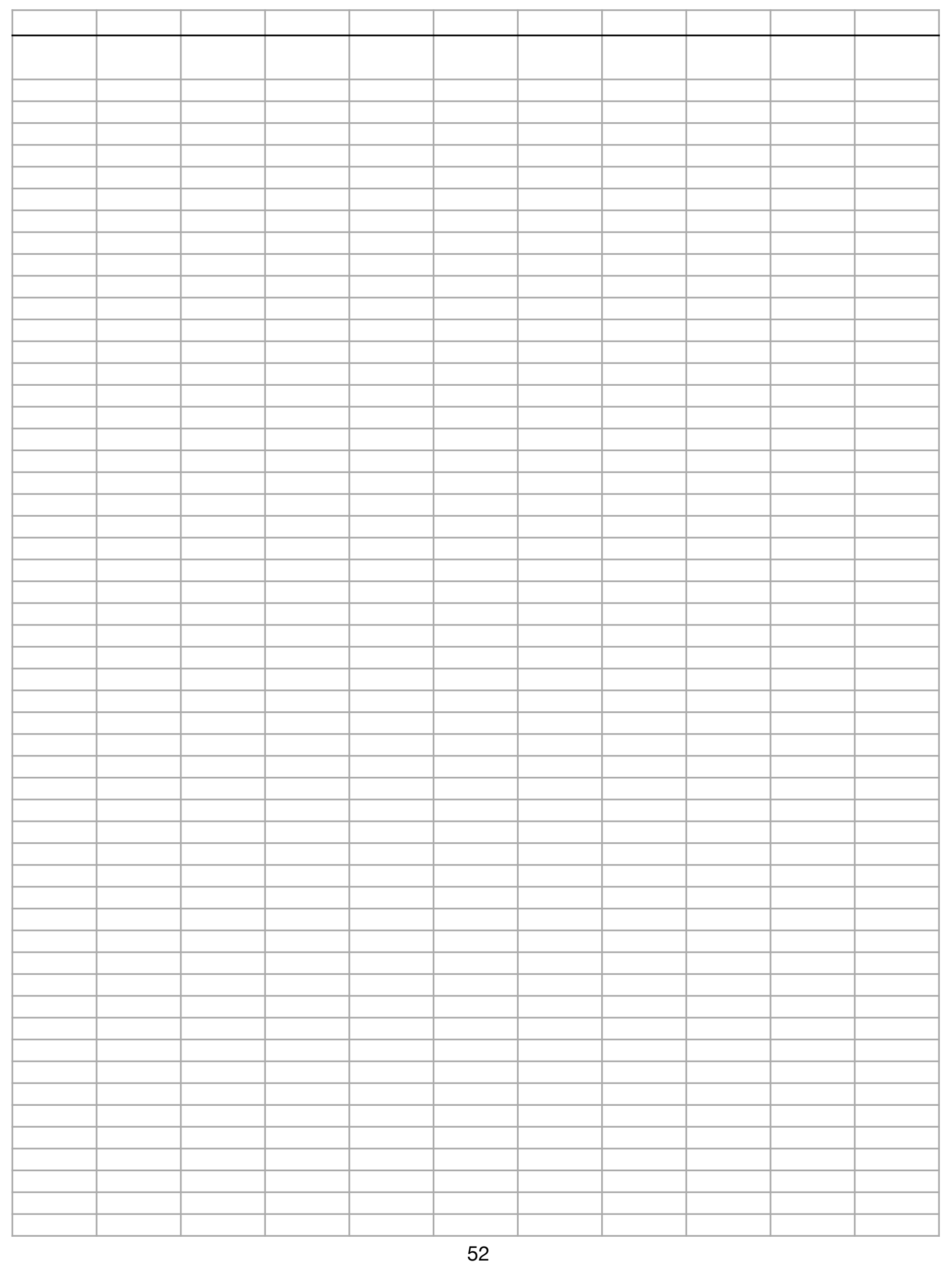



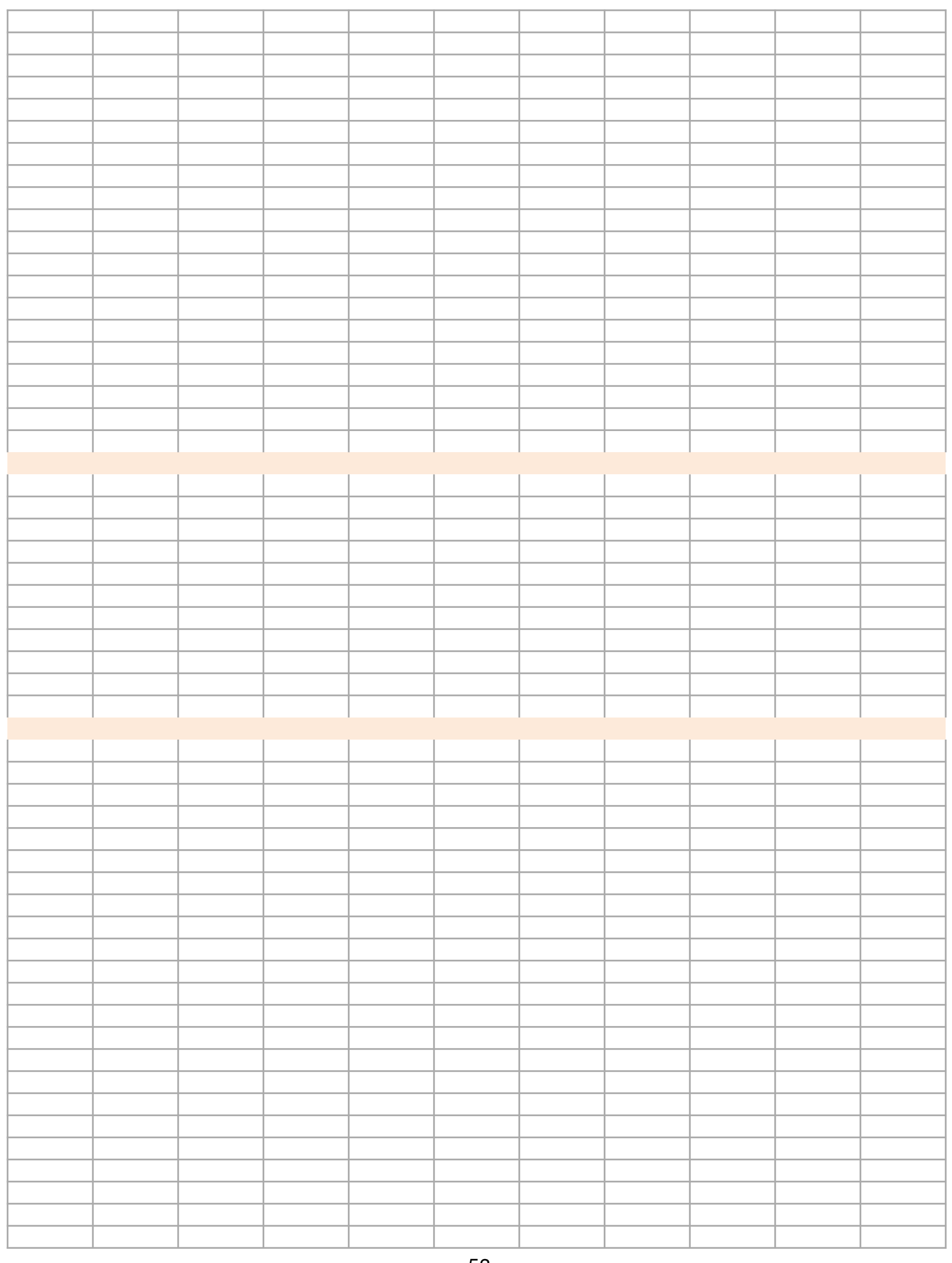

$$
53
$$




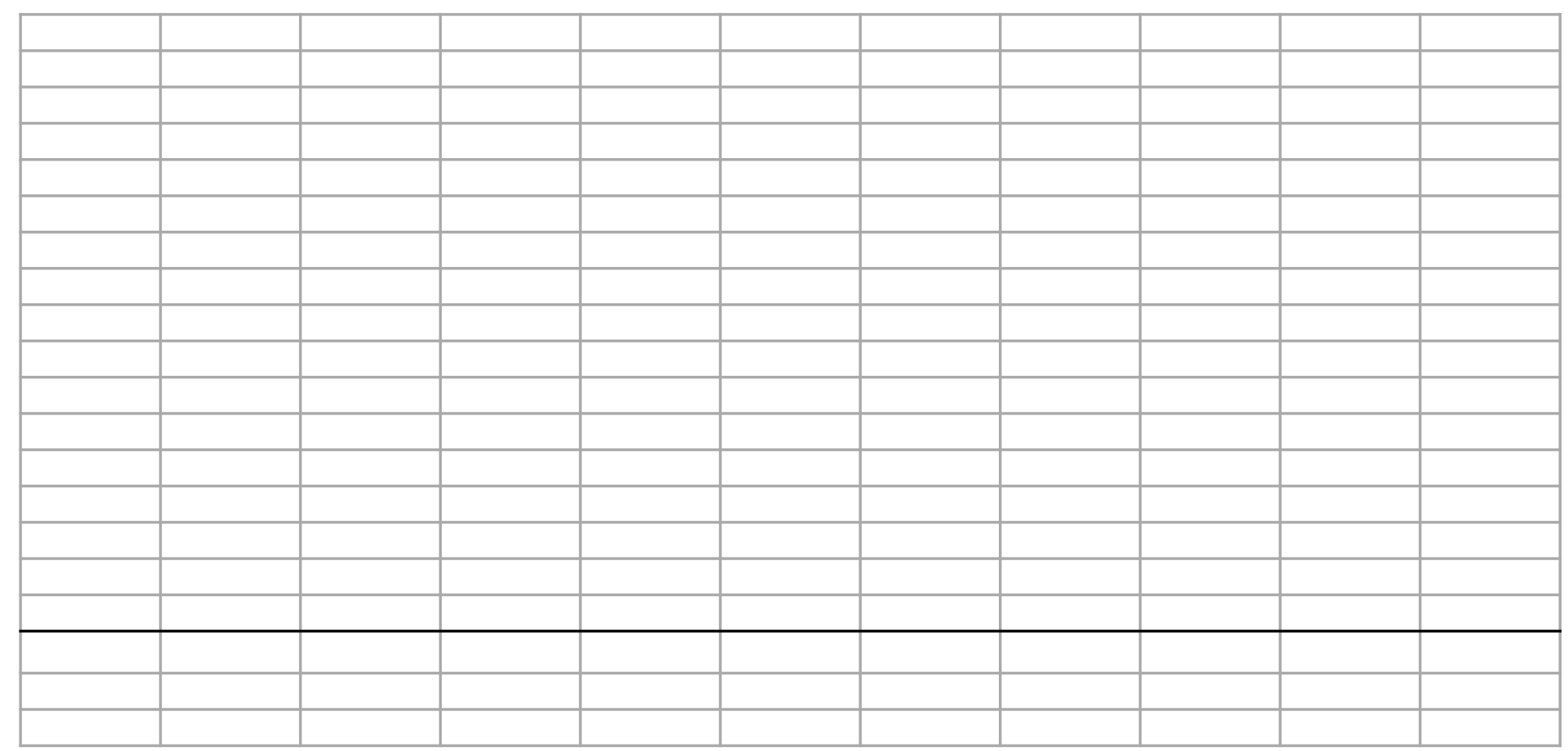




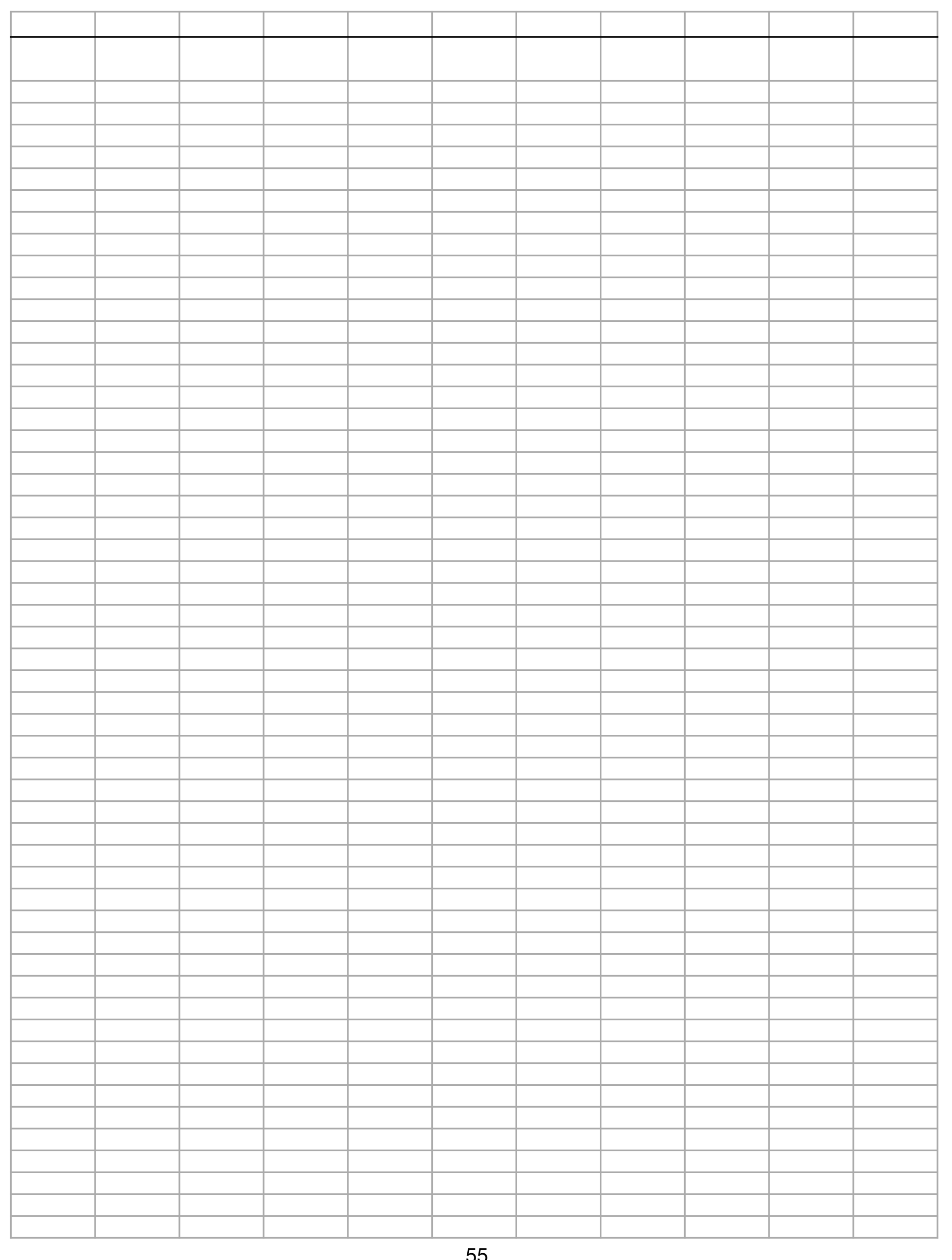



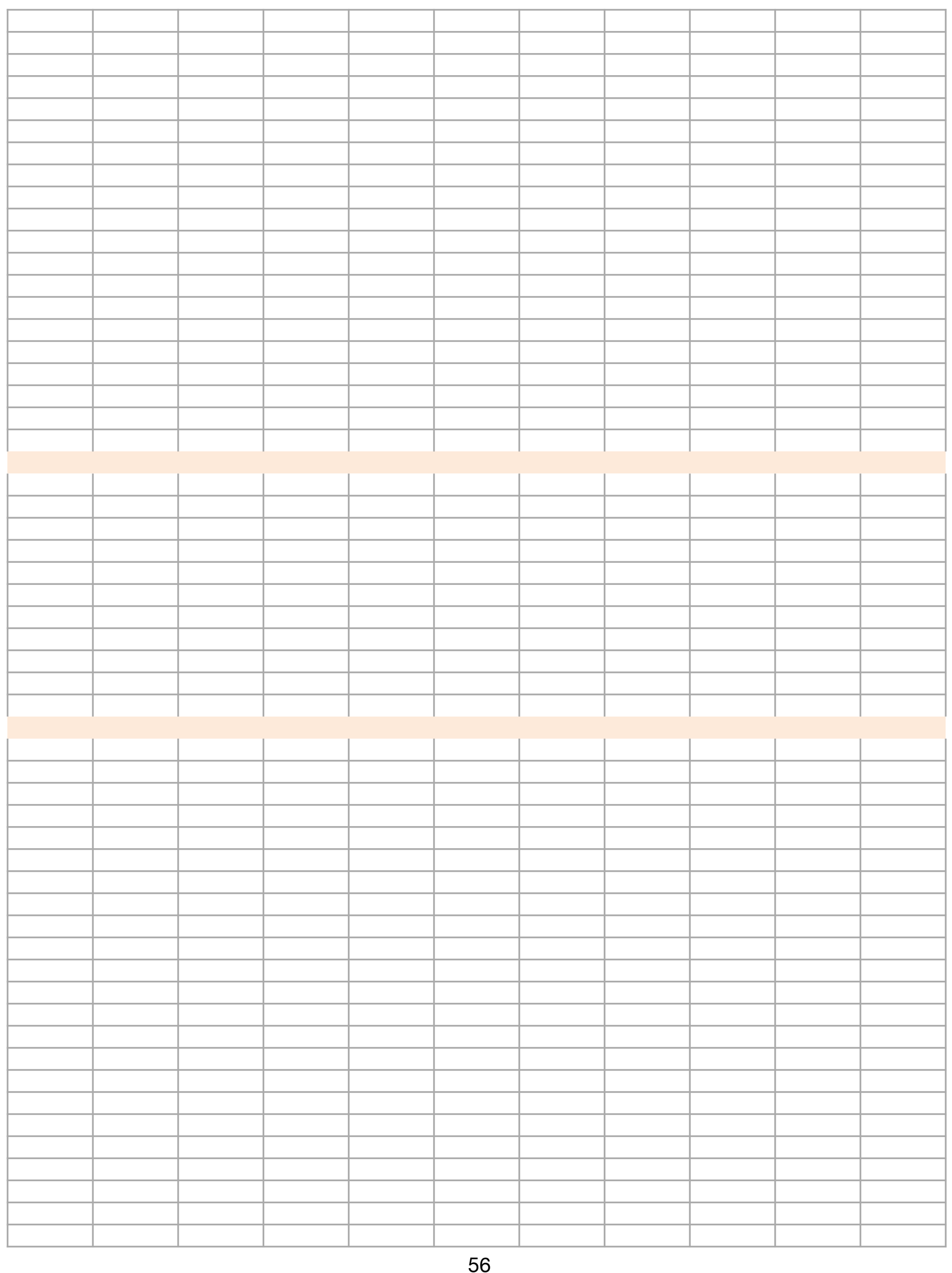


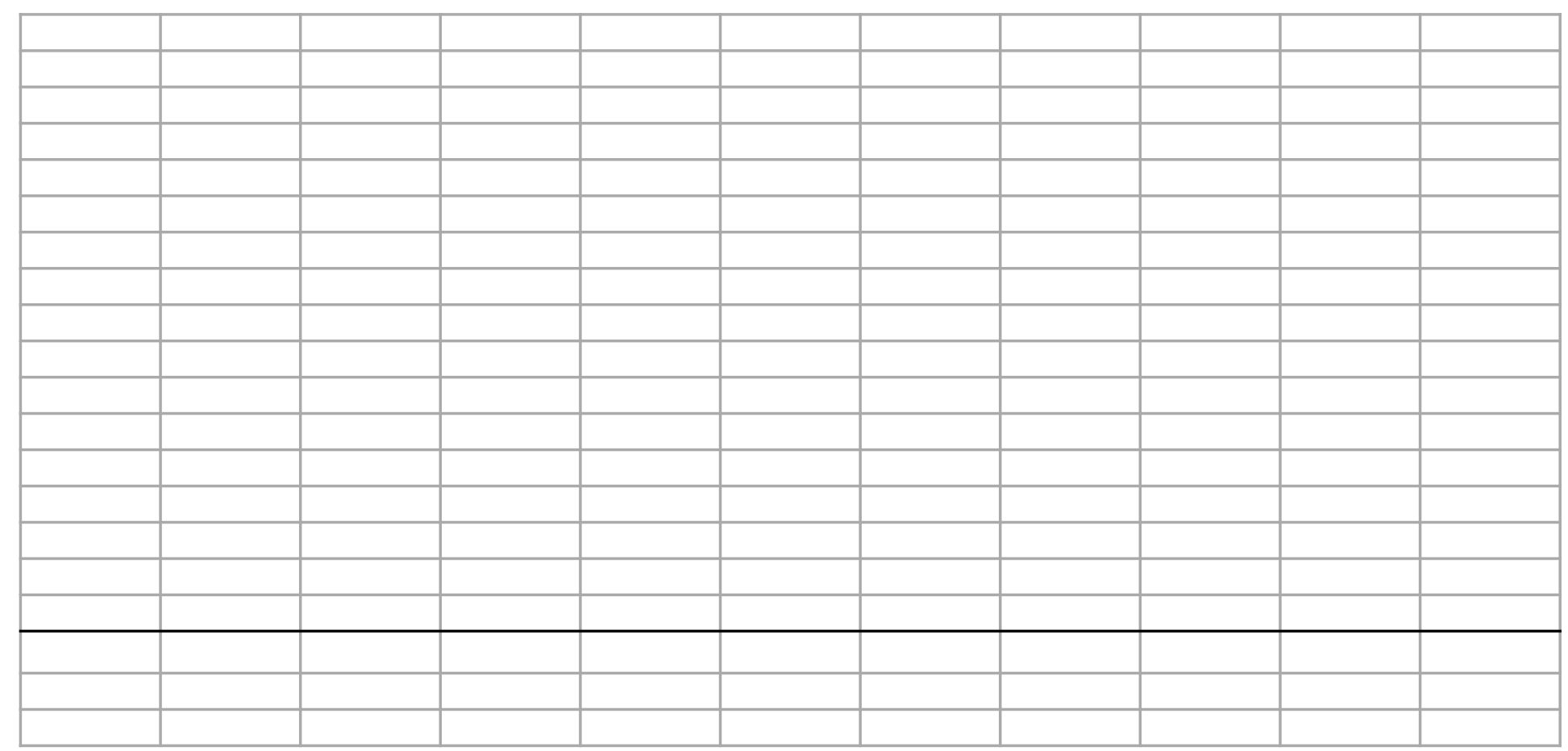




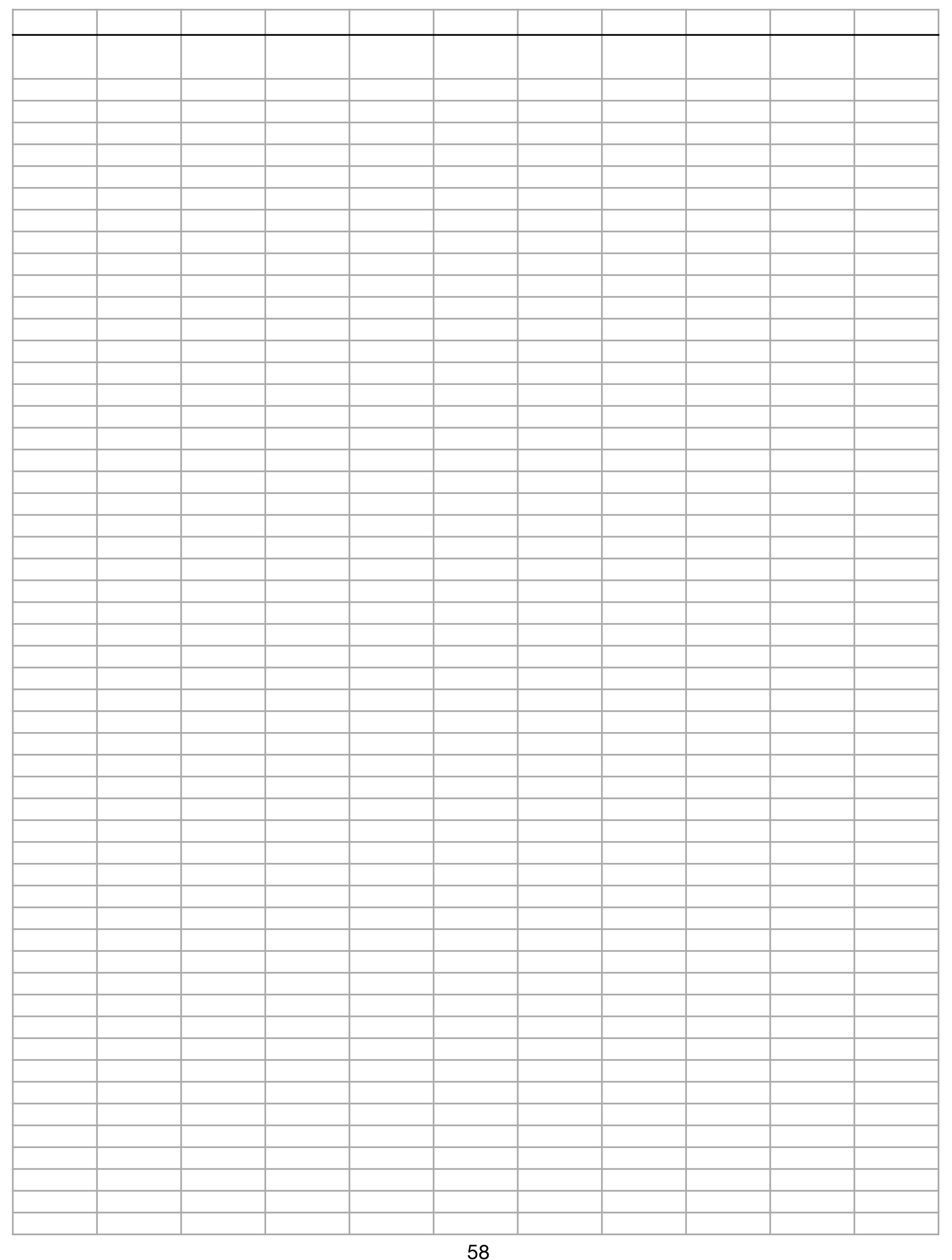



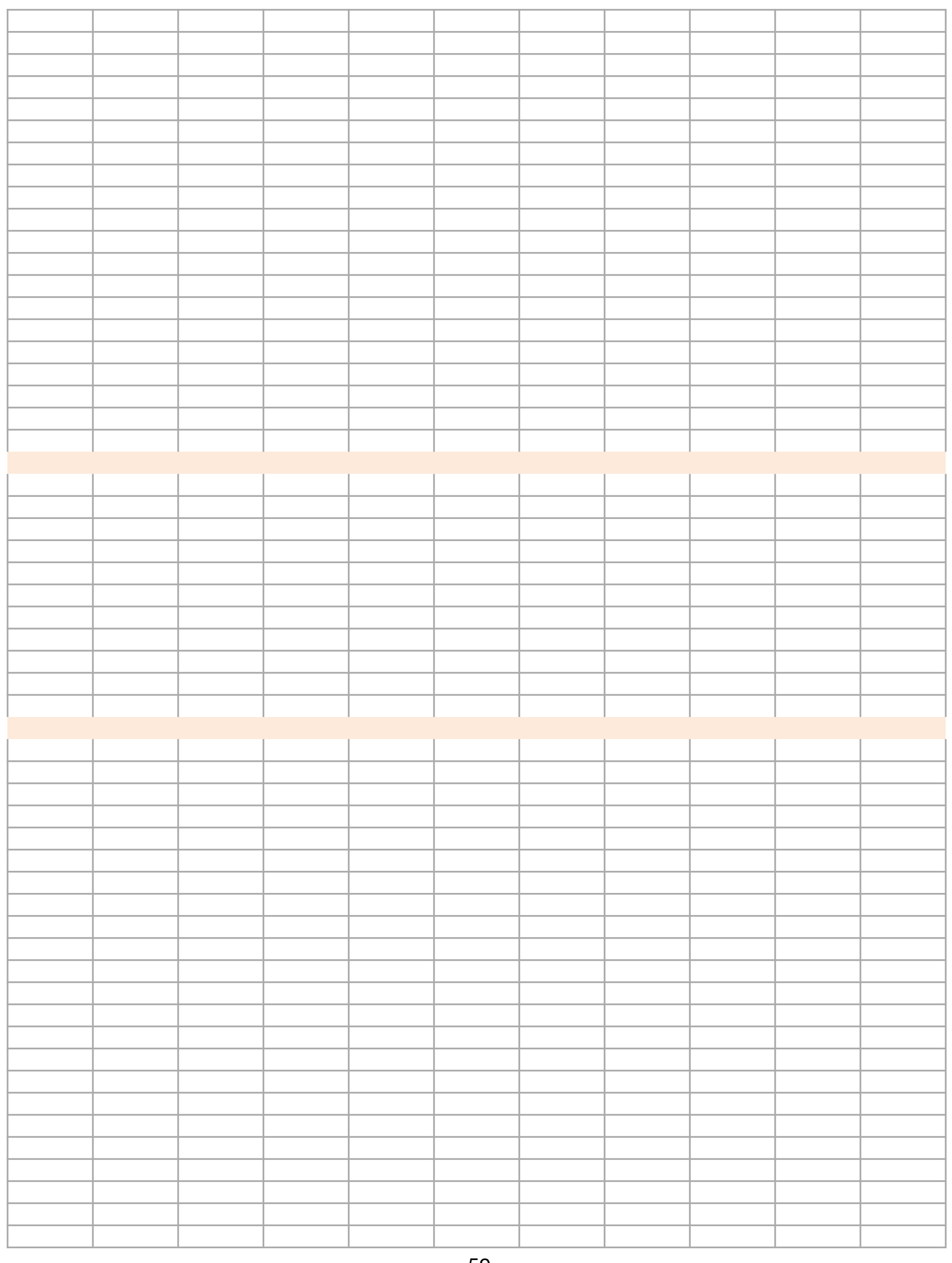


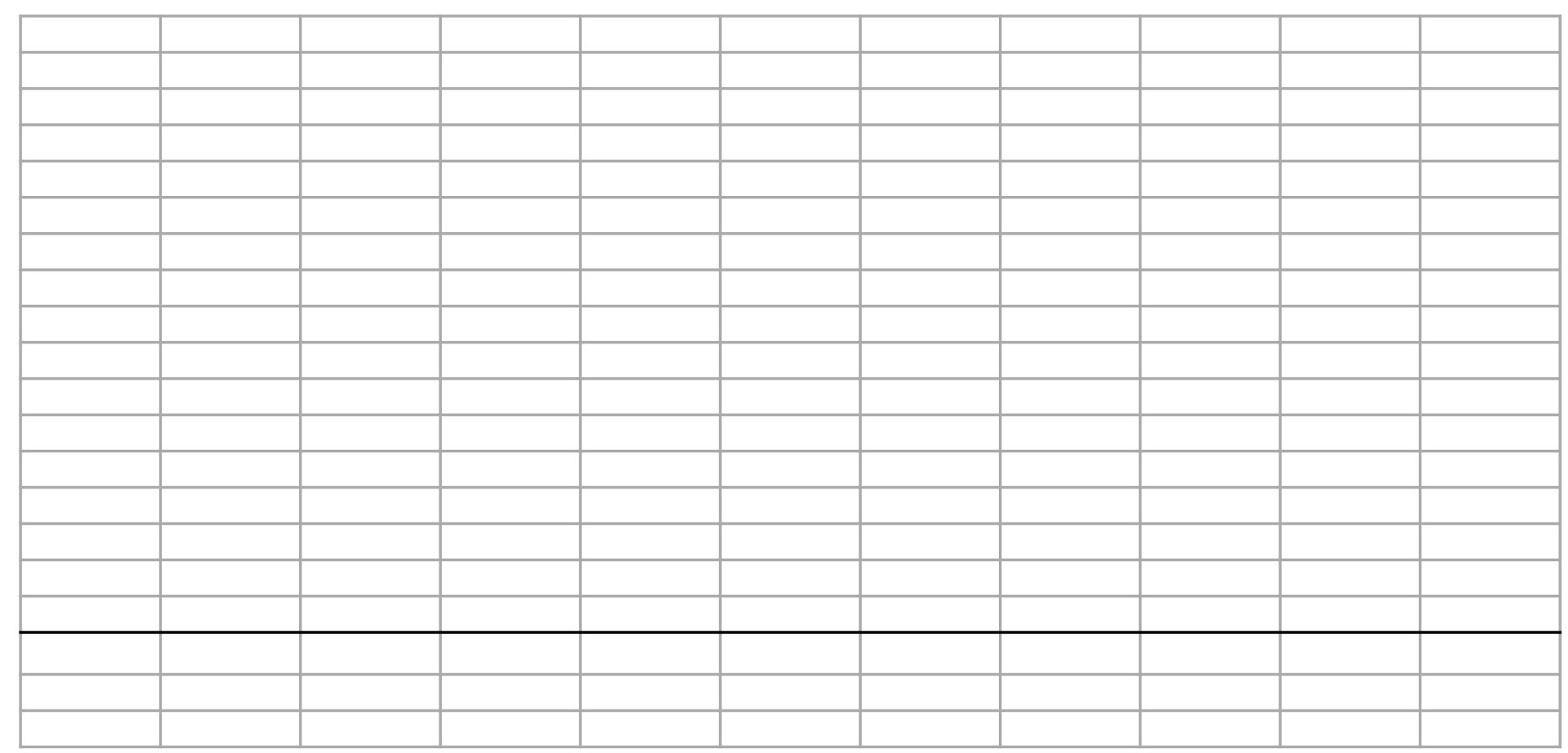




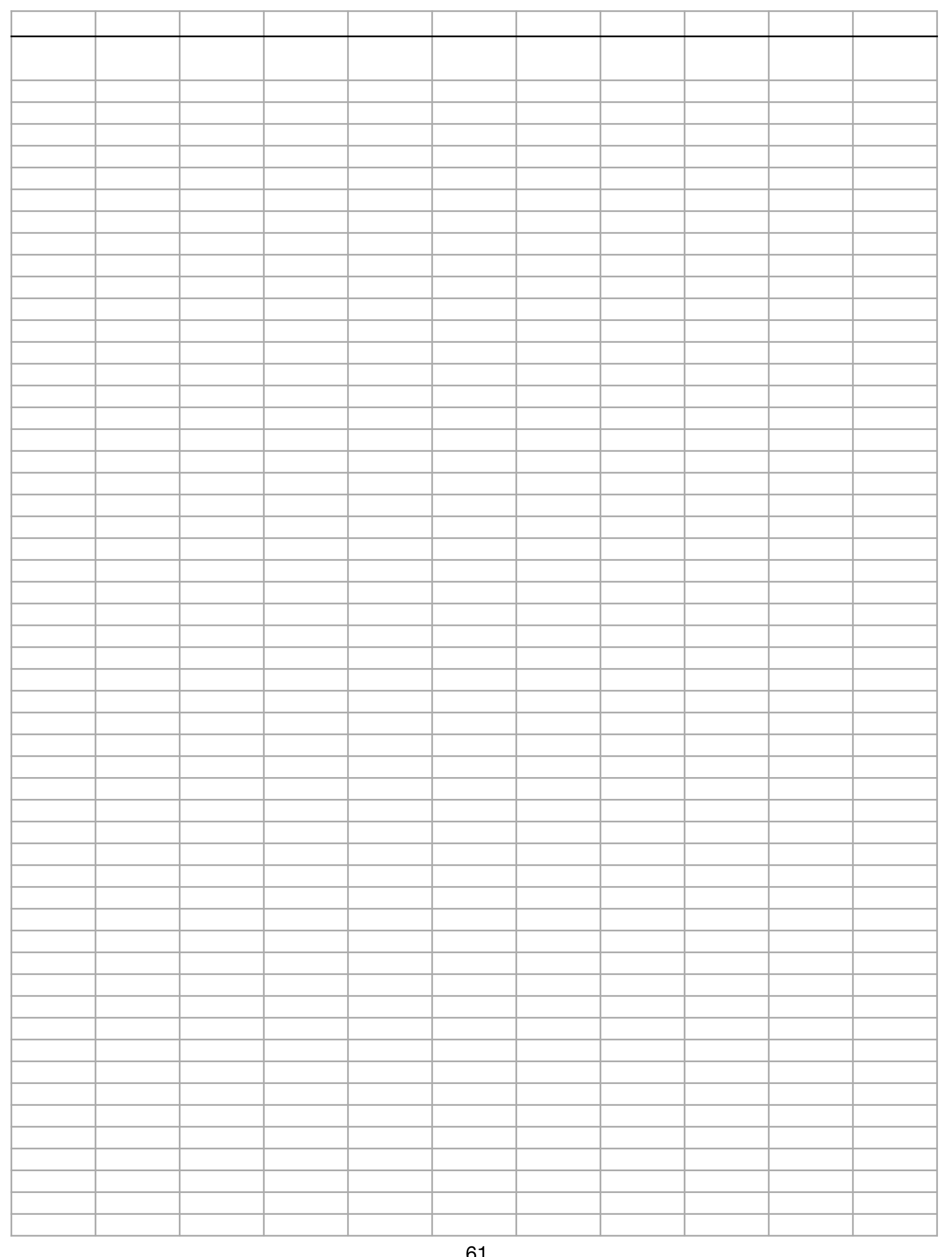



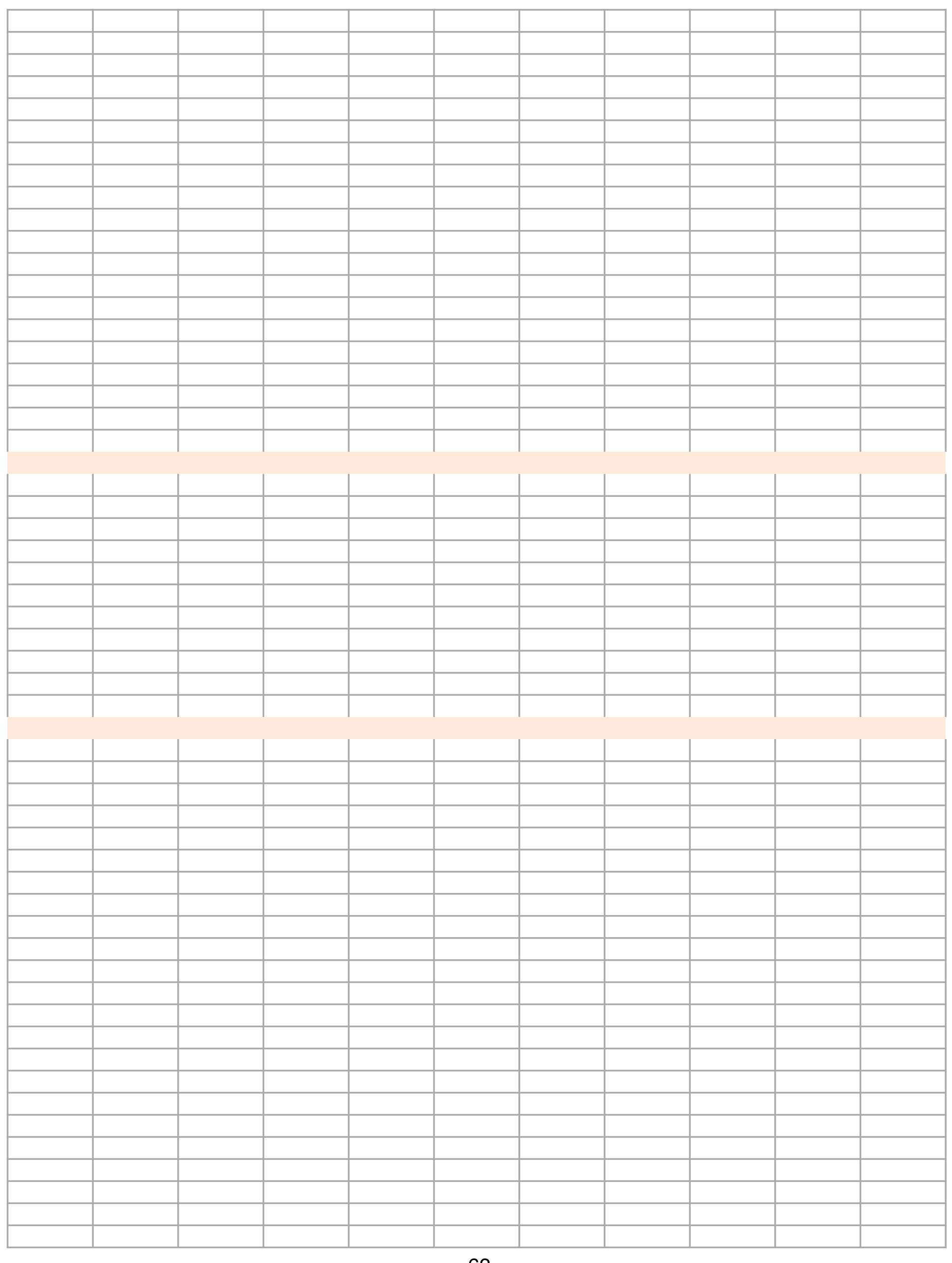


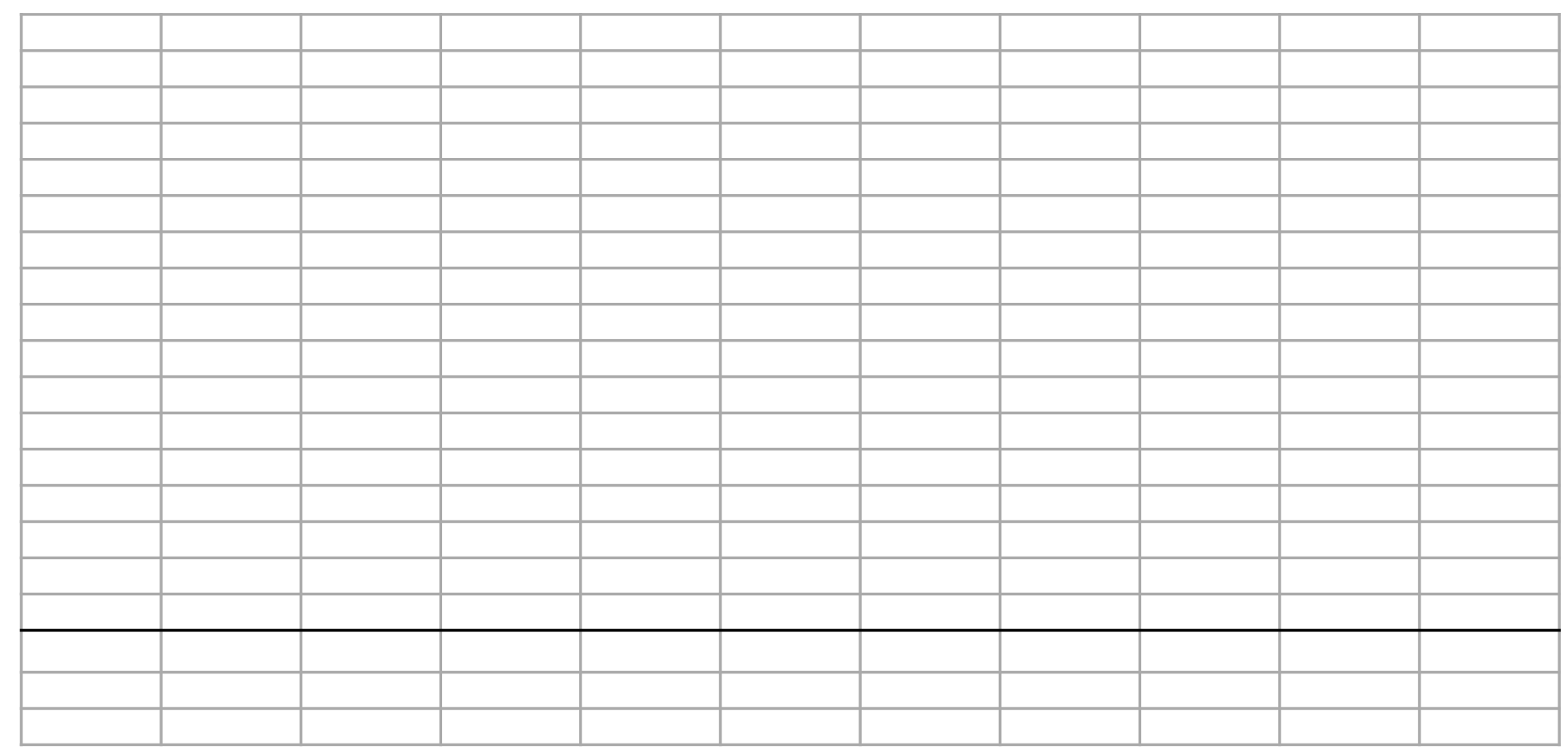




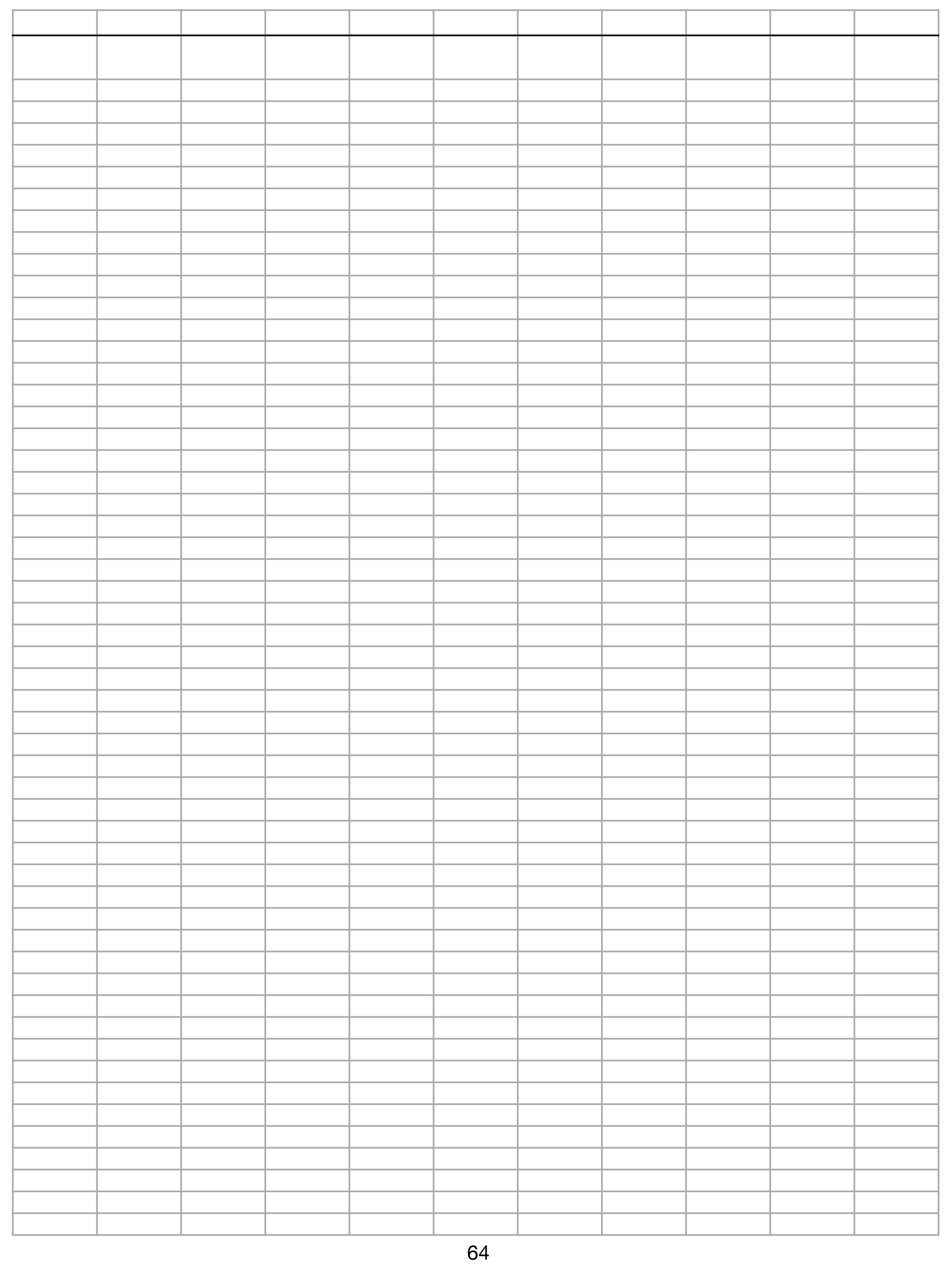



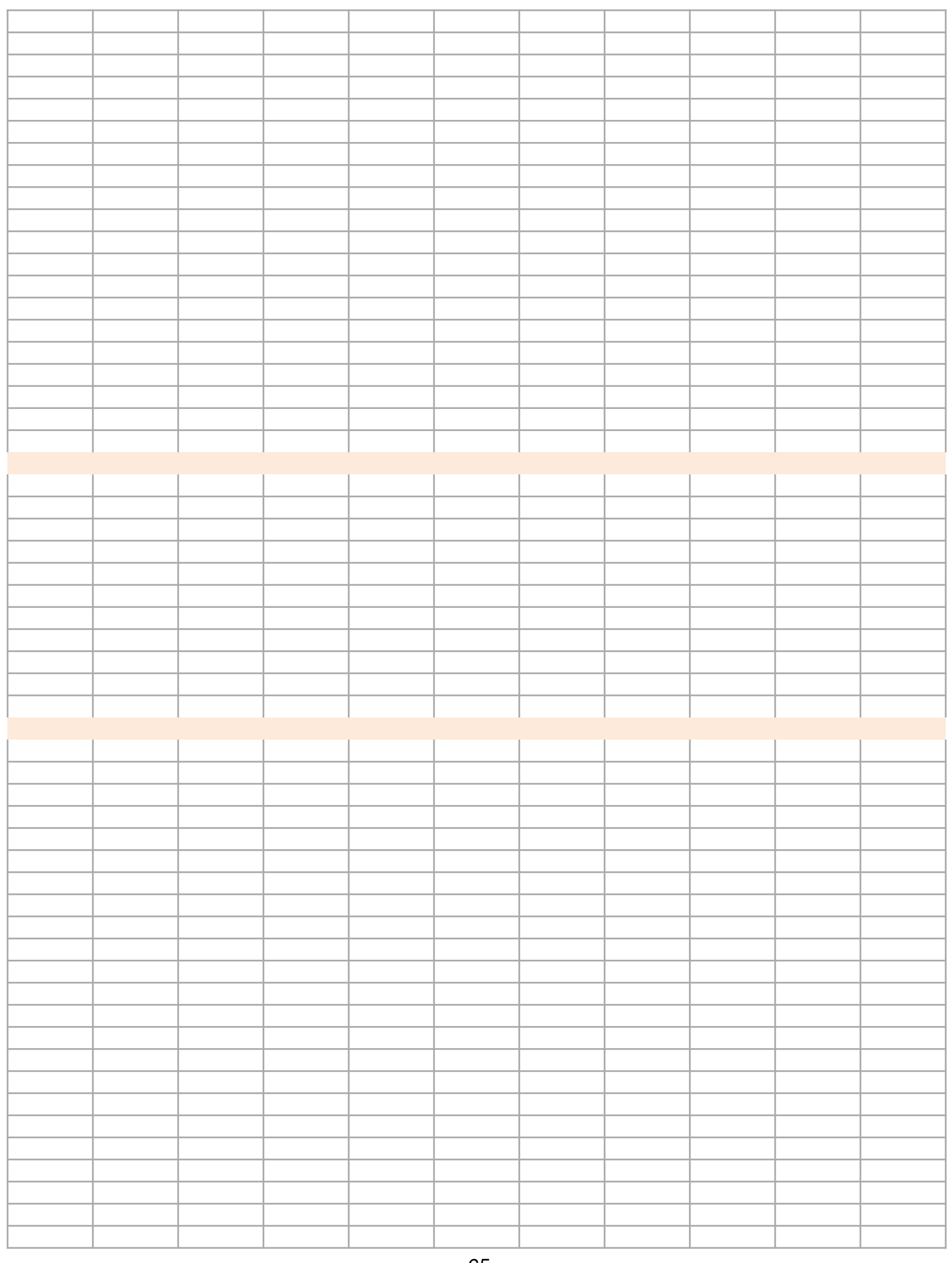


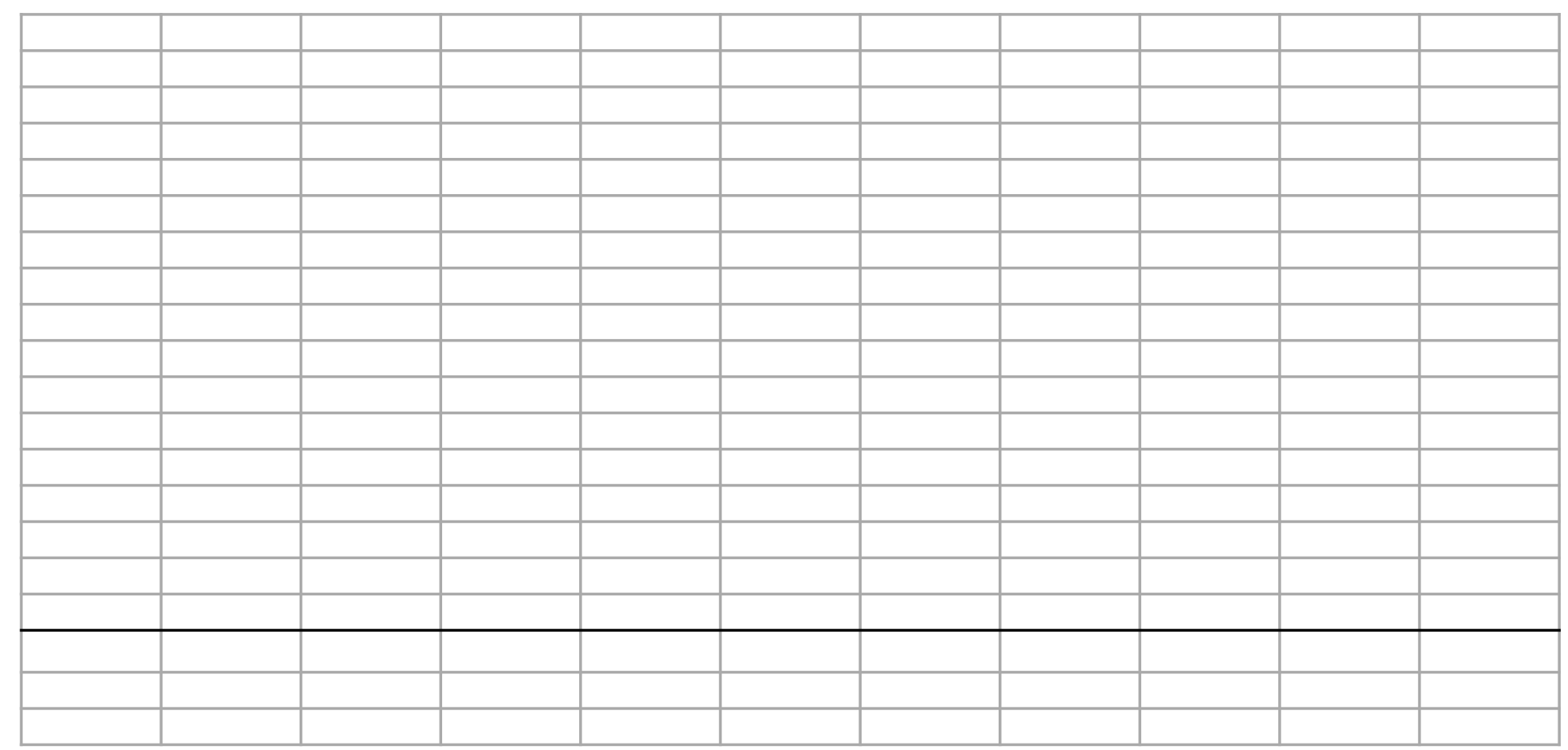




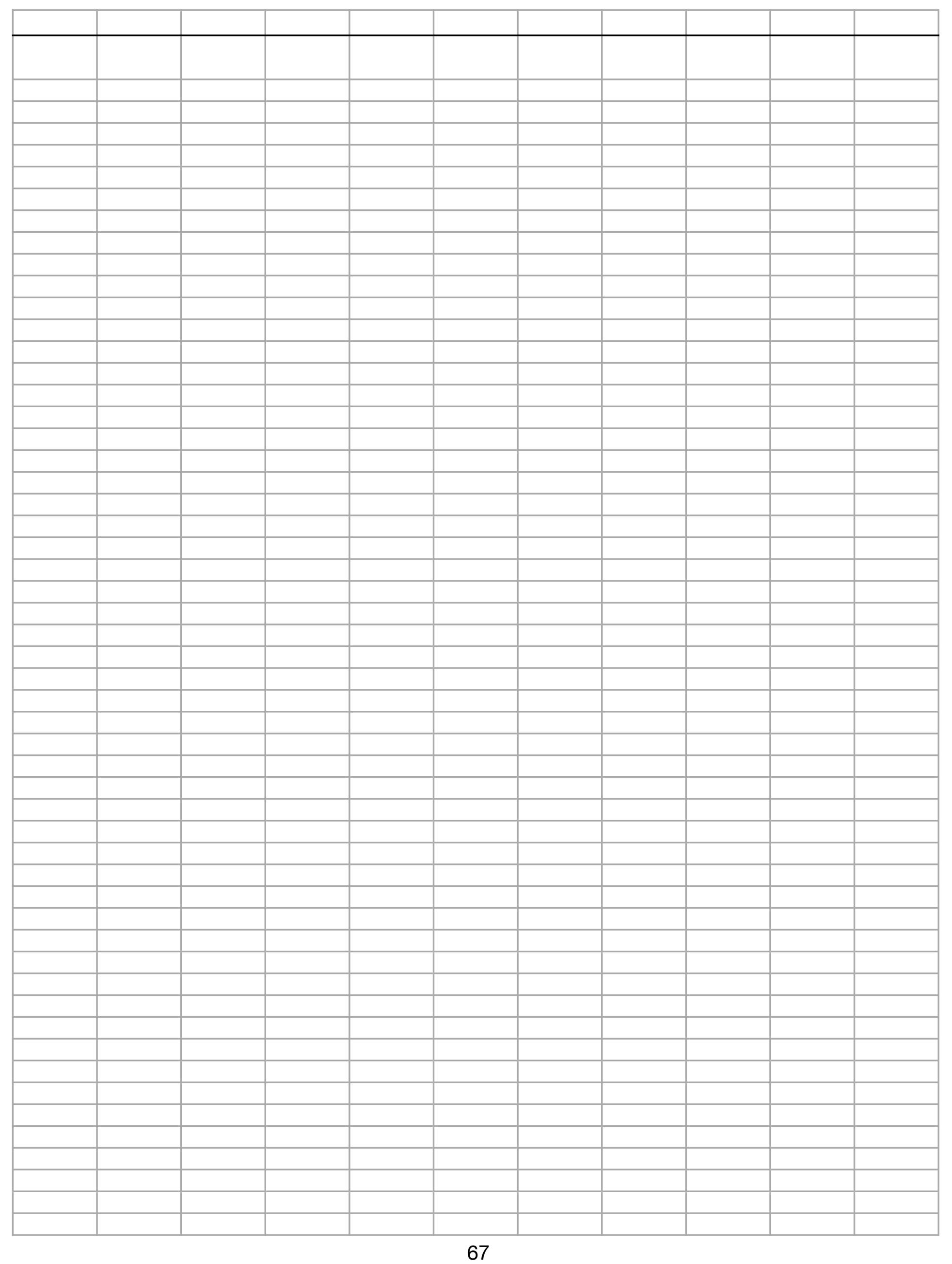



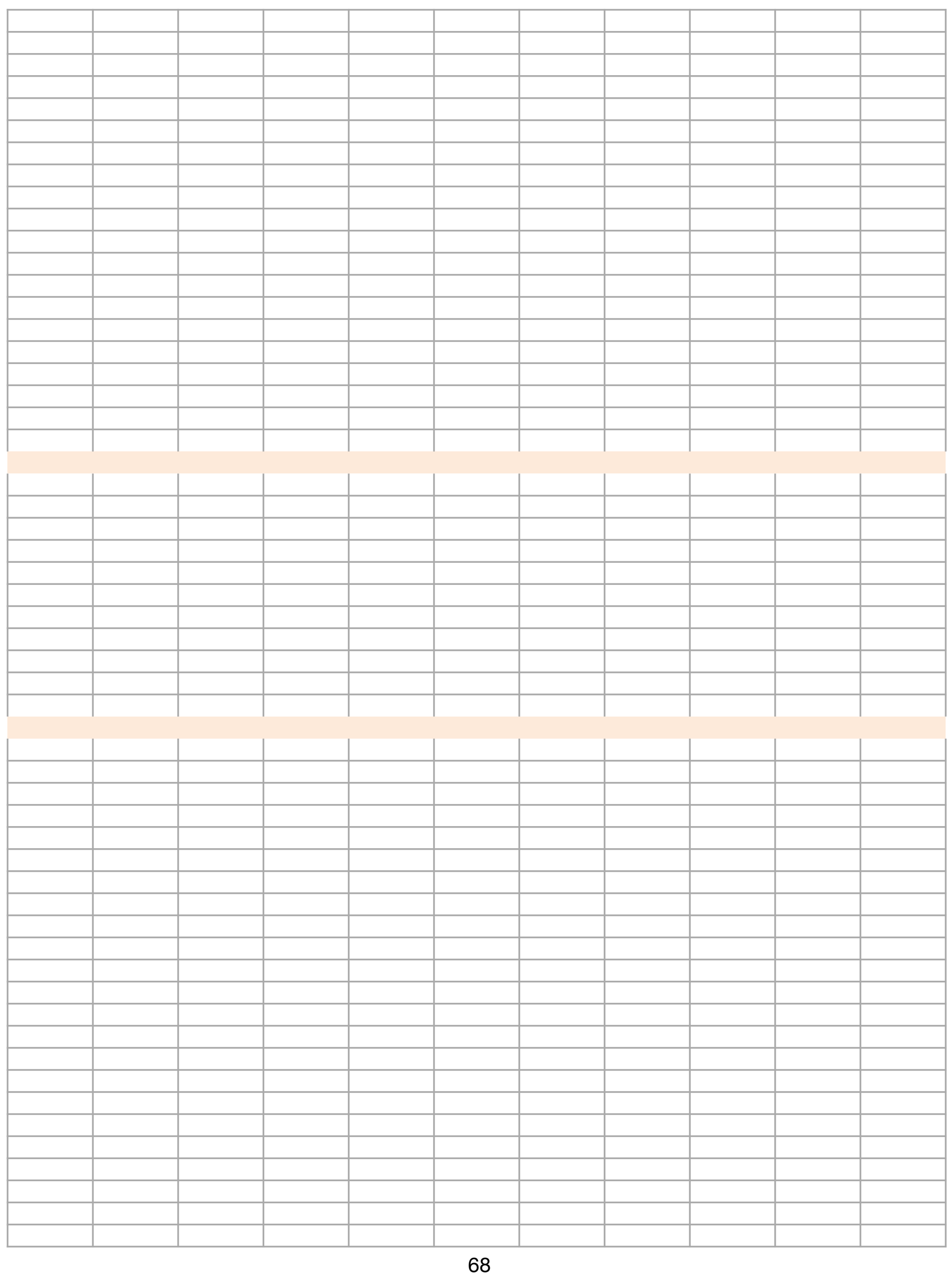


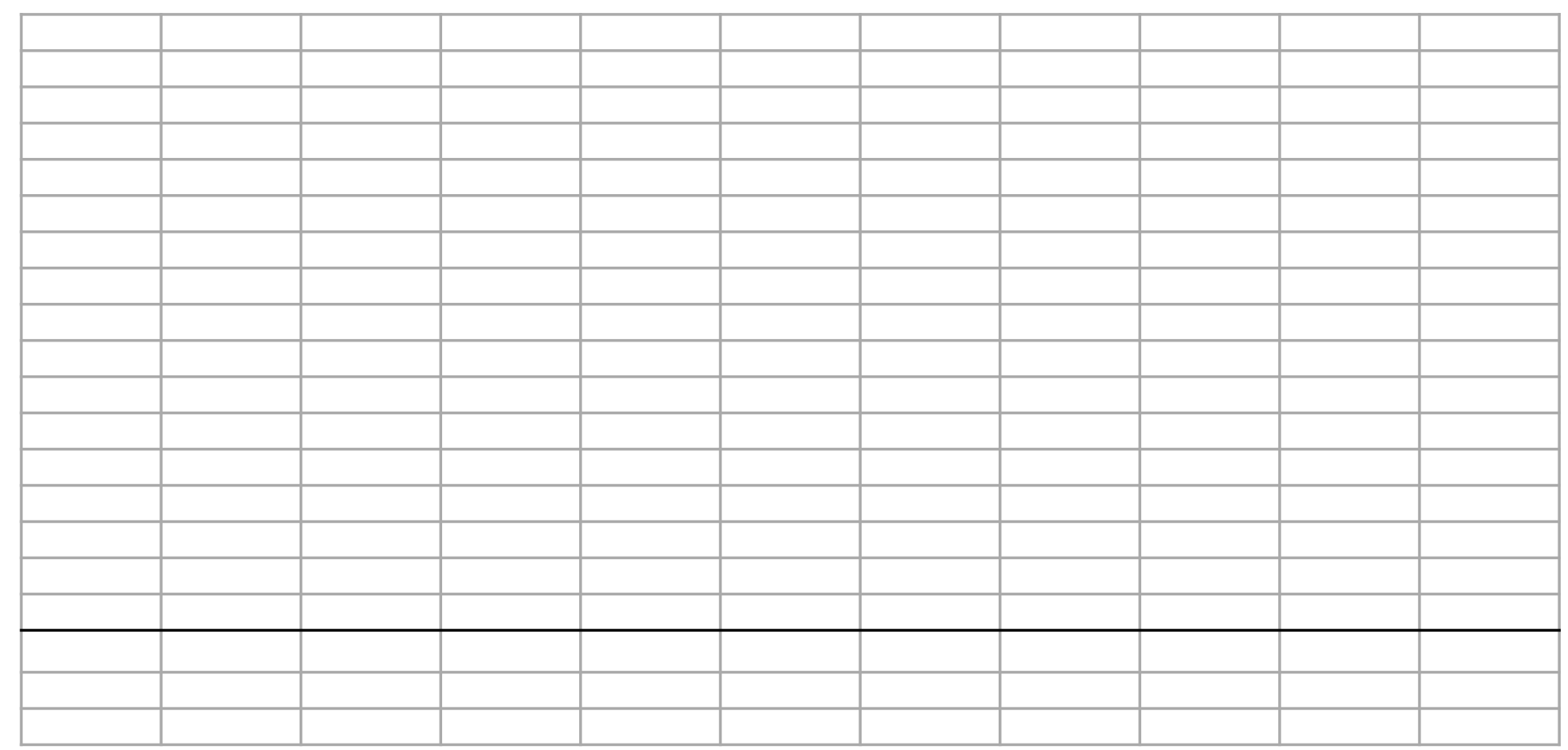




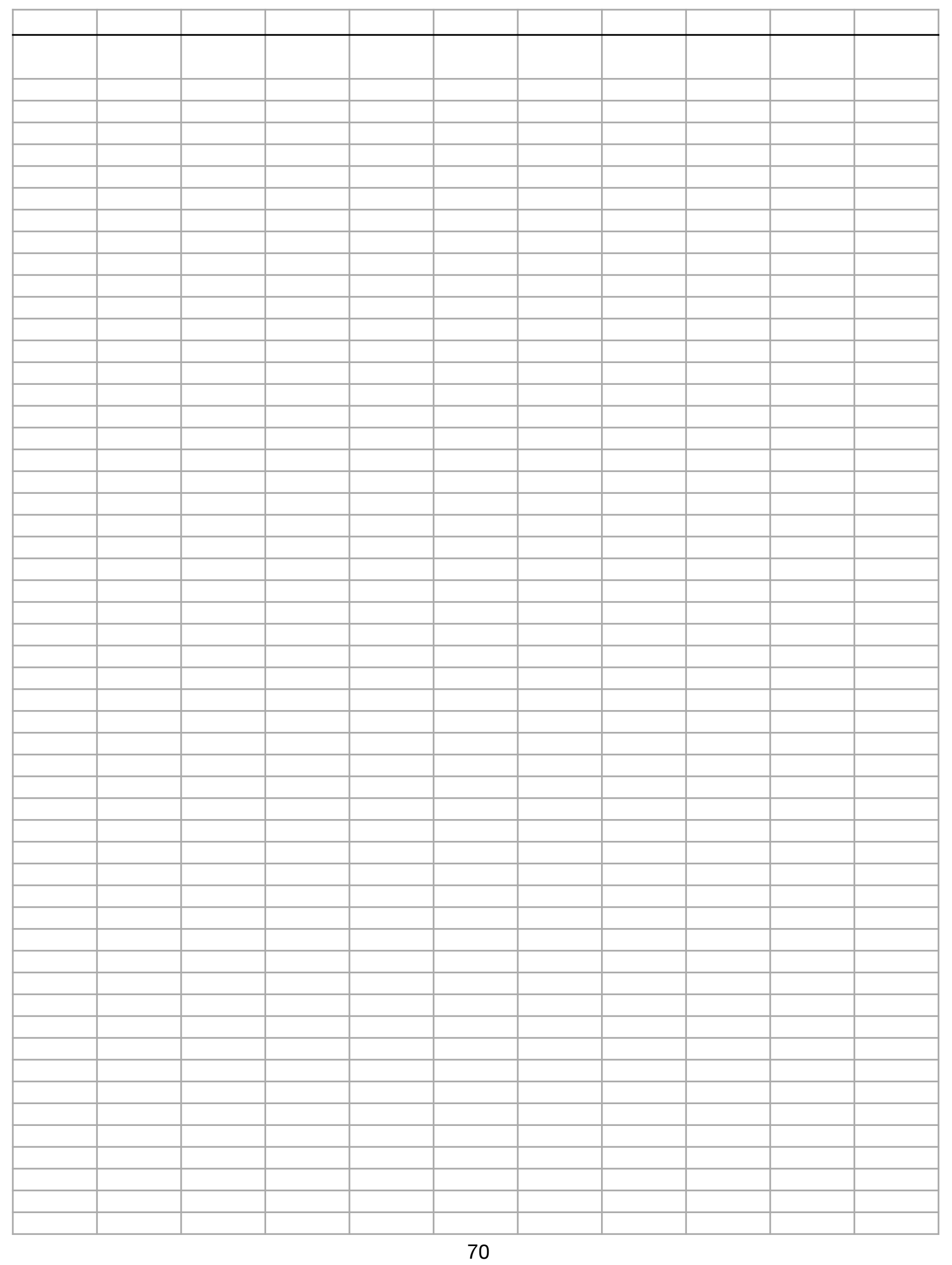



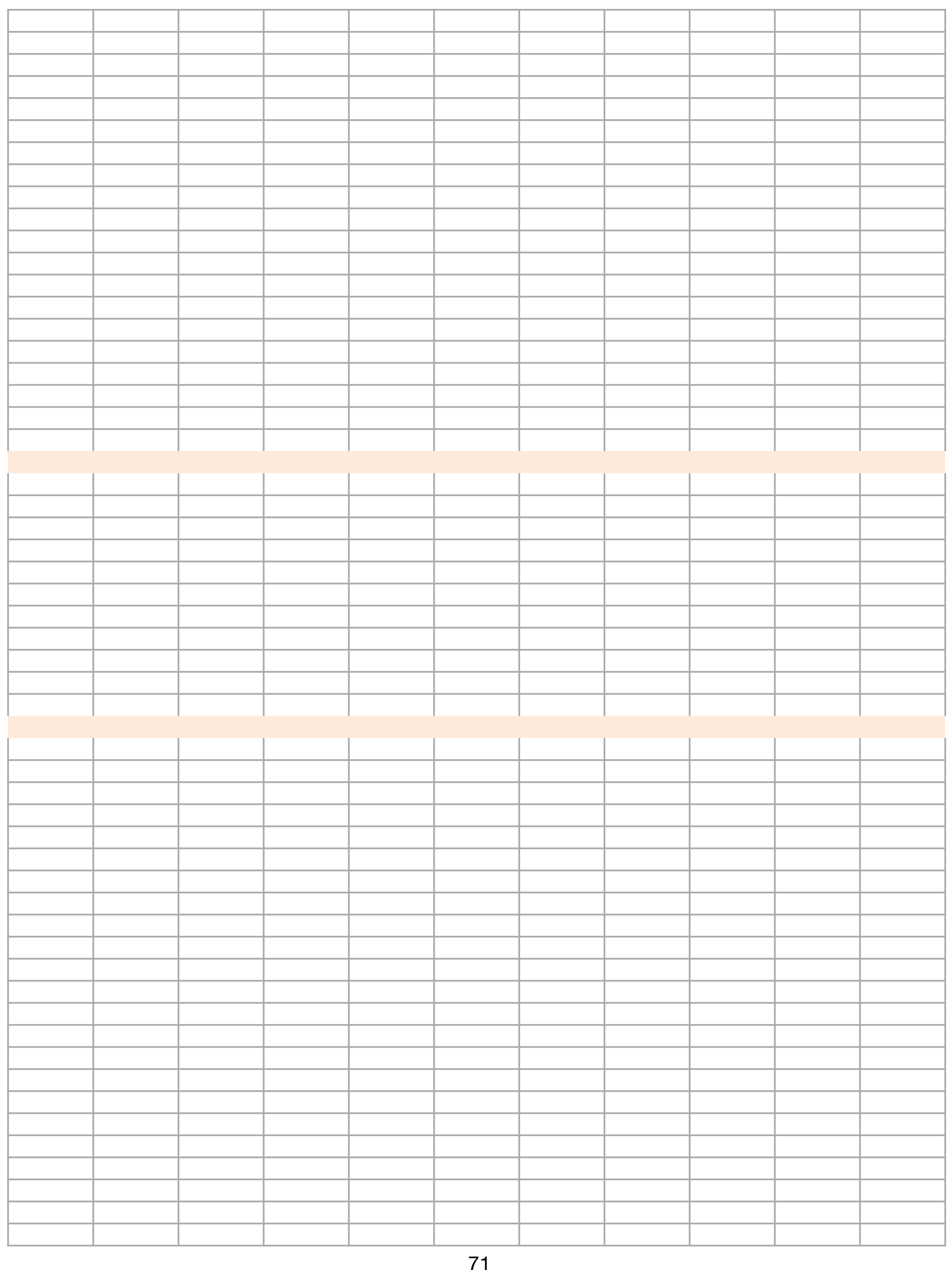


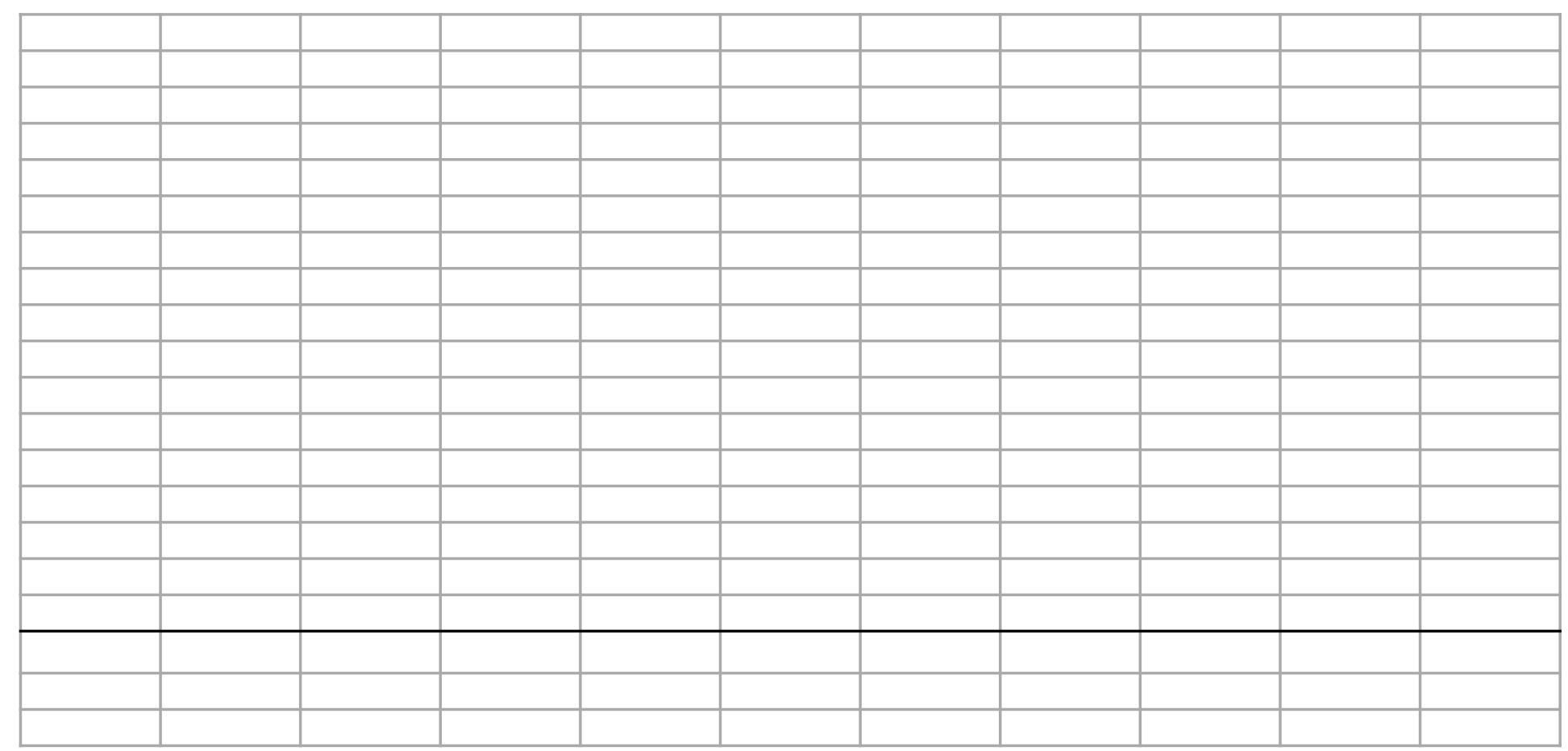




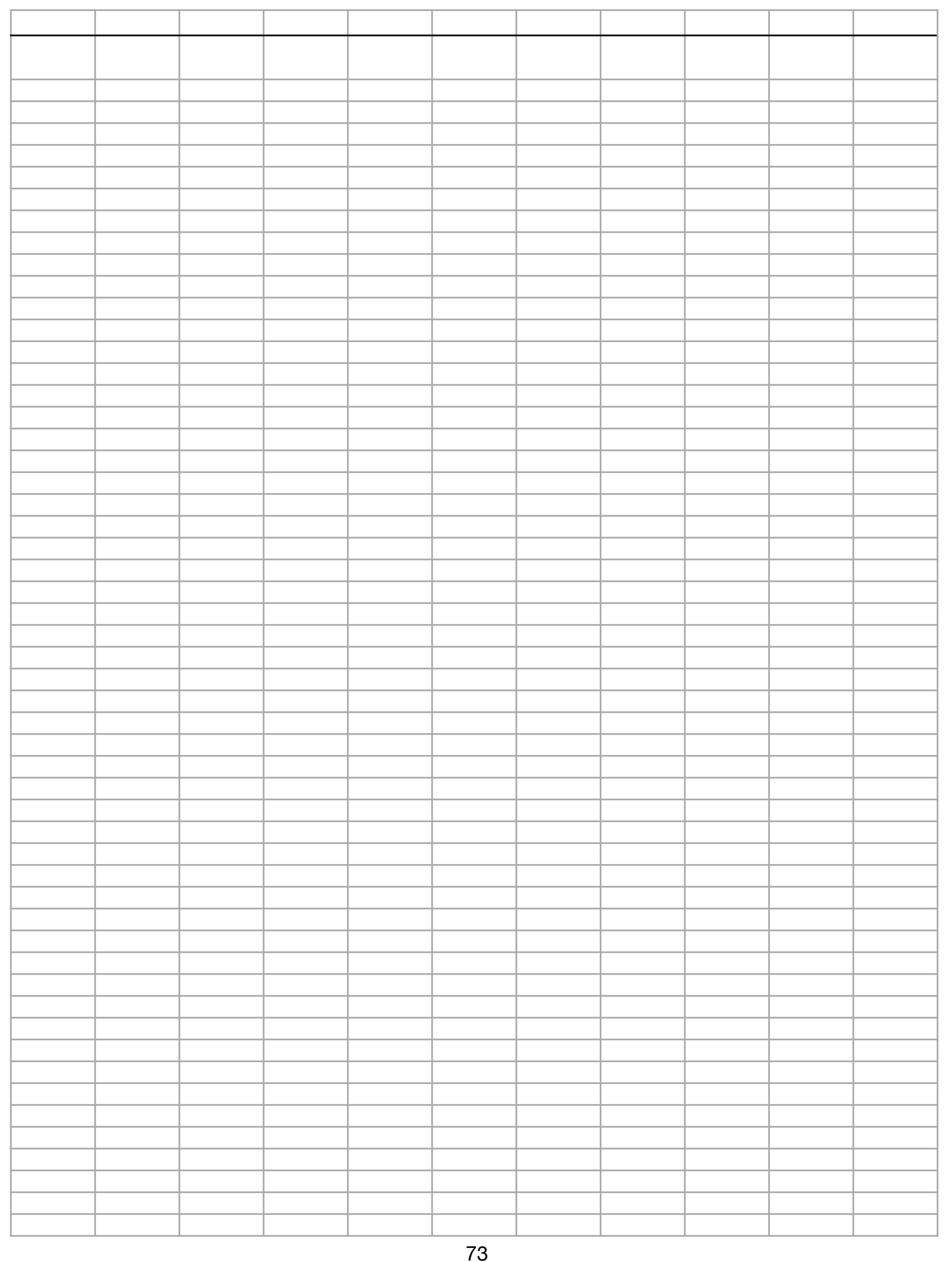




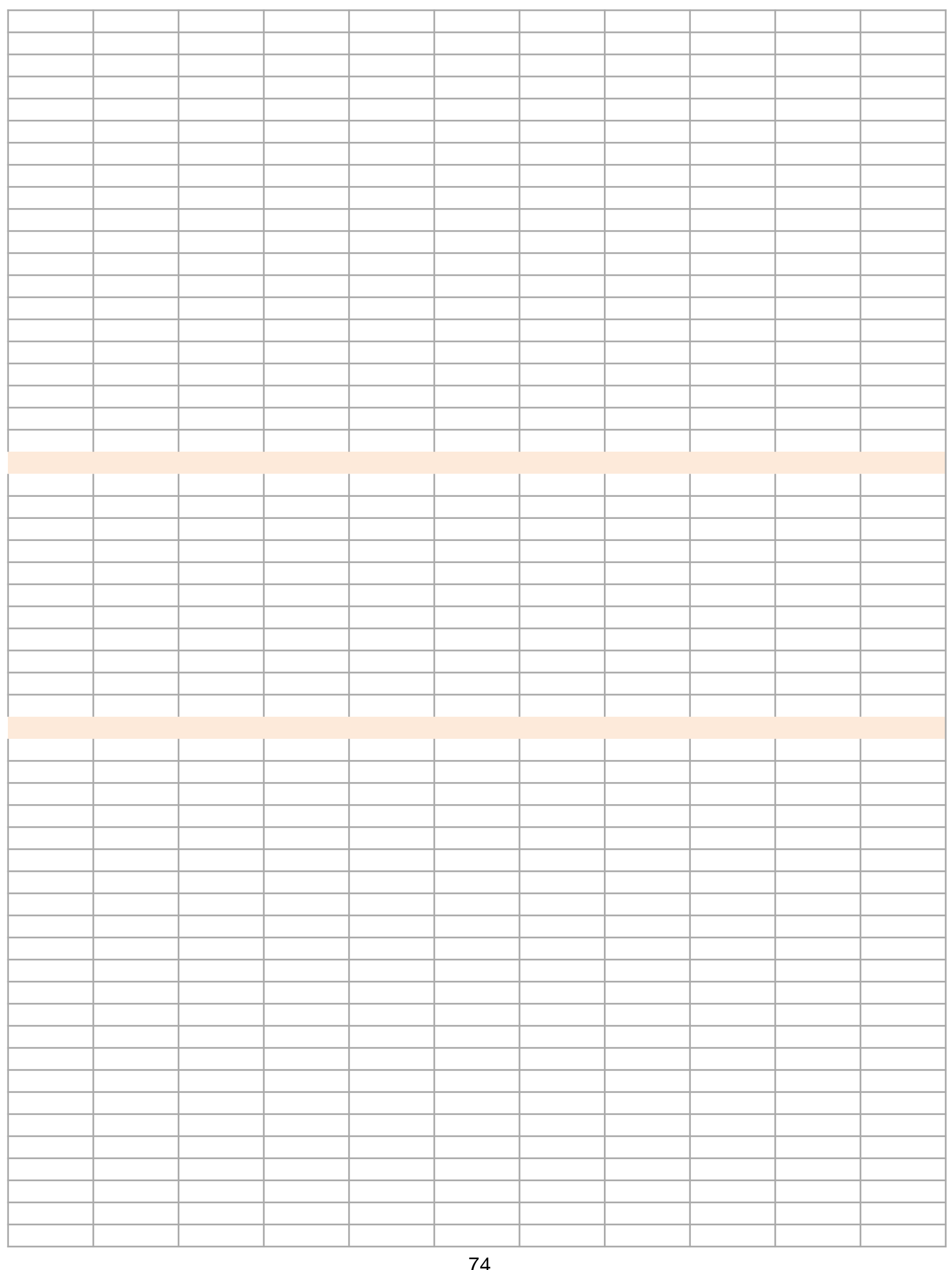




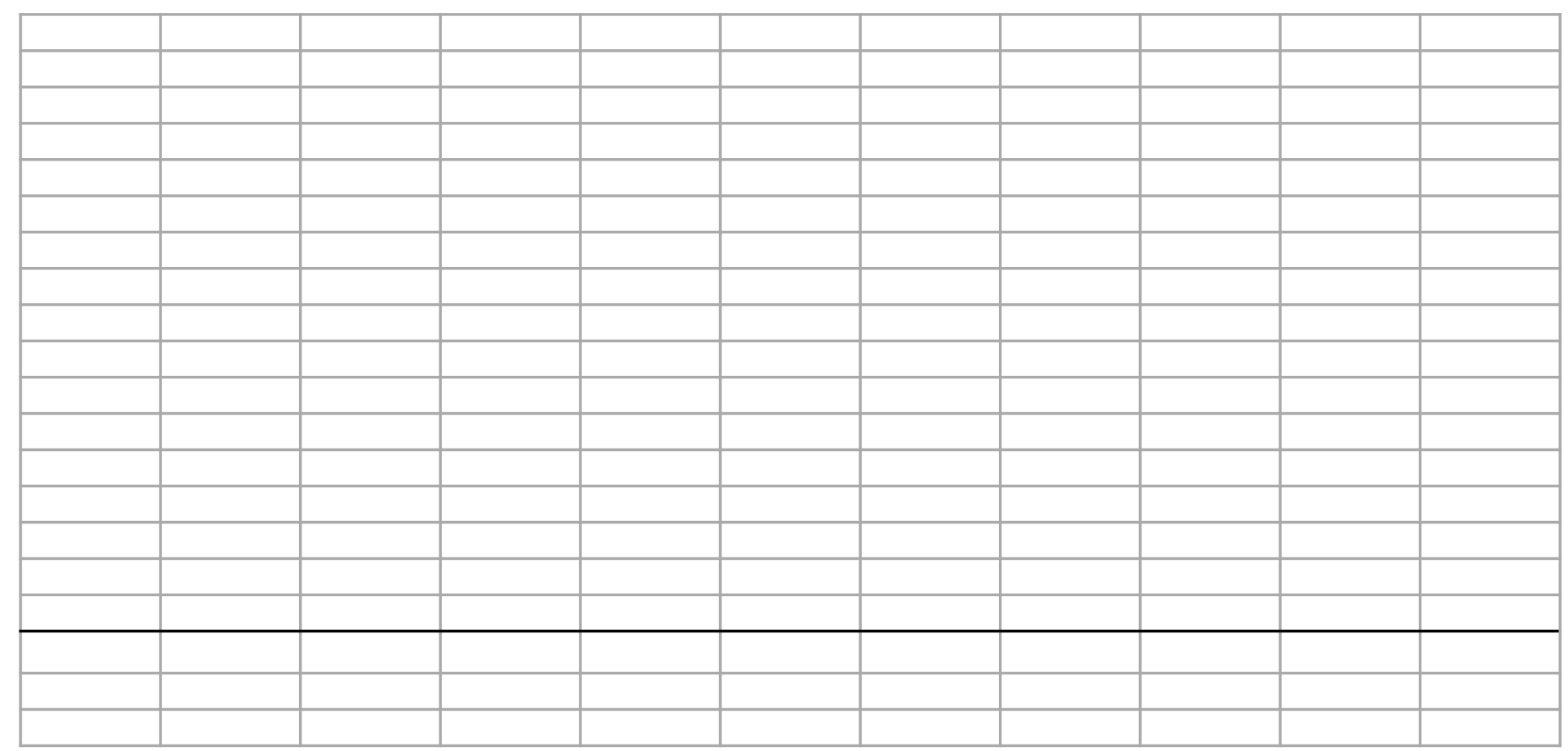




\begin{tabular}{|l|l|l|l|l|}
\hline & & & & \\
\hline & & & & \\
\hline & & & & \\
\hline & & & & \\
\hline & & & & \\
\hline & & & & \\
\hline & & & & \\
\hline & & & & \\
\hline & & & & \\
\hline & & & & \\
\hline
\end{tabular}

